\title{
FINANZAS PRÁCTICAS PARA MICRO, PEQUEÑAS $Y$ MEDIANAS EMPRESAS
}

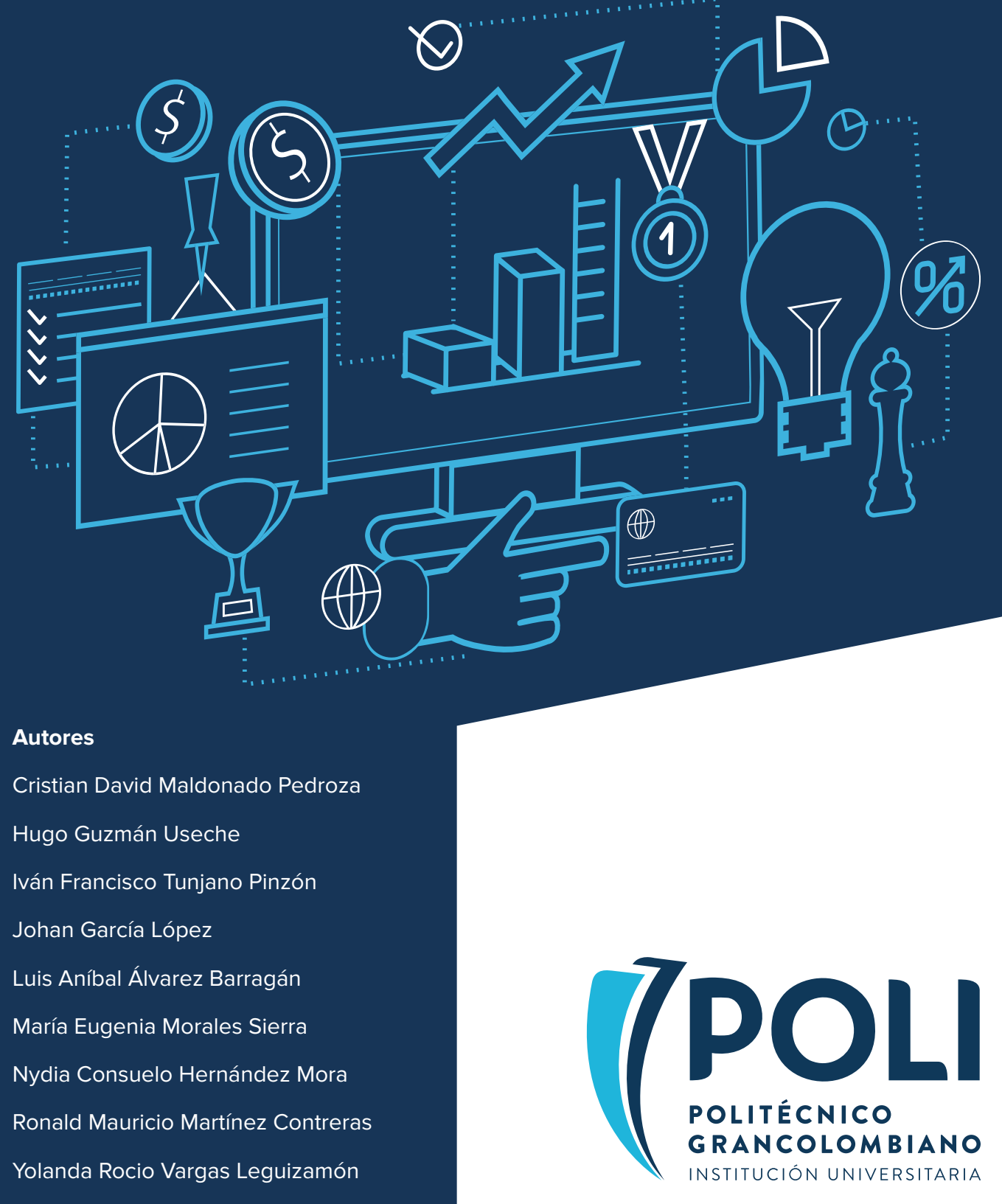




\section{LOGO POLI}

(C) Institución Universitaria Politécnico Grancolombiano

Calle 61 No. 7 - 66 - City Campus

Tel: 7455555, ext. 1171

Bogotá, Colombia

Finanzas prácticas para micro, pequeñas y medianas empresas

E-ISBN: 978-958-5142-11-4

Digital ISBN: 978-958-5142-12-1

\section{Editor literario:}

Iván Francisco Tunjano Pinzón

\section{Autores}

Cristian David Maldonado Pedroza

Hugo Guzmán Useche

Iván Francisco Tunjano Pinzón

Johan García López

Luis Aníbal Álvarez Barragán

María Eugenia Morales Sierra

Nydia Consuelo Hernández Mora

Ronald Mauricio Martínez Contreras

Yolanda Rocio Vargas Leguizamón 


\section{Director Editorial}

Eduardo Norman-Acevedo

\section{Analista de producción Editorial}

Carlos Eduardo Daza-Orozco

\section{Corrección de Estilo}

Rosario Gómez

\section{Diseño y Armada Electrónica}

Paula Romero Echeverry

No se permite la reproducción total o parcial de esta obra, ni su incorporación a un sistema informático, ni su tratamiento en cualquier forma o medio existentes o por existir, sin el permiso previo y por escrito de la Editorial de la Institución Universitaria Politécnico Grancolombiano

El contenido de esta publicación se puede citar o reproducir con propósitos académicos siempre y cuando se dé la fuente o procedencia

Las opiniones expresadas son responsabilidad exclusiva del autor(es) y no constituye una postura institucional al respecto.

Para usos académicos y científicos, la Institución Universitaria Politécnico Grancolombiano accede al licenciamiento Creative Commons del contenido de la obra con: Atribución - No comercial - Sin derivar - Compartir igual

La Editorial del Politécnico Grancolombiano pertenece a la Asociación de Editoriales Universitarias de Colombia (ASEUC)

La Editorial del Politécnico Grancolombiano está certificada con la Norma ISO 9001:2015

Creado en Colombia 


\section{CONTENIDO}

Resumen

Introducción

\section{CAPITULO 1}

El Tiempo y las matemáticas

Una introducción: ¿qué se entiende por dinero?

Valor del dinero en el tiempo

Equivalencias de dinero en diferentes horizontes de tiempo

La tasa de interés

Las cinco C del crédito y el acceso a financiación:

Factoring: una alternativa de financiación diferente al crédito

\section{CAPITULO 2}

El costo de capital y su aplicación en la pequeña y mediana empresa

Contexto teórico

¿Cuánto debe rentar cada negocio?

Rentabilidad libre de riesgo

Rentabilidad de Mercado

Beta

Estructura de capital y el Beta

\section{CAPITULO 3}

Valoración de proyectos

56

Conceptos Generales

¿Qué es Inversión?

Costos del proyecto

Flujo de caja libre

Métodos para construir el Flujo de Caja Libre

Flujo de caja por el método directo:

Flujo de Caja por el Método Indirecto

Depreciaciones y Amortizaciones 
Capex y Opex

76

Flujo de Caja de la Deuda

82

Flujo de Caja del Accionista

86

Análisis Aplicado de la Teoría

87

Métodos de decisión financiera para valoración de proyectos

Valor presente Neto

97

Tasa interna de Retorno TIR

101

Relación Beneficio Costo

Payback descontado

104

Caso Restaurante Comida De Mar

\section{CAPITULO 4}

105

108

Gestión continua de negocio, indicadores para la toma de decisiones

Indicadores financieros y toma de decisiones

126

EBITDA y Margen EBITDA

127

ROA

128

ROE

133

Costo promedio ponderado de capital

Teoría de Valor Económico Agregado

142

153

\section{CAPITULO 5}

160

Resumen:

161

Introducción

162

El riesgo y su presencia en la organización

163

La gestión de riesgos

167

El seguro como un instrumento de protección

Bitácora de la asegurabilidad y el riesgo en micro

176

y pequeñas empresas

180

Bibliografía

190

Lista de tablas

194

Lista de Gráficas

Lista de llustraciones

197

\section{ANEXOS}

Anexo 1: Cálculo del Beta para Nutresa S.A.

Anexo 2: formulación en Microsoft Excel 
- - 
Este libro está orientado a los líderes y directores de micro, pequeñas y medianas empresas. Considerando los retos en términos financieros que estas empresas enfrentan en su día a día, se presenta el siguiente contenido con el objetivo de brindar herramientas prácticas y necesariamente apegadas a la realidad de este tipo de empresas. El libro tiene como objetivo que los lectores puedan entender y utilizar en su gestión los conceptos básicos de las finanzas, para lo cual el libro despliega cinco temas que se consideran importantes para una gestión práctica de las finanzas, temas como: el tiempo y las matemáticas que presenta la teoría de valor del dinero en el tiempo y el concepto de intereses simple y compuesto. EI riesgo y la relación directa que tiene con la rentabilidad de cada negocio a través del modelo CAPM, un formato básico para la evaluación de pro- yectos, considerando el día a día de estas empresas en el abordaje de los diferentes proyectos que deben evaluar. Se mencionan indicadores de valor, su descripción y para qué sirven, con el fin de que el empresario pueda enfocar su gestión a través de un cuadro de mando, y por último se expone lo relacionado con el tema de gestión de riesgos. Es así como, el propósito general de este libro es entregar herramientas de gestión donde se describen las teorías y se entregan ejemplos enfocados en la realidad, para que el empresario pueda asociar los conceptos con la vida diaria de su compañía y encuentre su utilidad.

Al finalizar este libro se espera que los lectores tengan herramientas adicionales para desarrollar una mejor gestión financiera en micro, pequeñas y medianas empresas, teniendo en cuenta ejercicios y casos reales. 
- - 
La gestión continua de un negocio es análoga a la navegación de una embarcación. Este proceso será más o menos complejo dependiendo del tamaño de la nave, sin embargo, el objetivo será el mismo: mantenerla a flote y llegar a un destino en las mejores condiciones posibles. En ambos casos se requerirá de una serie de recursos y de personas que tengan la capacidad de maniobrar la embarcación, o la organización de leer las señales del entorno, de trazar una hoja de ruta o una estrategia y hacer frente a los retos que se presenten a lo largo del recorrido.

La gestión financiera hace parte de las actividades básicas que se desarrollan en una empresa, es decir, es un componente fundamental del proceso de navegación, y por medio de ésta se crean estrategias para lograr la continuidad del negocio y el cumplimiento de los objetivos que se tengan. Requiere de un proceso de administración de activos y de recursos pero, además de ello, demanda una estructura financiera que permita tomar las mejores decisiones con argumentos sólidos, soportados tanto en el análisis de la contabilidad que se lleve del negocio como en la estrategia que se haya planteado. Así como las mareas y contra mareas a las que se puede enfrentar una embarcación en el agua, las empresas compiten entre sí en mercados dinámicos influenciados no sólo por la ley de oferta y demanda, sino también por las decisiones institucionales relacionadas con la política monetaria y fiscal del país, que generan escenarios a los cuales se deben acomodar los negocios, haciendo uso de herramientas como la gestión financiera para lograr un buen desempeño empresarial.

Cuando se navega, se utiliza una bitácora que lleva el registro de las acciones que se toman en cada momento; de igual forma, la contabilidad se convierte en esa bitácora de navegación para las empresas, porque recoge toda la información de los sucesos que afectan en un determinado momento su situación financiera. El barco navega para llegar a un destino, en términos de la gestión financiera, este destino es el objetivo básico financiero (OBF), el cual no se limita a la generación de utilidades, o a la generación 
de ingresos, o a un buen proceso de apalancamiento, sino que va más allá. Así como la navegación no se limita a acelerar y frenar, o maniobrar la dirección, ya que existen muchas otras labores relacionadas, y ninguna de estas actividades por sí sola logra hacer llegar a la embarcación a su destino final, en finanzas, la suma de todas las gestiones realizadas también permite que la empresa llegue a su "destino", el cual es generar crecimiento patrimonial. Para esto debe de manera conjunta gestionar una serie de recursos físicos, humanos e intangibles, así como definir la forma más eficiente de financiar esos recursos para poder mantener y crecer el patrimonio en cada periodo que transcurra.

Es importante tener en cuenta que dentro del patrimonio se registran los aportes que realicen los socios, así como los resultados netos que se puedan acumular de cada ejercicio, es decir, de cada periodo de actividad en el cual se generan ingresos y gastos, se pagan impuestos y también intereses y se calculan valores de depreciación y amortización, dejando un saldo que se conoce como utilidad neta final. Una visión limitada de objetivo básico financiero diría que este objetivo sería el aumento de utilidades para la empresa, pero esto no es el OBF, a pesar de hacer parte del mismo, ya que lograr el crecimiento patrimonial, no sólo se hace por medio de utilidades, sino que también se puede ver un crecimiento en las diferencias de valor del activo y del pasivo, por lo que el cumplimiento del OBF no solo se logra generando mayores utilidades, sino que se logra también con una adecuada gestión de los recursos disponibles.

Teniendo en cuenta lo anterior, esta obra busca convertirse en una hoja de ruta donde se desarrollen éstos y otros aspectos que ayuden al lector a tener un mayor conocimiento financiero y/o a profundizar el conocimiento que tenga, para lograr una "mejor navegación" de su organización y entender y cumplir con el objetivo básico financiero de todo negocio.

Cuando una empresa cumple con el objetivo básico financiero se puede concluir que se está desarrollando una gestión financiera adecuada, y 
este proceso se facilita cuando se incluyen en el plan estratégico, primero; conceptos como el valor del dinero en el tiempo, que hace parte del conocimiento de matemáticas financieras. Segundo; entender cómo se valora el riesgo y cómo se identifica la relación con la rentabilidad, genera ventajas para el desarrollo de la gestión financiera. Tercero; conocimientos en técnicas de evaluación de proyectos y proyección de ingresos y egresos, así como una correcta identificación de costos fijos y variables, hace que las posibilidades de éxito en el cumplimiento del OBF sean mayores.

Cuarto; En una empresa en funcionamiento, existen algunas medidas llamadas indicadores financieros, que hacen posible conocer cómo se están desarrollando las operaciones y cómo se están relacionando los ingresos, egresos, el valor del activo y del pasivo con respecto al valor del patrimonio, por lo que observar estos indicadores aumenta las posibilidades de cumplir el objetivo.

Quinto; finalmente, no se puede olvidar que el riesgo es omnipresente y que así lo debemos entender, por lo que una correcta gestión de riesgos es otra pieza clave para lograr diseñar y liderar una estrategia con todas las ventajas posibles y que asegure el cumplimiento del OBF, que como se mencionó, corresponde a un crecimiento patrimonial.

Mediante este libro se abordan estos cinco aspectos relevantes para el desarrollo de una gestión financiera práctica. 


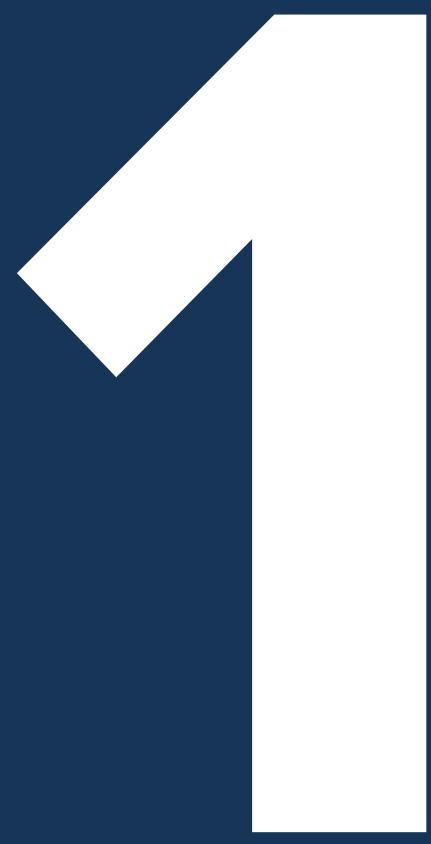

- - -

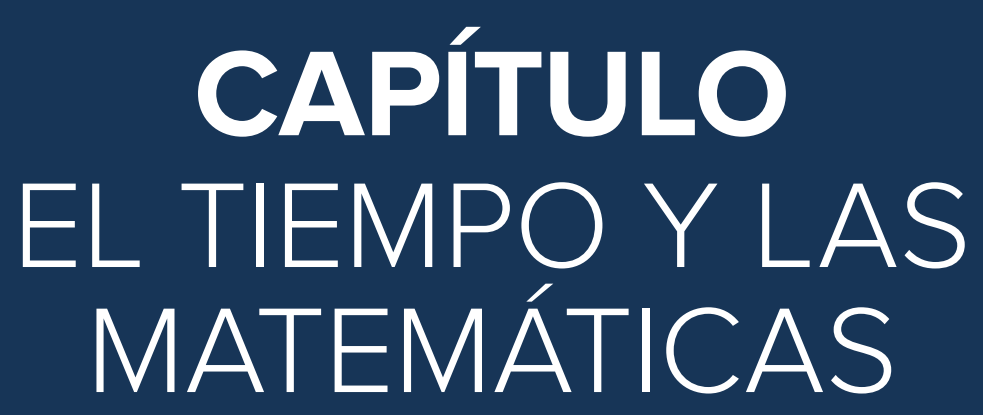




\section{Guía práctica para entender por qué el tiempo es tan importante en la gestión de un negocio y cómo afecta decisiones de inversión basadas en el valor del dinero durante el tiempo; en este capítulo el empresario recordará lo relacionado con las tasas de interés y cómo la periodicidad es tan importante para su correcta interpretación.}

García, Johann \& Maldonado, Cristian

\section{UNA INTRODUCCIÓN: ¿QUÉ SE ENTIENDE POR DINERO?}

A lo largo de la historia el hombre ha empleado diferentes objetos: metales o elementos como representación de dinero o moneda, con el fin de facilitar los intercambios que demandan la satisfacción de sus necesidades básicas. Inicialmente se presentaban incipientes formas de intercambio (trueque), hasta hoy donde se propugna por un menor uso del dinero en su forma física a cambio de utilizar diferentes medios de pagos electrónicos.
Independientemente de las condiciones económicas, del entorno, de los países y de otras consideraciones, la mayoría de las personas y empresas usan de manera frecuente dinero para comprar o vender productos y/o servicios, para pagar una obligación o por concepto de ingresos, por lo que se observa que el dinero es fundamental para el funcionamiento de la economía.

No obstante, ante la relevancia que tiene el dinero, no existe una definición única y su concepto depende de las funciones para las que esté destinado, así: 
»El dinero como depósito de valor, es decir, se espera que su valor se mantenga de una manera presumible a lo largo del tiempo; un ejemplo típico es el caso de los metales preciosos, oro y plata. Sin embargo, el poder adquisitivo del dinero (es decir, la cantidad de bienes y servicios que se pueden comprar con una cantidad determinada de dinero) no es constante, y en condiciones inflacionarias el uso del medio de intercambio como reserva de poder adquisitivo implica una pérdida real del mismo. Por ejemplo, si se atesora $\$ 1.000 .000$ en efectivo durante un año, se estaría exponiendo esta cantidad de dinero a una pérdida de poder adquisitivo ya que por efecto del aumento del nivel de precios de una economía, la cantidad de bienes que se pueden adquirir con esta suma de dinero es, a lo largo del tiempo, cada vez menor. Esta situación implica un dilema para el individuo ya que el valor del dinero podría deteriorarse más rápidamente que otros activos alternativos (acciones, metales preciosos, etc.), pero el uso de esos activos como reserva de poder adquisitivo significa un sacrificio de liquidez.
»El dinero como unidad de cuenta, determina el precio de los productos, o servicios, o como la unidad en términos de la cual se expresan los valores de los demás bienes y servicios; también es la unidad usada para medir y comparar la riqueza.

Como medio de cambio, lo cual facilita y permite el intercambio para adquirir productos o servicios, pagar obligaciones u otros fines, es decir, se refiere al hecho de mantenerlo porque piensa intercambiarse por otra cosa, en vez de desearlo por sí mismo, lo cual se traduce en reducción del tiempo y simplifica las transacciones. Como lo menciona Cole (2014, pág. 1) "permite que el intercambio se lleve a cabo lo más económicamente posible a fin de facilitar el grado óptimo de especialización, con el correspondiente aumento en la productividad", de ahí que el dinero es un determinante fundamental en su utilidad como medio de intercambio, al tener una aceptabilidad por cualquier agente económico. 
Keynes (1965) en su Teoría General de la Ocupación, el Interés y el Dinero, menciona un aspecto importante para considerar: ¿cuál es la recompensa que obtienen las personas de preferir dinero líquido, sacrificando el consumo actual? La respuesta bastante simple, pero de gran transcendencia hace referencia a un concepto fundamental en las finanzas y en el mundo de los negocios en general: la tasa de interés, puesto que el dinero en efectivo (papel moneda) no gana interés y por el contrario puede perder poder adquisitivo al tener menos capacidad de compra ante un incremento en el nivel de los precios (inflación). En el contexto actual, es posible afirmar que el precio del dinero es la tasa de interés y como cualquier otro producto, en la medida que exista mayor cantidad de dinero en la economía, el precio tiende a bajar y viceversa (ceteris paribus).

En el mercado financiero existe la oferta y demanda de recursos con pretensiones opuestas, es así como quienes demandan dinero (prestatarios), ante un incremento en la tasa de interés, estarán dispuestos a solicitar menos créditos (mayor costo de financiamiento). De otra parte, los oferentes (inversionistas), estarán dispuestos a llevar sus recursos para obtener mayores ingresos (rendimientos financieros). El caso contrario se presenta cuando la tasa de interés baja, las personas y empresas estarán dispuestas a solicitar más créditos (menor costo financiero), no obstante, a quienes tengan excedentes de recursos no les es atractivo invertir dados los bajos ingresos (vía menores intereses) y no compensa el sacrificio de dejar de consumir en el presente.

\section{VALOR DEL DINERO EN EL TIEMPO}

Seguramente la anterior introducción le habrá permitido al lector familiarizarse con la situación de que las personas no son indiferentes al hecho de recibir una cantidad de dinero hoy, a recibir esa misma cantidad de dinero en el futuro (ya sea dentro de un mes, un año, etc.). Normalmente, se tendrá una preferencia por el consumo actual y debe haber algún incentivo para sacrificarlo por consumo futuro. Esta preferencia es resultado de dife- 
rentes hechos económicos relacionados, tales como el aumento del nivel de precios de la economía (inflación), la incertidumbre del futuro, y el costo de oportunidad, entre otros. A continuación, se explican brevemente estos conceptos:

» La inflación es entendida como el aumento del nivel general de precios de la economía, esto quiere decir que, por distintos factores tanto internos como externos (aumento del precio de las materias primas, de las importaciones, etc.), los precios que pagan los consumidores finales por los diferentes bienes y servicios de la economía aumentan con el paso del tiempo (recuerde el lector cuánto le costaba un pasaje de transporte público en su adolescencia y compárelo con el precio actual).

» Incertidumbre y riesgo: ya lo dice el adagio popular: más vale pájaro en mano, que cien volando, y este es un principio que rige la conducta de la mayoría de las personas. En general, los seres humanos son adversos al ries- go y muchas de las transacciones económicas que se hacen implican algún grado de riesgo.

El costo de oportunidad: este término está asociado con el costo, ya sea monetario o no, explícito e implícito, de las decisiones que se toman. En el ámbito específico de las finanzas, se asocia con el hecho de que los recursos son finitos, mientras que las alternativas de inversión no lo son. En este sentido, al tomar una decisión, se está renunciando a los beneficios posibles de las alternativas que se excluyen, por tanto, siempre se optará por aquella alternativa que genere un mayor beneficio porque si se renuncia a esta el costo será mayor. Por ejemplo, si usted como empresario está acostumbrado a que sus negocios le generen una rentabilidad promedio del $20 \%$, no sería racional aceptar nuevas alternativas de inversión cuya rentabilidad sea inferior (por ejemplo, el 15\%) porque estaría comprometiendo recursos que podrían generar un mayor beneficio. Recuerde, "en economía no hay almuerzo gratis”. 
La variación entre la percepción de valor del dinero el día de hoy y cualquier momento en el futuro se puede expresar en términos porcentuales, como la tasa de interés. Cuando se analiza desde el punto de vista del inversionista, la tasa expresa la rentabilidad que se tiene por comprometer una cantidad de recursos en un activo o conjunto de activos (empresa, proyectos, activos financieros). Desde el punto de vista del prestatario, la tasa de interés representa el costo que debe pagar por el uso de los recursos que le están facilitando!.

De acuerdo con la forma como se capitaliza, es decir, si el cálculo del interés tiene en cuenta la variación del capital, se pueden encontrar la forma de interés simple e interés compuesto.
Para entender mejor esta diferenciación, imagine el lector la siguiente situación: usted deposita en una cuenta de ahorros, al inicio del año, la suma de $\$ 1.000 .000$ y no hace ningún retiro durante seis meses, la cuenta reconoce un interés del $1 \%$ cada mes. Veamos cómo funcionan los diferentes tipos de interés.

De acuerdo con la tabla 1, se observa que, mediante la modalidad de interés simple, los intereses siempre se calculan sobre la misma base o lo que es lo mismo que decir que los intereses no se capitalizan (no se convierten en capital). Por tanto, mediante esta modalidad estos siempre serán iguales, siempre y cuando no se modifique el capital sobre el que se calculan.

\footnotetext{
1. Usualmente, las tasas de interés que se encuentran en los diferentes productos financieros, específicamente productos de crédito reflejan diferentes factores relacionados con el riesgo, la oferta de recursos disponibles para préstamo, y la política monetaria del país. En Colombia, las instituciones financieras tienen la libertad de cobrar la tasa de interés que refleje sus costos administrativos y que además deje un margen de utilidad, teniendo en cuenta las variables antes mencionadas, siempre y cuando ésta no sobrepase el límite de usura establecido para el tipo de producto. La tasa de usura es la tasa máxima que por regulación pueden cobrar las instituciones financieras por los créditos desembolsados, incluyendo las tarjetas de crédito. En el país, la superintendencia reporta con distinta periodicidad de certificación la tasa de usura para el crédito de consumo y ordinario y también para los microcréditos, siendo ésta última más elevada dado el perfil de riesgo del mercado al que se encuentra dirigido.
} 


\section{TABLA 1}

\section{LIQUIDACIÓN DE INTERESES BAJO LA MODALIDAD SIMPLE Y COMPUESTA}

Fuente: Elaboración propia

\section{Interés simple}

Base sobre la

Tiempo que se calculan

los intereses
Capital acumulado al final del período

1

1.000 .000

10.000

1.010 .000

2

1.000 .000

10.000

1.020 .000

3

1.000 .000

10.000

1.030 .000

4

1.000 .000

10.000

1.040 .000

5

1.000 .000

10.000

1.050 .000

6

1.000 .000

10.000

1.060 .000 


\section{Interés compuesto}

Base sobre la

Tiempo

que se calculan

los intereses

Interés

Capital acumulado

al final del período

$\begin{array}{llll}1 & 1.000 .000 & 10.000 & 1.010 .000\end{array}$

2

1.010 .000

10.100

1.020 .100

3

1.020 .100

10.201

1.030 .301

4

1.030.301

10.303

1.040 .604

5

1.040 .604

10.406

1.051 .010

6

1.051 .010

10.510

1.061 .520

\subsection{0}

Por otra parte, el interés compuesto sí comprende la capitalización de los intereses, es decir, que éstos se convierten, al final de cada mes, en parte del capital sobre el cual se calcularán los intereses del mes siguiente. Por tanto, bajo esta modalidad la acumulación de intereses es mayor.
La situación es análoga al caso de un crédito en la modalidad de interés compuesto, los intereses pagados por una deuda serán cada vez menores en la medida en que parte de la cuota pagada sea destinada a disminuir el capital adeudado. 


\section{CASO DE ESTUDIO:}

\section{¿CUÁNTO CUESTA REALMENTE UN CRÉDITO CON UN "GOTA A GOTA"?}

En el contexto económico del país, el acceso a crédito formal a las micros, pequeñas y medianas empresas (mipymes) es, por diferentes causas, muy restringido. De acuerdo con la Asociación Colombiana de Pequeñas y Medianas Empresas (Acopi) el $62 \%$ de las mipymes no cuenta con acceso a fuentes formales de préstamos financieros que son claves para su permanencia y crecimiento (El Espectador, 2018). Esta situación obliga a este tipo de organizaciones a hacer uso del mercado extrabancario o agiotistas, también conocidos coloquialmente como préstamos gota a gota. Además de los riesgos a la seguridad de los empresarios que pueden representar estas fuentes de financiación, su costo financiero es muy elevado, toda vez que, en la mayoría de los casos, la liquidación de intereses se hace bajo la modalidad de interés simple, generalmente a una tasa mayor a la de usura, encareciendo el costo financiero para las empresas.

A manera ilustrativa se presenta un ejemplo, mediante el cual se realiza un paralelo entre los costos asumidos por los deudores en un préstamo a un año con una entidad financiera tradicional y cuando se acude a préstamos otorgados fuera del sistema financiero así: (ver tabla página 23)
Como se puede observar en este ejercicio, la diferencia es de $\$ 72.238$ de menor valor pagado en la deuda contraída en una entidad financiera con respecto al valor pagado en el mercado extrabancario. Además del beneficio económico obtenido, se pueden mencionar otros que los deudores consiguen en el sistema financiero: en la medida en que vayan cancelando oportunamente sus obligaciones, alcanzan mayor visibilidad ya que construyen historial crediticio, mejoran el perfil de riesgo, lo que se traduce en menores tasas para futuros créditos y mayores plazos y montos. Así mismo, en el caso de créditos que tengan seguro de vida para deudores, ante el fallecimiento del deudor o que éste presente incapacidad total y permanente, el seguro cubre la totalidad de la deuda con la entidad financiera.

Por último, en la medida que una mayor población acuda a entidades especializadas, tal como lo menciona Barona (2004, pág. 98) "se contribuye a que los esfuerzos de prestación de servicios financieros a los pobres y a los microempresarios tenga un mayor impacto en la reducción de la pobreza y a que las instituciones que atienden las necesidades financieras de estas 
poblaciones lo hagan de manera más eficaz y eficiente".

*Para fines ilustrativos se utiliza como referente la tasa de usura para un crédito Mipyme. Tener en cuenta que las tasas de interés cobradas en el mercado extrabancario son mucho más elevadas que las propuestas en este caso. Estas se si- túan entre el 10\% y el 20\% mensual, lo que en términos efectivos anuales (ver aparte de sección de la tasa de interés) se traduce a una tasa del $214 \%$ y del $792 \%$ respectivamente.

**este valor se obtiene aplicando la modalidad de interés simple, se invita al lector a verificar el resultado

Nota: NA: No aplica

Fuente: Elaboración propia

Entidad

Financiera

\begin{tabular}{lll}
\hline Valor préstamo & $\$ 1.000 .000$ & $\$ 1.000 .000$ \\
\hline Plazo (meses) & 12 & 12 \\
\hline $\begin{array}{l}\text { Tasa nominal } \\
\text { mes vencido }\end{array}$ & $3,40 \%$ & $3,40 \% *$ \\
\hline $\begin{array}{l}\text { Comisión ley } \\
\text { mipyme } 7.5 \%\end{array}$ & $\$ 75.000$ & NA \\
\hline IVA $19 \%$ & NA \\
\hline $\begin{array}{l}\text { Cuota fija } \\
\text { mensual* }\end{array}$ & $\$ 14.250$ & NA \\
\hline $\begin{array}{l}\text { Seguro vida } \\
\text { deudores }\end{array}$ & $\$ 102.876$ & NA \\
\hline $\begin{array}{l}\text { Valor total } \\
\text { intereses }\end{array}$ & $\$ 12.000$ & $\$ 408.000 * *$ \\
\hline
\end{tabular}

Mercado

Extrabancario

$\$ 1.000 .000$

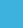




\section{EQUIVALENCIAS DE DINERO EN DIFERENTES HORIZONTES DE TIEMPO}

La comprensión del concepto de interés (como una medida de la variación del valor del dinero en el tiempo) permite que el lector se pueda relacionar con el concepto de equivalencias de dinero en el tiempo. La tabla 1 muestra que, sin importar la forma cómo se calculan los intereses, la cantidad de dinero inicial se transforma en una cantidad de dinero diferente en el futuro. Por tanto, si bien $\$ 1.000 .000$ y $\$ 1.061 .520$ (para interés compuesto) no son numéricamente iguales, en términos financieros se puede decir que son cantidades de dinero equivalentes, ya que sería indiferente recibir $\$ 1.000 .0000$ el día de hoy o recibir $\$ 1.061 .520$ dentro de seis meses, si la tasa de oportunidad fuera del $1 \%{ }^{2}$
La generalización de la operación matemática que se hace para obtener la equivalencia entre una suma de dinero el día de hoy y en el futuro, permite construir una de las ecuaciones en las que se fundamenta gran parte del análisis financiero y que posibilita hacer este cálculo para cualquier horizonte de tiempo:

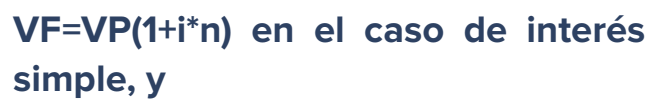

VF $=\mathrm{VP}\left(1+\mathrm{i}^{*} \mathrm{n}\right)$ en el caso de interés simple, $y$

\section{$\mathrm{VF}=\mathrm{VP}(1+\mathrm{i})^{\mathrm{n}}$ en el caso de interés compuesto}

Donde VF es el valor futuro equivalente a una cantidad de dinero presente, VP, la tasa de interés de la operación es $i$, y $\mathrm{n}$ representa el número de períodos. De esta fórmula se puede despejar cualquiera de las variables de interés y encontrarlas siempre y cuando se conozcan todas las demás: ${ }^{3}$

\footnotetext{
2. Si recibe el millón de pesos el día de hoy, usted lo podría invertir en sus alternativas normales de inversión, en este caso la cuenta de ahorros, y recibir dentro de seis meses $\$ 1.061 .520$ o lo que equivalente a no recibir nada el día de hoy sino $\$ 1.061 .520$ en seis meses.

3. Dado que el interés simple es de poco uso en el contexto de las finanzas, se presentan las fórmulas asociadas a este pero los ejemplos y los temas que se tocarán en las siguientes secciones del capítulo se basarán en el interés compuesto.
} 


\section{TABLA 2}

\section{FORMULAS BÁSICAS EQUIVALENCIAS \\ DE DINERO EN EL TIEMPO}

Fuente: Elaboración propia

Valor futuro (VF)

$V F=V P(1+i * n)$

$V F=V P(1+i)^{n}$

Valor presente (VP)

$V P=V F /(1+i * n)$

$V P=V F /(1+i)^{n}$

Tasa de interés

$$
\mathrm{i}=(\mathrm{VF}-\mathrm{VP}) /(\mathrm{VP} * \mathrm{n}) \quad \mathrm{i}=(\mathrm{VF} / \mathrm{VP})^{(1 / \mathrm{n})-1}
$$

Número de períodos

$$
n=(V F-V P) /(V P * i) \quad n=\log V F-\log V P / \log (1+i)
$$




\section{EJEMPLOS4:}

» Búsqueda del valor futuro: El día de hoy usted invierte $\$ 5.000 .000$ en un negocio de comidas, donde estima que la rentabilidad esperada del mismo será del $25 \%$ anual, usted quisiera saber en cuánto se convertirá el capital invertido al final de cinco años, teniendo en cuenta que reinvierte las ganancias que se generan cada año en el negocio:

Valor presente (VP): $\$ 5.000 .000$

Tasa de interés (i): 25\% anual

Tiempo de la operación (n): 5 años

Valor futuro (VF) =

$V F=V P(1+i)^{n}$

$V F=5.000 .000^{*}(1+25 \%)^{5}$

$V F=\$ 15.258 .789,06$
Por tanto, al final de cinco años, su capital se habrá transformado en $\$ 15.258 .789,06$.

\Búsqueda del valor presente: Al cabo de dos años usted estima que deberá renovar una máquina que le costará $\$ 7.000 .000$, si su negocio genera una rentabilidad del 2,1\% mensual, ¿cuánto deberá invertir el día de hoy para acumular la cantidad de dinero suficiente en el tiempo necesario?

$V F=\$ 7.000 .000$

$\mathrm{i}=2,1 \%$ mensual

$\mathrm{n}=24$

$V P=V F /(1+i)^{n}$

$\mathrm{VP}=\$ 7.000 .000 /(1+2,1 \%)^{24}$

$=\$ 4.250 .893,55$

Por tanto, para poder tener disponible el dinero necesario para 
la renovación de los equipos, se deben invertir el día de hoy .

" Búsqueda de la tasa de interés: Una persona quiere invertir el día de hoy $\$ 50.000 .000$ en un fondo de inversiones de forma que cuando estime llegue su momento de jubilación (dentro de 20 años) pueda disponer de $\$ 120.000 .000$, ¿a qué tasa anual debería rendir este fondo para permitir acumular esta cantidad de dinero?

$$
\begin{aligned}
& V P=\$ 50.000 .000 \\
& V F=\$ 120.000 .000 \\
& n=20 \\
& i=(V F / V P)^{(1 / n)}-1 \\
& i=(120.000 .000 / 50.000 .000)^{1 / 2} \\
& -1=4,4746 \% \text { anual }
\end{aligned}
$$

Es decir, el fondo debería rentar en promedio el $4,4746 \%$ anual para poder acumular la cantidad de dinero indicada al final de 20 años.

"Búsqueda de la duración de la operación: Para el ejemplo anterior, si la tasa de interés disminuye al 2,5\% anual, ¿Cuánto tiempo debe pasar para que los $\$ 50.000 .000$ se conviertan en $\$ 120.000 .000$ si permanecen en dicho fondo?

$V P=\$ 50.000 .000$

$V F=\$ 120.000 .000$

$i=2,5 \%$ anual

$n=\log V F-\log V P / \log (1+i)$

$\mathrm{n}=\log (120.000 .000)$

$-\log (50.000 .000) /$

$\log (1+2,5 \%)=35,5$ años

Deben transcurrir aproximadamente 35 años $^{5}$ y medio para lograr acumular la cantidad de dinero esperada.

5. Tener en cuenta que el resultado de la ecuación dará en la misma periodicidad que esté expresada la tasa de interés. En este caso, como la tasa de interés está expresada de manera anual, el tiempo también se expresará en años. 


\section{LA TASA DE INTERÉS}

Hasta este punto se han trabajado los conceptos y casos presentados, partiendo del hecho de que no deben transformarse las tasas de interés. Sin embargo, como podrá constatar el lector, no siempre este es el caso que se presenta en el entorno de los negocios. Por ejemplo, ¿cómo se puede comparar una alternativa de inversión cuya rentabilidad está expresada en una tasa mensual y otra que esta expresada en términos anuales? En este contexto es muy importante entender cómo la periodicidad de la tasa afecta los valores obtenidos cuando se están evaluando equivalencias de dinero en el tiempo.

En términos generales, una tasa de interés puede expresarse de tres formas diferentes:

Forma 1: Como tasa nominal: la palabra nominal viene de nombre; cuando la tasa de interés se expresa de esta forma, se asocia con el concepto de interés simple (es decir, cuando no hay variación del capital), por lo que en el contexto de interés compuesto solamente es de referencia y no puede emplearse directamente para hacer operaciones. Esta tasa de interés normalmente se expresa en términos anuales y debe estar acompañada de su "frecuencia" de capitalización. Por ejemplo: 24\% Nominal Anual Mes Vencido (NAMV); 35\% Nominal Anual Trimestre Vencido (NATV).

Pero ¿qué es la frecuencia de capitalización? Este término, guarda relación con el número de veces que los intereses se capitalizan, es decir, "se vuelven capital” en un período de un año. Entonces, si se tiene una tasa del $24 \%$ NAMV, se estaría diciendo que cada mes una fracción de esta tasa se "convierte” en capital, pero ¿cuál fracción? Para responder a esta pregunta, es necesario observar la siguiente forma de expresar la tasa de interés.

Forma 2: Tasa periódica: surge de dividir la tasa nominal entre la frecuencia de capitalización indicada. Siguiendo con los anteriores ejemplos, la tasa periódica correspondiente a una Tasa Nominal Anual Mes Vencido, será la que resulta de dividir dicha tasa entre 12 (porque hay 12 meses en 
un año). Entonces, la tasa de interés mes vencido (periódica) correspondiente a una tasa del 24\% NAMV será del $24 \% / 12=2 \%$ (mes vencido) ${ }^{6}$. Es decir, que el $2 \%$ es la porción de los intereses que mes a mes se capitaliza. Y dado que se da este proceso de capitalización, surge, por tanto, otra forma de expresar la tasa de interés: la tasa efectiva anual.

Forma 3: La tasa efectiva anual, se da como resultado del proceso de acumulación de intereses que se da en la modalidad de interés compuesto y hace que el capital sobre el que estos son calculados cambie período a período. Un ejemplo ayudará a clarificar esta situación: imagine el lector que tiene la oportunidad de invertir $\$ 1.000 .000$, en un fondo de inversión que reconoce una tasa del $12 \%$ NATV, esto quiere decir, que cada trimestre se aplicará una tasa del $3 \%$ al capital acumulado. Usted espera permane- cer en el fondo por un año, y retirará los intereses y el capital al final de este período. Por tanto,

En el primer trimestre se tendría por concepto de interés: $\$ 1.000 .000 * 3 \%$ $=\$ 30.000$

Si no se retiran los rendimientos ganados, estos se convierten en capital, por lo que los intereses del segundo trimestre serán: $\$ 1.030 .000 * 3 \%=30.900$. Esta operación se repite trimestre a trimestre de la siguiente forma:

6. Los términos vencidos y anticipados hacen referencia al momento en el que se calculan los intereses, si es al inicio o al final del período (ya sea del mes, del trimestre, semestre, etc.). En el caso primero serán anticipados y en el caso del último, serán vencidos. Los intereses vencidos son los de mayor utilización en el contexto de los negocios, por lo que se deja al lector en libertad de indagar más sobre las implicaciones de los intereses anticipados. 


\section{TABLA 3}

\section{ACUMULACIÓN DE INTERESES MEDIANTE LA MODALIDAD DE INTERÉS COMPUESTO}

Fuente: Elaboración propia

\begin{tabular}{|c|c|c|}
\hline Trimestre & $\begin{array}{l}\text { Saldo al iniciar } \\
\text { el trimestre }\end{array}$ & Intereses \\
\hline
\end{tabular}
1
1.000 .000
30.000
1.030 .000

2

1.030 .000

30.900

1.060 .900

3

1.060 .900

31.827

1.092 .727

4 
Los intereses acumulados en toda la operación ascienden a 125.509 (diferencia entre 1.125 .509 y 1.000 .000 ), que en términos porcentuales representan el 12,55\% (125.509/1.000.000) y que se conoce como Tasa Efectiva Anual (EA). Por tanto, se observa que la tasa que se logra en un año es superior a la simple suma aritmética de la tasa de interés trimestral.

\section{PARA TENER EN CUENTA:}

Si bien, de acuerdo con la normatividad colombiana, las instituciones financieras están obligadas a indicar cuál es la tasa efectiva anual que se cobra (en el caso de un crédito) o que se genera (en el caso de una inversión), no olvide nunca, al momento de realizar una operación financiera, estar enterado de esta variable ya que esta indicará el costo o la rentabilidad real del producto.

La tasa de interés EA, será mayor en la medida en que la frecuencia de capitalización sea más alta; se invita al lector a comprobar este resultado, reproduciendo el anterior cuadro teniendo en cuenta una tasa del $12 \%$ nominal anual mes vencido, la misma inversión inicial y el mismo plazo de un año. Este resultado se da como consecuencia de que los intereses se convierten en capital un mayor número de veces en el año. El dominio de este concepto es fundamental ya que ésta es la tasa a la que se deben expresar los productos financieros de deuda y de inversión a los que normalmente tiene acceso una MIPYME (ver recuadro anterior). 


\title{
CASO DE ESTUDIO:
}

\author{
¿CUÁL ES EL COSTO REAL DE NO \\ APROVECHAR LOS DESCUENTOS \\ POR PRONTO PAGO QUE \\ OFRECEN LOS PROVEEDORES?
}

Es importante habituarse a la idea de que, en un negocio, uno de los costos financieros más altos que se puede enfrentar es el desaprovechamiento de los descuentos por pronto pago. El ofrecimiento de crédito a los clientes es una realidad en el entorno competitivo de los negocios, sin embargo, la necesidad de liquidez también lo es. Por tanto, en muchos casos, los proveedores, con el fin de recuperar su cartera de la forma más rápida posible, ofrecen descuentos por pronto pago que muchas veces no se aprovechan bajo la noción equivocada de que la financiación con proveedores no tiene costo, así que i¿para qué pagar antes?! Sin embargo, como se tratará de ilustrar con el siguiente caso, la situación es otra:
Una empresa de implementos para oficina y colegios hace una compra de mercancía para venta por valor de $\$ 15.000 .000$, su proveedor le otorga para su pago un plazo de 30 días. Sin embargo, también le ofrece la opción de otorgarle un descuento por pronto pago del 3\% del valor de la factura si la paga el día 10, si no, puede pagar el 100\% del valor el día 30.

Primero, se debe conocer cuál sería el valor de la factura con descuento, que sería: $15.000 .000 *(1-3 \%)=14.550 .000$.

Segundo, se debe determinar cuál es la tasa de interés que convierte 14.550 .000 en 15.000 .000 transcurridos 20 días 



\section{LAS CINCO C DEL CRÉDITO Y EL ACCESO A FINANCIACIÓN:}

En la gran mayoría de los casos, los productos financieros utilizados por las PYMES están relacionados con productos de crédito (exceptuando las cuentas de ahorro y corrientes). Por lo tanto, es muy importante, no sólo conocer acerca de los costos efectivos de este tipo de operaciones sino de aspectos relacionados con variables que determinan las condiciones en que las empresas pueden acceder a financiación. En este sentido, de acuerdo con los principios básicos de la teoría para un análisis de crédito, se deben contemplar como mínimo diferentes elementos fundamentales, conocidos como las cinco C del crédito (Morales \& Morales, 2014), (Pampillón, de la Cuesta, Ruza, Vázquez, \& Bustarviejo, 2017), así:

\section{Carácter: Corresponde al compor-} tamiento o hábito de pago y al historial crediticio del cliente. Ante un buen comportamiento en el pago de las obligaciones, se genera una mayor probabilidad de que la enti- dad financiera le otorgue el préstamo solicitado. Este comportamiento se puede validar con fuentes de información interna y externa (consultas a las centrales de riesgo) en donde se observa la trazabilidad de las obligaciones, el monto de cada una de ellas, la periodicidad del pago, el valor de las cuotas, si ha presentado mora en el pago de estas o han sido atendidas oportunamente y las garantías ofrecidas. Las entidades financieras pueden emplear métodos estadísticos que asignan puntajes y permiten predecir la viabilidad de la operación, la calidad del deudor, la probabilidad de incumplimiento, para de esta forma, de acuerdo con el puntaje obtenido, aprobar o rechazar la solicitud.

\section{Capacidad: Se establece cuál es} la fuente de los flujos de caja que permitan determinar su capacidad de pago y la periodicidad en la generación de efectivo. En el caso de las empresas, es importante identificar si los flujos de efectivo son constantes, como en el caso de una comercializadora, 
por cuanto compran el producto terminado y lo venden (generalmente sin ninguna transformación), al consumidor final, lo cual les permite un mayor volumen de recursos (flujo de caja) en el corto plazo, o si los flujos corresponden a periodos más largos, por ejemplo las empresas manufactureras. Éstas requieren de un proceso que inicia desde la compra de la materia prima y que pasa por la transformación, elaboración del producto y la venta (en muchos casos a intermediarios), lo cual demanda mayor tiempo y por lo tanto no se cuenta con la misma liquidez que las empresas comercializadoras. De ahí que cuando se otorgue el crédito, la frecuencia en el pago de las cuotas deba corresponder con la generación del flujo de efectivo de las empresas para evitar que incumplan sus compromisos. Es necesario revisar el endeudamiento actual y futuro de acuerdo con el nuevo préstamo, ya q que entre menor sea la relación deuda/ingreso, mayor es la capacidad de pago que tiene el solicitante del crédito.
3. Capital: corresponde al aporte realizado por los socios o accionistas; a mayor capital presentado por la empresa, mayor compromiso de los propietarios, lo cual es un buen indicador para los bancos a la hora de realizar el análisis de crédito. Si la participación del capital con relación al activo de la empresa es alta, es un indicador de bajo endeudamiento y más equilibrio en su estructura financiera. Ahora bien, existen empresas que por su dinámica y por el sector donde llevan a cabo sus actividades, la estructura de financiación puede estar más comprometida con terceros (pasivos) y por lo tanto requieren de mayor apalancamiento.

4. Colateral: corresponde a la garantía ofrecida o exigida por el establecimiento bancario; una garantía idónea que tenga un buen margen de cobertura, le da mayor peso en el análisis de crédito y permite mejorar las condiciones financieras del crédito. Actualmente existen en el sistema financiero múltiples garantías que flexibilizan el otorgamiento de crédito y permiten a 
las entidades financieras recuperar parcial o totalmente la deuda en caso de no pago por incumplimiento del deudor. Se puede considerar como una segunda fuente de recuperación del crédito, y no implica que si el cliente ofrece una excelente garantía y con un margen de cobertura muy amplio (de 3 o más veces al monto solicitado) el banco esté obligado a otorgar el préstamo. Las garantías se consideran como reales cuando recaen sobre bienes muebles o inmuebles (por ejemplo una hipoteca) o también se conocen como avales cuando éstas recaen sobre las personas (codeudores).

\section{Condiciones: se refiere al destino} del crédito, a qué sector económico se dirigen los recursos, si corresponde a un sector que está en dificultades o se prevé una recesión es muy probable que los bancos sean más cautelosos en el análisis de crédito. Por el contrario, si corresponde a un sector que presenta auge y crecimiento es más factible que se apruebe el crédito. No obstante, se pueden presentar empresas que se encuentran en sectores con dificultades, pero con excelentes indicadores y variables positivas cuyo resultado es la aprobación del crédito. De otra parte, se puede presentar empresas con indicadores negativos en sectores con bastante dinamismo y crecimiento, lo cual no las hace sujetos de crédito. Como en la economía se presentan periodos de recesión y expansión, sin determinar la extensión en tiempo ni la profundidad de éstas, se establece que los sectores que correspondan a los bienes de capital están directamente relacionados con estos ciclos, mientras que sectores que atienden o cubren necesidades básicas están menos expuestos. Por lo tanto, un buen análisis de crédito contempla diferentes escenarios y la exposición al riesgo de crédito que asume la entidad financiera.

El empresario deber ser consciente de que el negocio de un banco es prestar dinero y saber que, si las medidas adoptadas por el departamento de crédito son muy rigurosas y exigentes los efectos se pueden reflejar 
en el menor volumen de operaciones tramitadas, aprobadas y, por lo tanto, menores ingresos para los bancos. Si por el contrario, se adoptan medidas laxas y con pocos criterios, el volumen de operaciones aprobadas se incrementará, lo cual genera en el corto plazo mayores ingresos, pero en el mediano o largo plazo las consecuencias por pérdidas (no pago de los créditos) serán mayores; de ahí que el departamento debe ser lo más eficiente, pero a la vez lo más rentable con bajo riesgo.

\section{FACTORING: UNA ALTERNATIVA DE FINANCIACIÓN DIFERENTE AL CRÉDITO}

Uno de los mayores problemas que se presenta en las micro y pequeñas empresas está relacionado con la disponibilidad de efectivo para atender las necesidades diarias de la operación, tales como pago de nómina, dilación en el pago a proveedores, pago de servicios públicos, arriendo, entre otros (riesgo de liquidez), lo cual dificulta el margen de maniobra y puede afectar el normal funcio- namiento de la organización. De ahí que sea necesario adoptar medidas y mecanismos que minimicen este riesgo. Para tal efecto, el factoring ofrece otra alternativa para la obtención de recursos para las empresas, además de los productos de crédito tradicionales ofrecidos por las entidades financieras (cartera ordinaria, sobregiro, cupos rotativos entre otros).

Como un mecanismo para obtener liquidez, el factoring consiste en la transformación anticipada de las cuentas por cobrar que los clientes tienen con la empresa en efectivo para, de esta forma, obtener los recursos líquidos necesarios para la operación. Esta alternativa le permite a las Mipymes continuar con sus actividades misionales sin necesidad de acudir a fuentes de financiación que en muchos casos no son fáciles de conseguir, dado el nivel de riesgo, de condiciones, requisitos y garantías exigidas por parte de las entidades financieras.

En estas operaciones el acreedor, la empresa, cede la factura a favor de un tercero (denominado factor), que puede ser una entidad financiera, quien le 
pagará a la empresa y a la vez se hará cargo de la gestión de cobro. El factor puede o no asumir el riesgo ante el incumplimiento del pago del deudor al vencimiento del plazo de la factura. Entonces, se denomina factoring con recurso, cuando la empresa que expide la factura por la venta de un producto o servicio asume el pago de la factura ante el vencimiento de ésta y el deudor incumple en el pago de la obligación, exonerando a la entidad financiera del riesgo de no pago del cliente; en este tipo de operaciones, es la misma empresa que expide la factura quien asume el riesgo. Por su parte, el factoring sin recurso, en este caso la entidad financiera - la empresa factor, es quien asume el riesgo ante el incumplimiento en el pago de la factura por parte del deu- dor al vencimiento de esta. Actualmente algunas entidades financieras ofrecen los dos tipos de contrato, una vez analizadas las empresas que emiten las facturas y las empresas deudoras de dichas facturas. Esta fuente de financiación adquirió mayor fuerza en Colombia a partir de la expedición de la ley 1231 de 2008, que simplificó los requisitos para que las facturas puedan ser consideradas como títulos valores facilitando su negociación.

A manera de ejemplo, se presenta una operación de factoring asumida por una entidad financiera así:

Valor de la Factura $\$ 30.000 .000$

Porcentaje de reserva

$15 \% \$ 4.500 .000^{7}$ 
Valor de la factura al

$85 \% \$ 25.500 .000$

Plazo de la factura 30 días

Año base 360 días

Tasa efectiva anual $11.80 \%$

Al aplicar la fórmula de valor presente,

$$
\begin{aligned}
& \mathrm{VP}=\$ 25.500 .000 / \\
& (1+11, .80 \%)^{(30 / 360)}=\$ 25.264 .073
\end{aligned}
$$

Por lo tanto, al valor de la negociación de la factura se resta el valor presente y arroja el descuento

Valor descuento $=\$ 25.500 .000$

- $\$ 25.264 .073=235.927$

Valor descuento $\$ 235.927$

Valor neto a entrega $\$ 25.264 .073$

Las condiciones en cuanto a tasa, porcentaje de reserva y año base, pueden variar de una entidad a otra.
En este ejercicio la empresa recibe a la fecha de la negociación \$25.264.074 y al cabo de los 30 días siguientes recibirá $\$ 4.500 .000$, por lo tanto, el costo asumido es de $\$ 235.927$, a cambio de ello la organización obtiene recursos para atender sus necesidades operacionales sin tener contratiempos en el flujo de caja. 


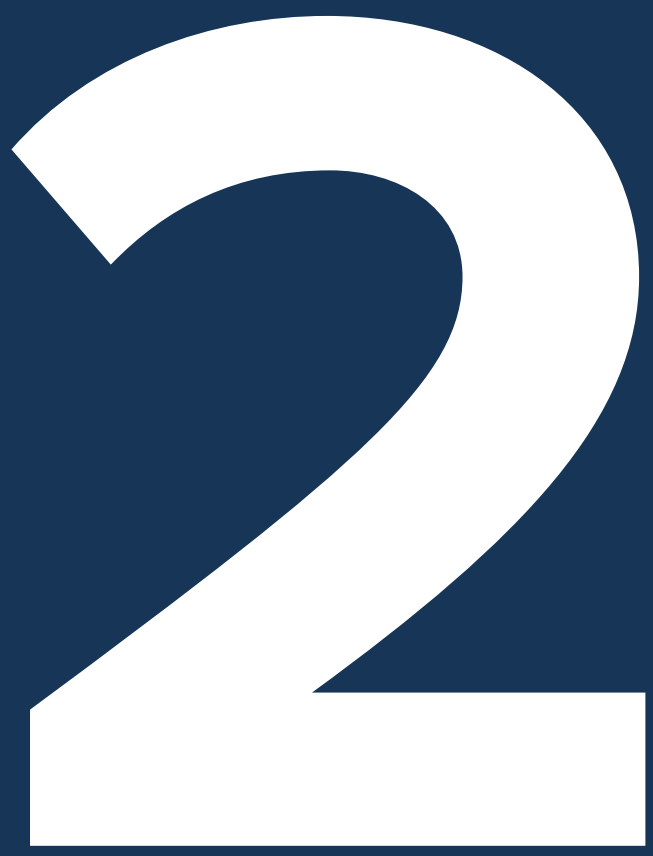

- - - - - - - - - -

CAPÍTULO

EL COSTO DE CAPITAL Y SU APLICACIÓN EN LA PEQUEÑA Y MEDIANA EMPRESA 


\section{¿Cómo un empresario puede valorar el riesgo?, metodología CAPM (Modelo de Valoración de Activos de Capital) explicada desde otra perspectiva para que un micro, pequeño y mediano empresario pueda entender su origen y la pregunta que quiere resolver, además de analizar el riesgo asociado al apalancamiento.}

Maldonado, Cristian \& Tunjano, Iván

\section{CONTEXTO TEÓRICO}

Normalmente, cuando un empresario decide invertir su dinero en determinado negocio, lo hace teniendo una expectativa de obtener de éste unos recursos superiores a lo comprometido. La diferencia entre lo primero y lo segundo es lo que se conoce como rentabilidad. Sin embargo, una de las cuestiones a resolver a la hora evaluar un negocio tiene que ver precisamente con cuál es la rentabilidad esperada del mismo, teniendo en cuenta que ésta no es un valor que se establece por deseo del inversionista, sino que debe responder al riesgo que repre- senta la alternativa y que se relaciona con la probabilidad de que las expectativas de ganancia se materialicen o que, desafortunadamente, se incurra en una pérdida.

Lo anterior, permite hacer énfasis en que el concepto de rentabilidad en muchos casos no se comprende de manera correcta al asociarse siempre con valores positivos y desconociendo que ésta puede ser negativa (por ejemplo, la expectativa de rentabilidad puede ser (+) 20\% pero también puede ser (-) 20\%). Al relacionarse con diferentes niveles de riesgo, las inversiones generan diferentes tasas de rendimiento 
$y$, de acuerdo con uno de los postulados fundamentales del mundo de los negocios, a mayor riesgo, mayor es (o debería ser) la rentabilidad esperada por el inversionista. Con esto en mente, el presente capítulo introduce una herramienta fundamental en la valoración del riesgo de alternativas de inversión y por consiguiente en la determinación de una tasa de rentabilidad acorde con dicha estimación: el Modelo de Valoración de Activos de Capital o CAPM por sus siglas en inglés.

\section{¿CUÁNTO DEBE RENTAR CADA NEGOCIO?}

Señor lector, suponga que cuenta con un capital que puede ser invertido y para eso tiene una alternativa de negocio, pero sólo puede invertir en una de las dos opciones:

Opción 1: invertir en una estación de distribución de combustibles en una vía que pertenece a la Red secundaria de vías en Colombia.

Opción 2: invertir en una compañía de tecnología que se dedicará a la fa- bricación de relojes inteligentes, que se conectan a los dispositivos celulares de los usuarios.

Suponiendo que la inversión inicial necesaria es igual para cualquiera de las opciones y es igual al capital que usted tiene disponible, la primera pregunta que deberá hacerse es: ¿Cuál rentabilidad debería ser más alta? o dicho de otra forma ¿cuál negocio es más riesgoso?

Ante estas preguntas, cada lector hará una estimación dependiendo de su experiencia o de su grado de conocimiento sobre cada negocio planteado, y si el propósito de este escrito fuera capturar esta percepción seguramente se obtendrían tantas combinaciones de riesgo y rentabilidad como de lectores de este capítulo haya.

Cuando se busca definir de esta forma, se pone en evidencia el carácter subjetivo de la percepción de riesgo (y de rentabilidad). Sin embargo, más allá de la opinión que cada uno de nosotros pueda tener sobre el riesgo asociado con determinado negocio, es una realidad que actividades econó- 
micas similares van a enfrentar riesgos inherentes a la misma y que no son necesariamente iguales a los de otra. Por ejemplo, un factor que puede afectar la rentabilidad de un negocio con una vocación tecnológica es la rápida obsolescencia de algunas tecnologías, mientras que una empresa dedicada a la distribución de combustibles va a ser muy sensible a la variación del precio del petróleo. Por lo tanto, es importante contar con una herramienta que pueda medir de manera objetiva la rentabilidad esperada de una inversión, teniendo en cuenta los riesgos que se derivan de desarrollar dicha actividad en específico. Este es el papel del modelo CAPM, cuya forma de aplicación se indica a continuación:

\section{ECUACIÓN 1 FÓRMULA MODELO CAPM}

\section{$\mathrm{KE}=\mathbf{R f}+(\mathbf{R m}-\mathbf{R f}) *$ Beta APA}

La figura 1 indica la ecuación que define este modelo. En la misma lo que se busca es estimar la rentabilidad esperada para el inversionista $(\mathrm{Ke})$ de determinado negocio basándose en los siguientes parámetros:
$\mathrm{Rf}=$ Rentabilidad libre de riesgo

$\mathrm{Rm}=$ Rentabilidad de mercado

Beta APA= Beta apalancado

¿Cómo funciona este modelo? Para responder a esta pregunta se explicarán cada uno de los componentes del mismo y los supuestos teóricos que facilitan y soportan su utilización:

\section{RENTABILIDAD LIBRE DE RIESGO}

En los mercados financieros existen activos que son cobijados por esta categoría y que, teóricamente, implica que, si usted realiza una inversión en este tipo de instrumentos, no existen posibilidades de no obtener la rentabilidad prometida por estos. Sin embargo, esto no es necesariamente cierto ya que el riesgo es un hecho inherente a la realidad de los negocios y de la vida en general, pero para este tipo de activos, su nivel de riesgo es tan bajo que son considerados como inversiones que prácticamente garantizan unos retornos. 
Dentro de este grupo de activos se encuentran los títulos de deuda ${ }^{8}$ de empresas muy reconocidas y que nunca han incumplido una obligación y también los títulos de deuda soberana o pública, estos últimos con un nivel de riesgo aún menor y corresponden a los bonos emitidos por los gobiernos. Para el caso de Colombia se denominan TES, y por medio de estos el gobierno pide al mercado recursos prestados, a corto mediano y largo plazo. Mediante esta modalidad el gobierno puede contar con recursos en el presente, que posteriormente devolverá y por cuyo uso pagará un interés. Este último correspondería a la rentabilidad del título para su tenedor y es considerada como un beneficio libre de riesgo por las siguientes razones:

»El ingreso del gobierno son los impuestos, por lo tanto, en la medida que no tenga dinero para pagar los intereses de sus deudas, entonces tendría la posibilidad de aumentar los impuestos para poder conseguir recursos para el pago.

»Los gobiernos tienen control sobre los recursos naturales y algunos commodities, como lo son el oro, el petróleo o los minerales, entonces en el momento en que no pueda responder por los intereses o el capital de un préstamo, aún tiene la posibilidad de utilizar estos recursos para el pago.

»Un Estado que no honre sus deudas se enfrentaría a un mercado de valores que no financiaría sus operaciones, por lo que no es un escenario admisible para un gobierno.

El análisis previo no desconoce el hecho de que no han sido pocos los casos en que gobiernos de diferentes

8. En algunos casos, las empresas para poder financiarse hacen uso de títulos de deuda denominados bonos. Mediante estos instrumentos las empresas recaudan recursos del público (quienes se convierten en acreedores de la misma), y se comprometen a devolver estos recursos en un plazo determinado y pagando unos intereses preestablecidos. Para la empresa el título es un pasivo que se extinguirá cuando se cumpla la obligación pero para quién lo compra es un activo cuya rentabilidad estará determinada por el pago de los intereses pactados. 
países de América Latina, por variadas razones, se han visto en la situación de no poder honrar estas obligaciones al momento de su vencimiento, por lo que no se puede hablar de una rentabilidad realmente "libre de riesgo". Sin embargo, es uno de los supuestos sobre el cual se soporta el modelo CAPM. Una forma más realista de entender este tipo de activos es considerarlos como aquellos que permiten obtener rentabilidad en los mercados financieros exponiéndose al menor riesgo posible.

\section{RENTABILIDAD DE MERCADO}

Un inversionista, podría diversificar sus inversiones, recordando esa máxima que dice que "no coloques todos los huevos en la misma cubeta", de esta forma, en la medida que pueda existir un evento que materialice el riesgo de pérdida, entonces se minimizaría su efecto.

Las inversiones funcionan de la misma manera, no todas las inversiones tienen buenos resultados y no todas tienen malos resultados en el mis- mo período de tiempo. Por tanto, de acuerdo con la teoría de portafolio, se debe distribuir el capital en diferentes alternativas para minimizar de forma colectiva el riesgo, y de esta manera cuando una inversión esté generando resultados negativos, el impacto se puede minimizar con otra inversión que pueda estar generando resultados positivos. Por ejemplo, en la gráfica 1 se tiene el rendimiento de diferentes activos financieros en un momento del tiempo, si por fortuna, hubiese invertido en alguno de los activos con un rendimiento positivo iperfecto! podría gozar de las ganancias obtenidas. Si, por el contrario, hubiese invertido ya sea en el activo dos o cinco, la situación sería otra. 


\section{GRÁFICA 1}

\section{RENTABILIDAD ACTIVOS}

\section{HIPOTÉTICOS}

Fuente: Elaboración propia

Rentabilidad diferentes activos

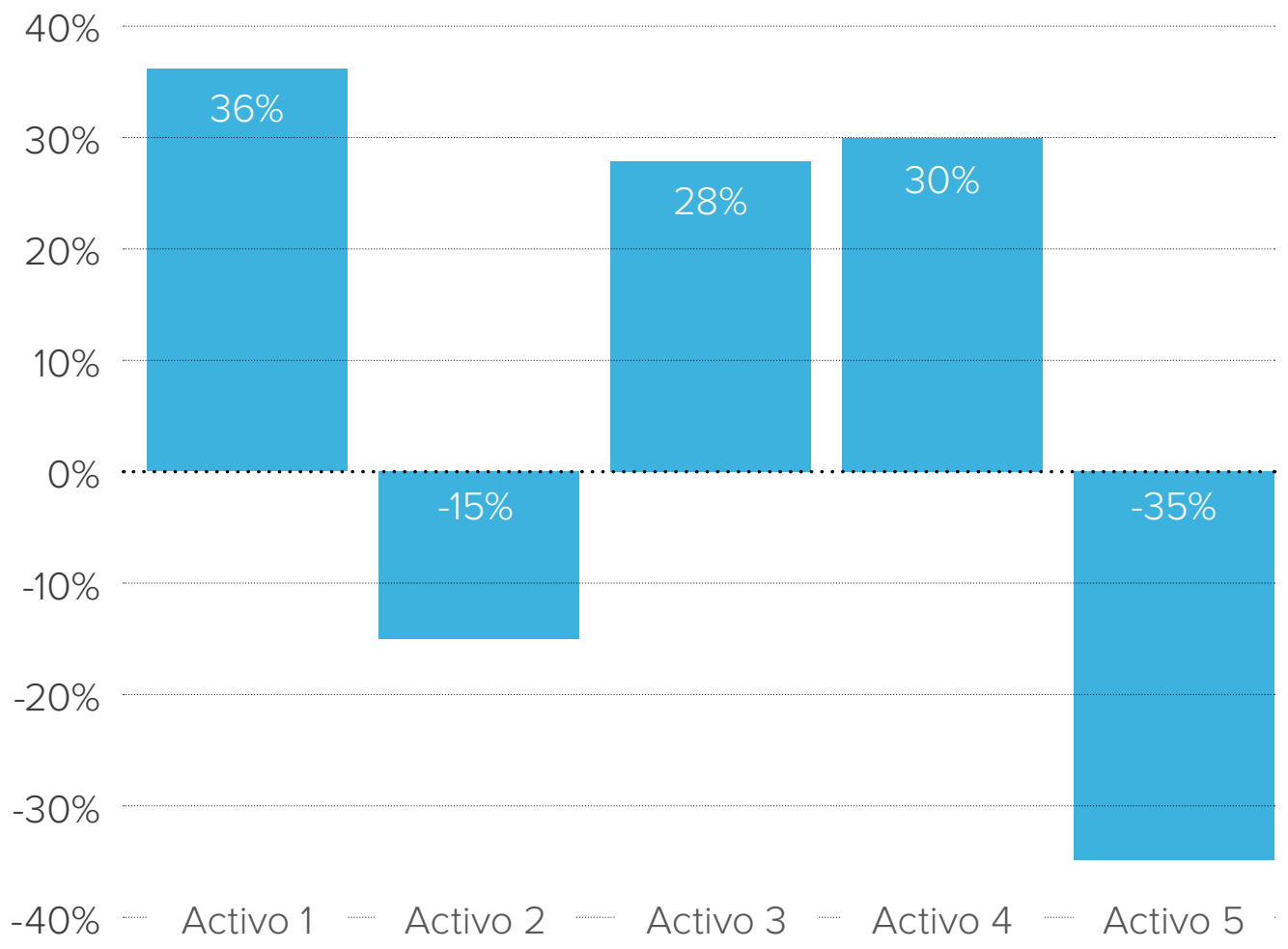


Entonces, un inversionista prudente realizaría un proceso de diversificación y realizaría inversiones en diferentes activos para así minimizar su exposición al riesgo de forma colectiva. En nuestro ejemplo hipotético, el inversionista obtiene una rentabilidad promedio de su portafolio del $9 \%$, lo que genera una pregunta, ¿cómo un inversionista puede obtener una rentabilidad de inversiones diversificadas?

Para resolver esta duda, podemos observar que en el mercado público de valores se negocian diferentes activos, en algunos países más activos que en otros, pero en esencia un inversionista podría utilizar este canal de inversión para adquirir participación en diferentes negocios, comprando acciones de diferentes empresas y en diferentes sectores, y de esta manera tendría entonces una rentabilidad promedio asociada al comportamiento del precio de las acciones en las que invirtió. Pero en el mercado ya existen los Índices de mercado, que, al estar compuestos por varias acciones de diferentes sectores, logran en alguna medida y dependiendo del ín- dice, representar una rentabilidad de mercado, es decir una rentabilidad diversificada o con homogeneidad de diferentes riesgos, y a esto lo llamaremos rentabilidad de mercado, lo cual será útil al momento de valorar la rentabilidad de un negocio en particular.

\section{BETA}

Como en muchos casos el inversionista no cuenta con los recursos suficientes para constituir un portafolio conformado por todos los activos que se negocian en el mercado, deberá decidirse por alguno o algunos títulos en específico, los cuales pueden ser más o menos riesgosos que el mercado en promedio y por lo tanto generar una rentabilidad por encima o por debajo que la del promedio del mercado respectivamente.

El beta es un indicador que permitirá capturar el efecto antes descrito de un activo en particular, es decir, si éste presenta variaciones en su rendimiento más pronunciadas que las del mercado en general. Para hacer su cálculo se aplica la siguiente fórmula: 


\section{ECUACIÓN 2 CÁLCULO DEL BETA DE UNA ACCIÓN}

\author{
Beta= \\ Covarianza (\% Activo; \% Mercado) / \\ (Varianza (\% Mercado))
}

\section{Donde}

\% Activo: Serán las diferentes mediciones de rentabilidad de un activo

\% Mercado: Serán las diferentes mediciones de rentabilidad de un mercado representado en su índice.

\section{EJEMPLO:}

Mercado colombiano de capitales, rentabilidad de las acciones de Nutresa, con respecto al índice COLCAP ${ }^{9}$ :

Supongamos que tenemos la información que se presenta en la tabla 4:
Con el cálculo de la variación en la rentabilidad del COLCAP y de Nutresa (columna 4 en ambos casos) ${ }^{10}$ se procedería a aplicar las fórmulas de estadística descriptiva de varianza y covarianza, como se indica en la ecuación 2 para obtener una estimación del beta para la acción de Nutresa de 0,58 (para ver de forma más detallada el cálculo del indicador referirse al anexo 1).

El cual representa la sensibilidad de los rendimientos de las acciones de Nutresa respecto a los rendimientos del mercado representado por el COLCAP. Es decir, representa los cambios que se presentan en los rendimientos de las acciones de Nutresa, con respecto a los rendimientos que obtienen en conjunto las acciones que se encuentran en el índice de mercado COLCAP.

9. EI COLCAP es un indicador que refleja las variaciones de los precios de las 20 acciones más líquidas de la Bolsa de Valores de Colombia (BVC) (Bolsa de Valores de Colombia, 2011, pág. 3).

10.Para obtener la variación día a día en términos absolutos (monetarios), ABS, de cada uno de los títulos, simplemente se hace la resta del valor de la columna last del día que se está analizando con el registro del período anterior. Por ejemplo, para el Colcap la variación absoluta entre el 24 y el 27 de abril, resulta de restar \$1.392,29 - \$1.374,49 = 17,8. La variación en términos porcentuales (\%) resultará de dividir el dato antes obtenido entre el precio del período inicial $(17,8 / 1.374,49=1,3 \%)$, y así con cada par de datos. La zona gris representa todos los valores que podremos encontrar entre el año 2015 y el año 2020, los cuales no se colocan en este escrito, pero sí se tienen en cuenta en el cálculo. 


\section{TABLA 4}

\section{PRECIO Y RENDIMIENTO ÍNDICE COLCAP Y NUTRESA}

Fuente: Página web BVC

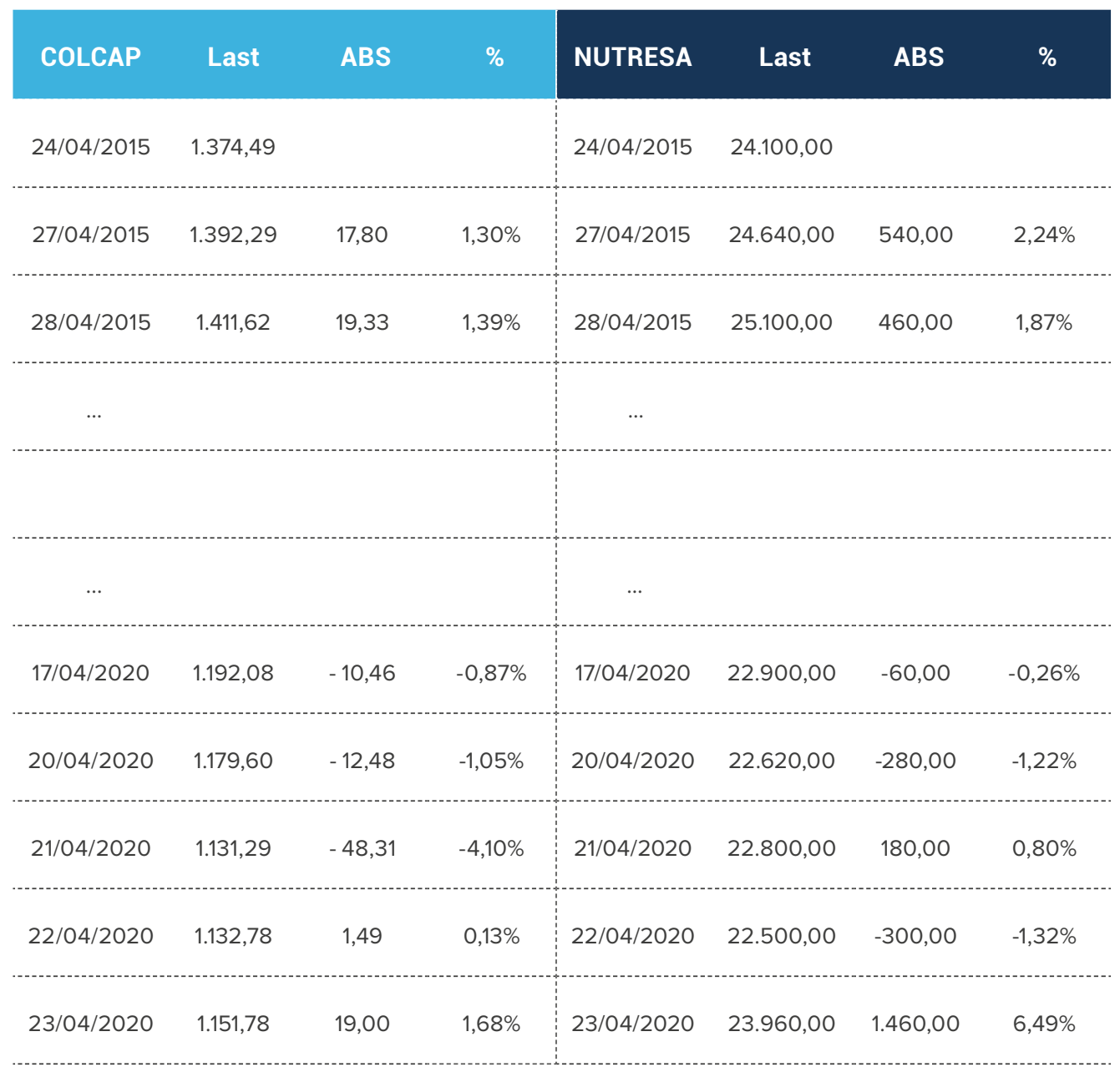


Para entenderlo mejor es necesario tener en cuenta las siguientes condiciones:

» Beta $=1$ (Los rendimientos de este activo se comportan igual a los rendimientos del mercado)

» Beta > 1 (Los rendimientos de este activo, amplifican los rendimientos del mercado)

»Beta $<1$ (Los rendimientos de este activo, amortiguan los rendimientos del mercado)

En el caso del ejemplo que se desarrolló anteriormente, el beta de la empresa Nutresa, amortigua los movimientos del mercado. Por tanto, Cuando el precio de las acciones que componen el índice COLCAP, baja un $10 \%$, entonces el rendimiento de las acciones de la empresa Nutresa, bajarán, pero no un $10 \%$. Solo bajarán un 0,58 de este valor.

Pero, cuando el precio de las acciones que componen el índice COLCAP, sube un $10 \%$, entonces el rendimiento de las acciones de la empresa Nutre- sa, subirán, pero no un $10 \%$. Solo subirán un 0,58 de este valor.

De esta forma, se puede representar el riesgo asociado a la gestión de un negocio, cuando se toman las variaciones en conjunto de los precios de las acciones de empresas que pertenecen a un mismo sector, y se comparan con el mercado, es decir con los rendimientos de varias acciones que pertenecen a un índice y que en conjunto involucran diferentes riesgos es decir diferentes negocios.

De otra forma, podemos decir que el beta representa, el comportamiento o sensibilidad de la rentabilidad de un sector, con respecto a los movimientos que puede tener el mercado. En este sentido podríamos suponer que el sector de turismo tiene un beta mayor a 1, porque cuando la economía se encuentra muy bien, los rendimientos que logra este sector son sobresalientes, pero cuando la economía se encuentra con síntomas de recesión, entonces el gasto hacia este sector se limitan, y sus pérdidas podrían ser mayores a las que en conjunto tendrán las empresas que pertenecen a esta economía hipotética. 
ESTRUCTURA DE CAPITAL Y EL BETA

Una empresa puede financiar sus activos de dos formas, ya sea con recursos ajenos (pasivo) y/o con recursos propios (patrimonio). La relación descrita se conoce como "estructura de capital", y cada negocio, a pesar de estar en un mismo sector, podría por diferentes proporciones entre deuda y patrimonio financiar sus ac- tivos (ver gráfica 2). Cada estructura de capital genera una condición de riesgo diferente asociada con la presión que se genera sobre las operaciones de la empresa para generar los recursos suficientes para cumplir sus obligaciones de deuda y generar una rentabilidad a sus propietarios. Por lo que el apalancamiento (nivel de endeudamiento) debe ser analizado a la hora de determinar una tasa de rentabilidad mínima.

\section{GRÁFICA 2}

\section{DIFERENTES ESTRUCTURAS} DE CAPITAL

Fuente: Elaboración propia

Patrimonio

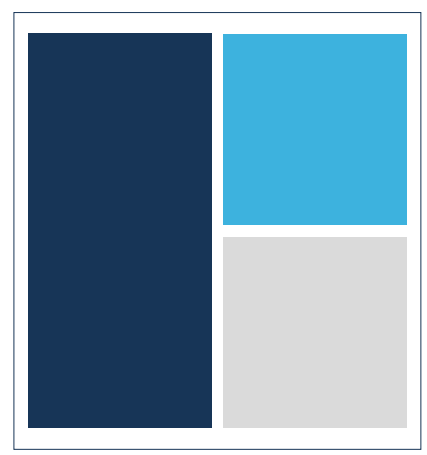

$\bar{\vdots}$
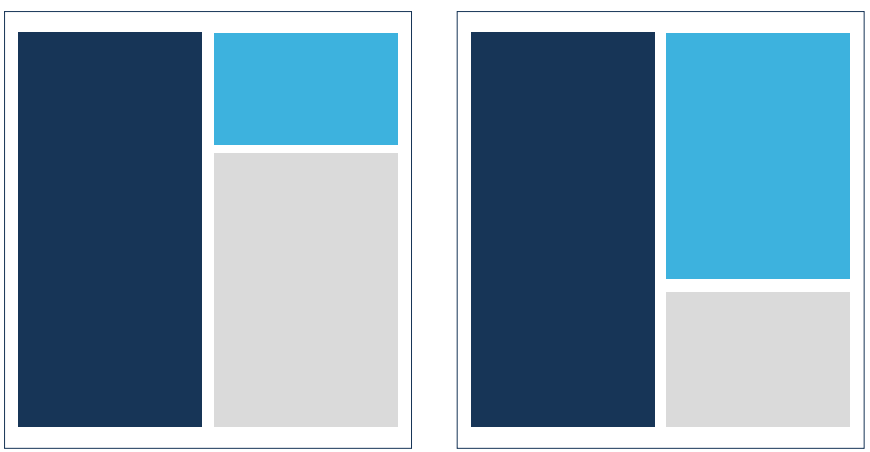

$\bar{\vdots}$ 
Las diferentes estructuras que se pueden dar tienen una incidencia en la generación de valor, debido a que, dependiendo de la estructura, cada empresa podría generar mayor o menor valor económico y por consiguiente la rentabilidad podrías ser mayor o menor que el grupo de empresas de un mismo sector, por lo que el precio de sus acciones también debería variar de la misma forma. $\mathrm{O}$, dicho de otra forma, cuando el beta se calcula con base en información de todas las empresas que conforman un determinado sector económico, está recogiendo no solo el efecto del riesgo operativo de tener un negocio que haga parte de dicho sector, sino que también incluye el riesgo asociado a la forma como las empresas del sector se están financiando y este es un riesgo que no se debería tener en cuenta a la hora de utilizar el beta del sector ya que la forma como una empresa financia sus activos es resultado de las decisiones de sus propieta- rios $^{11}$. Así que, para aislar el efecto del apalancamiento de las demás empresas, es necesario utilizar el beta sin apalancar del sector económico para luego incluirle el riesgo de la estructura financiera de la empresa que queremos valorar o apalancar el beta mediante la siguiente fórmula:

\section{ECUACIÓN 3 FORMULA PARA APALANCAR EL BETA}

\section{Beta APA= \\ Beta SA*(1+(1-tx)*(Deuda/Patrimonio)}

Donde:

Beta APA: Beta Apalancado

Beta SA: Beta sin apalancar

Tx: Tasa de impuesto de renta

Deuda: Total deuda

Patrimonio: Total capital aportado por los accionistas 


\section{NOTA:}

ALGUNOS AUTORES RECOMIENDAN SÓLO

UTILIZAR LA DEUDA QUE TIENE COSTO. SIN

EMBARGO, PARA DECIDIR SI INCLUIRLA O

NO, ES IMPORTANTE ENTENDER QUE LO QUE

SE BUSCA CON ESTA FÓRMULA, AL DIVIDIR

LA DEUDA SOBRE EL PATRIMONIO, ES

MULTIPLICAR EL APALANCAMIENTO POR UNA

SENSIBILIDAD DE RIESGO DETERMINADA

POR EL BETA. ES DECIR, INCLUIR LA

PARTICIPACIÓN QUE TIENEN LOS TERCEROS

SOBRE LOS RESULTADOS DE LA EMPRESA.

Esta fórmula busca agregar un nivel más alto de sensibilidad en la medida que el apalancamiento es mayor, para así lograr sumar el significado de mayor riesgo derivado del apalancamiento, en el análisis de sensibilidad que está buscando determinar el beta. Por ejemplo, suponga que un sector presenta un beta de 1,5 lo cual signi- fica que este sector amplifica los movimientos del mercado, tanto positivos como negativos. Pero suponga que por otro lado se tiene una empresa (que hace parte de este sector) y se quiere analizar la sensibilidad del beta ante diferentes niveles de deuda de la empresa (beta apalancado), así: (suponga una tasa de impuestos del 30\%) 


\section{TABLA 5}

\section{BETAS APALANCADOS}

Fuente: Elaboración propia

$\begin{array}{llll}\text { Empresa A Deuda total } & \text { Patrimonio Beta SA APA }\end{array}$

$\begin{array}{lllll}\text { Estructura } 1 & 600 & 200 & 1,5 & 4,65\end{array}$

$\begin{array}{lllll}\text { Estructura } 2 & 500 & 300 & 1,5 & 3,25\end{array}$

$\begin{array}{lllll}\text { Estructura } 3 & 400 & 400 & 1,5 & 2,55\end{array}$

$\begin{array}{lllll}\text { Estructura } 4 & 200 & 600 & 1,5 & 1,85\end{array}$

$\begin{array}{lllll}\text { Estructura } 5 & 100 & 700 & 1,5 & 1,65\end{array}$

Observando la tabla anterior, se pue- lógica en la medida que se asocia un de inferir que un mayor nivel de apa- mayor apalancamiento financiero con lancamiento aumenta la sensibilidad un mayor riesgo a los movimientos que representa el beta, y esto tiene del mercado, en consecuencia: 
» Una empresa con mayor deuda, en situaciones de un mercado a la baja (economía en recesión), tendrá mayores pérdidas, derivada del pago de intereses.

\section{Una empresa con menor deu-} da, en situaciones de un mercado a la baja (economía en recesión), tendrá pérdidas derivadas del pago de intereses, pero de una forma moderada respecto a la situación anterior.

» Una empresa con mayor deuda, en situaciones de un mercado al alza (economía en crecimiento), tendrá mayores ganancias, derivadas del apalancamiento, que aumenta su capacidad.

Una empresa con deuda moderada, en situaciones de un mercado al alza (economía en crecimiento), tendrá moderadas ganancias, derivadas del apalancamiento, que aumenta su capacidad, pero de forma moderada.

Por último, tenga en cuenta que la fórmula puede ser modificada para calcular el valor de un beta sin apalancar. Suponga que calculó el valor del beta con la variación de precio de las acciones de Nutresa que se presentó anteriormente, y el valor obtenido es de 0,58.

El valor obtenido, está teniendo en cuenta el apalancamiento de la empresa, debido a que el precio de las acciones y sus variaciones, ya están descontando el apalancamiento que la empresa tiene en la vida real, por lo tanto, ese beta calculado corresponde al beta con apalancamiento, y para conocer el beta sin apalancamiento entonces tendríamos que despejar esta variable de la fórmula, así:

\section{Beta SA=}

\section{Beta APA / (1+(1-tx)*(Deuda/Patrimonio)}

En los estados financieros tenemos que la deuda de esta empresa es de 2.709.263 millones, y un patrimonio de 12.953.977 millones para cierre del año 2019 , suponiendo una tasa de impuestos del $30 \%$, tendríamos:

\section{$0,50=$ \\ $0,58 /(1+(1-30 \%) *$}

\section{(2.709.263/12.953.977)}

Como se puede observar la sensibilidad representada por el beta, disminuye al ser evaluada sin apalancamiento. 
La aplicación del modelo CAPM como se mostró anteriormente, es decir, basándose en información de empresas listadas en la Bolsa de Valores de Colombia, presenta una serie de limitaciones relacionadas con la representatividad de este mercado con relación al resto de las empresas del país ya que esta es relativamente pequeña y con una alta concentración de sus operaciones en un reducido número de títulos. Por tanto, en la práctica para aplicar este modelo es mucho más común hacer uso de los betas basándose en los rendimientos de los activos que se negocian en el mercado de los Estados Unidos (S\&P500).

Muchas empresas de servicios de información financiera hacen el cálculo de la estimación de estos parámetros, sin embargo, tienen un costo. Una alternativa que se utiliza con mucha frecuencia a nivel académico y para pequeñas y medianas empresas, que no tienen el músculo financiero para pagar por estos servicios, y que permiten generar unos datos robustos para el análisis, son los cálculos hechos por el autor Aswath Damodaran (2020) (que son gratuitos y de libre acceso) con base en información de la economía más representativa en términos de sectores económicos del mundo.

De acuerdo con la información que utiliza el autor, se trabaja la rentabilidad del mercado como la que producen las acciones que componen el ín- dice S\&P 500. Este indicador mide el comportamiento de las 500 empresas más grandes que se listan en el mercado de valores de Estados Unidos, es uno de los más seguidos y es considerado uno de los más representativos de la economía. Para la rentabilidad del activo libre de riesgo utiliza los Treasury bonds o T-bonds que son títulos de deuda emitidos por la reserva federal de este mismo país, con vencimiento superior a 10 años.

Los betas son calculados para cada sector económico que compone este índice, se hacen estimaciones tanto del beta apalancado como del desapalancado para el sector.

La aplicación de este modelo sería como sigue: se quiere calcular el costo del patrimonio, es decir la rentabilidad mínima esperada, Ke, para una empresa que se encarga de la producción y comercialización a base de soya y que realiza sus operaciones en Colombia. Inicialmente, se deben identificar los parámetros de rentabilidad del mercado y rentabilidad del activo libre de riesgo (se recomienda revisar la bibliografía para encontrar la página del autor recomendado). Queda a juicio de quien realice la valoración, la utilización de la rentabilidad promedio de los últimos 10 años, la de un promedio más amplio, o la de un año de forma puntual (los autores del presente capítulo no recomiendan utilizar el promedio de toda la serie histórica, ni de períodos de tiempo 
muy amplios). Para este ejemplo se utilizará la rentabilidad media de los últimos 10 años (2019/2009). Entonces se tendría:

\section{$\mathrm{Rm}=14,02 \%$}

$\mathrm{Rf}=\mathbf{7 , 2 3} \%$

El siguiente paso implica identificar el beta desapalancado para el sector de alimentos, se utilizará, el que corresponde a Food Processing

\section{Beta SA \\ del sector Food Processing $=0,68$}

A continuación, y teniendo en cuenta que la empresa que se quiere valorar tiene un nivel de deuda total de $\$ 950$ millones, un patrimonio de $\$ 600 \mathrm{mi}-$ llones y una tasa de impuesto de renta del 30\%, se procede a apalancar el beta dada la estructura particular de capital de la compañía:

\section{Beta APA=}

Beta SA*(1+(1-tx)*(Deuda/Patrimonio)

\section{Beta APA=}

$0,68 *(1+(1-30 \%) *(950 / 600)=1,44$

Por tanto, el costo del patrimonio será:

\section{KE $=\mathbf{R f}-(\mathbf{R m}-\mathbf{R f})^{*}$ Beta APA}

$K E=7,23 \%+(14,02 \%-7,23 \%) * 1,44=17 \%$

Pero, como podrá notar el lector, el nivel de riesgo que enfrenta un em- presario colombiano no es el mismo de hacer negocios en EE. UU, por tanto, el valor obtenido anteriormente debe ser ajustado para capturar el hecho de que se está haciendo la estimación para Colombia. Esto puede hacerse mediante la inclusión de una prima por riesgo país, para lo cual se utilizará el EMBI o Emerging Markets Bonds Index o Indicador de Bonos de Mercados Emergentes para Colombia. Este indicador, calculado por la firma JP Morgan (2019), mide la diferencia entre los rendimientos de los títulos de deuda pública del tesoro de países emergentes y los de EE. UU. En la medida en que esta diferencia sea más grande, mayor será la percepción de riesgo del país que se esté analizando.

Para el caso de la elaboración de este escrito, se tenía que el EMBI para Colombia era de 517 puntos básicos, es decir $5,17 \%$.

Por tanto, el costo del patrimonio incluyendo la prima de riesgo país sería

Ke'=(1+KeEUU)*(1+riesgo país)-1

\section{$\mathrm{Ke}=(1+17 \%)^{*}(1+5,17 \%)-1=23,06 \%$}

Por lo que la rentabilidad esperada para el patrimonio de la empresa señalada será del 23,06\%. Este valor refleja el riesgo operativo del negocio y el riesgo de su estructura particular de financiación. 


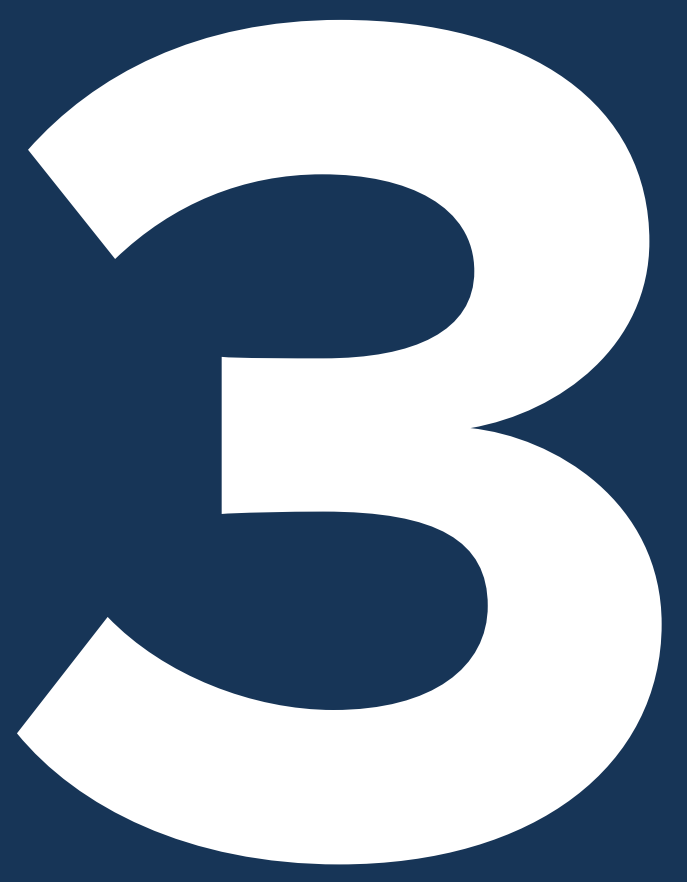

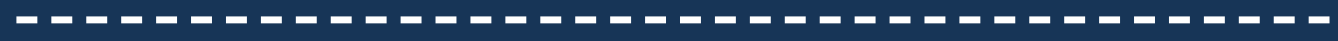

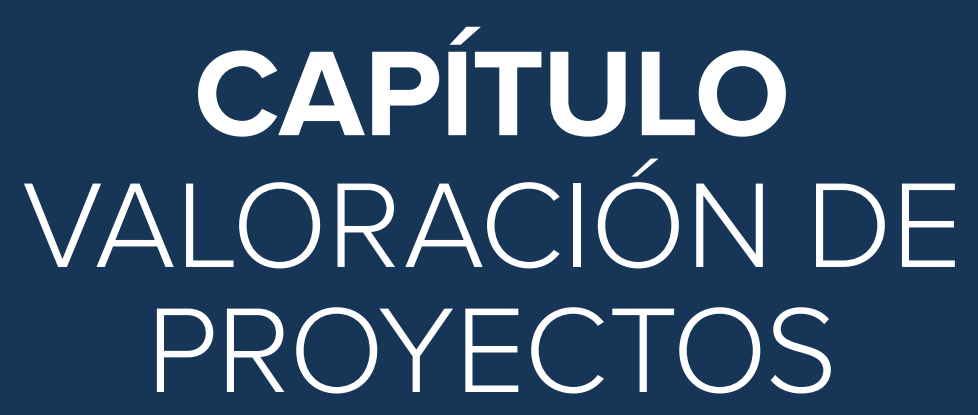




\title{
Al tiempo y al riesgo se le suma el dinero, para entender cómo la combinación de estas variables hace posible un análisis objetivo de la viabilidad financiera de un proyecto; no se trata de que un proyecto dé rentabilidad positiva, se trata de que rente lo mínimo que debe rentar.
}

\author{
Vargas, Rocío Hernández, Nydia \& Martínez, Mauricio
}

\section{CONCEPTOS GENERALES}

\section{¿QUÉ ES UN PROYECTO?}

Un proyecto se refiere al esfuerzo que se imprime en el planteamiento de un objetivo y las tareas interrelacionadas que se deben desarrollar para lograrlo. En este proceso intervienen unos recursos que pueden ser humanos, materiales, equipos, instalaciones y cualquier otro necesario para la operación. Un proyecto puede ser una modernización de una fábrica o un negocio, la introducción de un nuevo producto, la apertura de una sede nueva o cualquier proceso sistemático que nos permita llegar al planteamiento y ejecución de actividades para conseguir un fin.

Podemos entonces resumir algunos elementos básicos del proyecto: en el proyecto hay actividades interrelacionadas, el proyecto debe tener una ubicación específica, debe tener un tiempo preciso de inicio y fin; en el desarrollo del proyecto hay actores que intervienen, y se definen recursos necesarios para la ejecución; por último, existe una incertidumbre que acompaña su desarrollo. 


\section{FASES DE UN PROYECTO}

Todo proyecto tiene un ciclo y dentro de este ciclo podemos encontrar unas fases o etapas, las cuales van a estar interrelacionadas e influenciadas por diferentes actores, recursos, organizaciones que van a repercutir en el éxito del mismo.

En primer lugar, se sugiere que la persona piense en una idea ya sea de mejora, una necesidad o una oportunidad que conduzca a la realización del proyecto. Esta idea inicial se puede enmarcar en la siguiente figura: (Ver ilustración 1).

El primer momento de un proyecto se desprende de una idea e involucra el análisis, del sector en el cual se enfocará el mismo. Comprender la evolución, las particularidades y necesidades del sector en el cual se ubicará el proyecto es indispensable. Generalmente se busca satisfacer una necesidad, un ejemplo se presenta con la pandemia del Coronavirus COVID-19, ya que las personas conscientes de la necesidad de quedarse resguardados en casa preferirían hacer sus compras a través de plataformas virtuales que permitan no sólo mercar alimentos e insumos de necesidades básicas sino productos para sus hijos como materiales didácticos, rompecabezas, pinturas e incluso tintas para impresoras. De aquí puede nacer una idea de proyecto.

La idea es el primer contacto con el proyecto en sí, puede ser algo básico o puede ser un pensamiento innovador que evolucione hacia algo mucho más trabajado y que requiera una investigación más profunda. En ambos casos tendremos un proyecto que se va a desarrollar y que es susceptible de ser evaluado para determinar su viabilidad financiera.

Luego, se debe establecer cuál necesidad se va a cubrir. Para ello, es indispensable definir el segmento del cual se va a cubrir una necesidad existente, lo que nos lleva al mercado potencial. La información previa a la realización del proyecto es muy importante, fuentes de información como la Asociación Nacional de Instituciones Financieras ANIF, la Asociación Nacional de Industriales ANDI, la Confederación Colombiana de Cámaras de Comercio CONFECAMARAS, La Cámara Colombiana de la construcción CAMACOL entre 
otras que permitan a los microempresarios estar más enterados del panorama general y no solo apropiarse del día a día del negocio.

Paralelamente, el estudio de factibilidad busca analizar diferentes factores como son el entorno macro y micro, dentro de los cuales se hace un análisis legal, económico, político, social, ambiental y del sector particular; además el inversionista debe informarse sobre las amenazas y oportunidades que presenta el sector. En esta etapa el inversionista podría desarrollar un cronograma de actividades.

Luego de realizar el plan de factibilidad, el plan de negocio es el estudio de factibilidad convertido en un documento práctico y fácil de implementación.

A continuación, se presentan las etapas del ciclo del proyecto: (ver ilustración 2).

\section{ILUSTRACIÓN 1}

\section{PROCESO DE ANÁLISIS DE \\ LA IDEA A TRABAJAR}

Fuente: Elaboración

propia, modificado de

Formulación y evaluación de

proyectos. Lozano, R, p22, (2016).
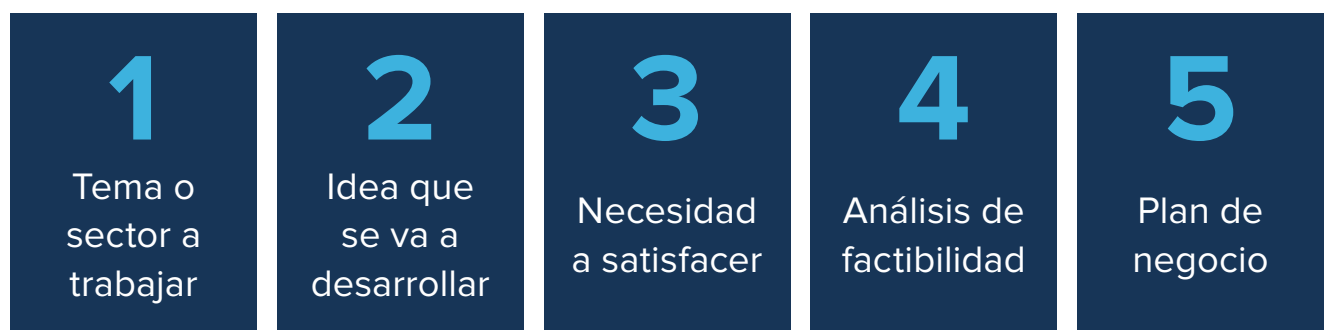


\section{ILUSTRACIÓN 2}

\section{FASES DEL CICLO DEL PROYECTO}

Fuente: Elaboración propia.

\section{Formulación}

Desde la concepcion de la idea hasta la decisión de invertir. Intervienen diferentes estudios.

\section{Evaluación}

Viabilidad, presupuesto Flujos de

caja. Análisis e indicadores.

\section{Ejecución}

Montaje y operación del proyecto. 


\section{FORMULACIÓN DEL PROYECTO:}

Esta etapa puede considerarse de preparación; se tiene una idea a partir de una necesidad observada, se establece un segmento de mercado a satisfacer y se realizan los estudios necesarios para entender la posición en la cual se encuentra la empresa a nivel interno y externo. Algunos estudios que se deben desarrollar son:

\section{ESTUDIO DE MERCADO:}

Se debe encontrar la participación del proyecto en el mercado, establecer esta participación es muy importante para luego poder proyectar adecuadamente los ingresos esperados. En este análisis se deben entender las amenazas y oportunidades que brinda el entorno y las capacidades y limitaciones internas para poder atender el proyecto.

\section{ESTUDIO DE ASPECTOS TÉCNICOS DEL PROYECTO:}

Entender el tamaño o necesidades en cuanto a magnitud, monto de inver- sión para poder producir, que tecnología se requiere. También se definirá dónde estará localizado el proyecto.

\section{ESTUDIO FINANCIERO:}

Este estudio define un momento de decisión y podemos encontrar dos fases claves: la construcción del flujo de caja del proyecto y su viabilidad. Para la construcción del flujo de caja se requerirá el mercado objetivo, la proyección de ventas (cantidad y precio), la proyección de costos, y el análisis de fuentes de financiación. Luego se evaluarán los flujos a través de diferentes indicadores que permitirán calcular la conveniencia de llevarlo a cabo o no; algunos ejemplos de estos indicadores son: VPN, TIR, RCB Y PAYBACK

\section{IDENTIFICACIÓN DEL SECTOR}

Los proyectos se pueden clasificar de diferentes formas; a continuación podemos encontrar una clasificación según el sector. El Instituto Latinoamericano de Política Económica y Social (ILPES) realiza la siguiente clasificación: 


\section{TABLA 6}

\section{CLASIFICACIÓN POR SECTOR}

Fuente: Mendez, R. (2016).

Formulación y evaluación

de proyectos. Enfoque

para emprendedores

\section{Producción de bienes}

Producción de servicios

Investigación

1 Primarios (Extractiva) 1 Infraestructura Física 1 Investigación

Agrícolas

Trasportes

Pecuarios

Comunicaciones

en ciencias

Mineros

Pesqueros

Irrigación

Exactas

Energía Eléctrica

Naturales

Forestales

Saneamiento

2 Secundarios

Urbanización

Sociales

3 Investigación aplicada

(Transformación)

2 Infraestructura social

Recursos Naturales

Procesos

Bienes de consumo Final

Salud

Bienes Intermedios

Educación

Bienes de Capital.

Vivienda

Organización social

3 Otros servicios

Financieros

Distribución

Informativos

Profesionales 


\section{¿QUÉ ES INVERSIÓN?}

La inversión es un componente fundamental en cualquier proyecto; es la cuantificación de los recursos monetarios que se necesitan para su puesta en marcha ya que el propósito de la inversión en un proyecto es incrementar los flujos de caja a futuro.. De la misma forma, la identificación de necesidades de financiamiento se hace indispensable.

\section{INVERSIÓN EN PROPIEDAD, PLANTA Y EQUIPO}

La inversión en propiedad planta y equipo, es usualmente llamada CAPEX por su sigla en inglés (Capital EXpenditures). En esta categoría se deben incluir aquellos activos tangibles que se requieran para desarrollar el proyecto de inversión; aquí podemos incluir toda la maquinaria, equipos de oficina, vehículos de transporte de mercancías, entre otros. La propiedad, planta y equipo, deben generar beneficios económicos futuros y deben ser valorados de manera fiable.

\section{INVERSIÓN EN CAPITAL DE TRABAJO}

También llamada OPEX, que corresponde a la sigla en inglés de Operational Expenditures. Son aquellos recursos que requiere la empresa para poder operar y garantizar el funcionamiento del proyecto en el corto plazo; se calcula desde la base del efectivo a corto plazo, requerimientos de cartera, necesidades de materia prima, producto en proceso y terminado.

El monto de capital de trabajo se debe escoger según las siguientes características:

»Efectivo para cubrir pagos a corto plazo. Ejemplo: Nómina, servicios.

» Inventarios, materias primas e insumos. Calcular rotación

»Productos en proceso: Costos de producción y rotación

»Cartera: Ventas a crédito 
Cuando se habla del capital de trabajo neto contable, se toma el activo corriente y se resta el pasivo corriente. Sin embargo, si se desea hacer un estudio más profundo, es pertinente determinar el capital de trabajo neto operativo (KTNO) en el que intervienen exclusivamente los activos que generan caja, es decir los inventarios y los deudores comerciales (clientes), restando la financiación de los proveedores.

Para este cálculo se elimina el efectivo y sus equivalentes, dado que se procura que este rubro sea lo más bajo posible para que la empresa no disponga de capital ocioso. Al tener un adecuado manejo de los inventarios, la cartera y los proveedores, respecto de la gestión y políticas que se deben tener con cada uno de estos, la empresa puede asegurar liquidez, teniendo un correcto manejo de sus inventarios para no incurrir en sobre costos y haciendo un eficaz cobro de la cartera. Por su parte, el tener suficiente plazo de financiación con los proveedores puede evitar incurrir en costos financieros a través de deuda.
Como ejemplo del cálculo de KTNO se puede suponer una tienda de abarrotes, donde el dueño de la tienda posee los siguientes activos y pasivos corrientes:

Efectivo en el banco: 1.000

Inventarios: 15.000

Cuentas por cobrar a clientes: 8.000

Cuentas por pagar a proveedores: 10.000

Gastos del mes: 4.500

Otras deudas: 7.000

KTNO = Inventarios + Cuentas por cobrar a Clientes - Cuentas por pagar a proveedores

$$
\mathrm{KTNO}=15.000+8.000-10.000
$$

$\mathrm{KTNO}=13.000$

\section{INVERSIÓN EN ACTIVOS INTANGIBLES}

Los activos intangibles son aquellos no físicos, pero que son controlables por 
la organización ya que se deben explotar para que genere beneficios futuros. Ejemplos de activos intangibles son: bases de datos de clientes, programas, franquicias, licencias, patentes.

\section{INVERSIÓN EN PREOPERATIVOS}

Antes de empezar la operación inherente al desarrollo del negocio, se deben contemplar unos gastos previos a las operaciones según las Normas Internacionales de Información Financiera NIIF, tales como los estudios de mercado, gastos de registro, investigaciones de profesionales contratados o personal de vigilancia; un ejemplo sería la construcción de una sede nueva para venta de materiales de construcción, la bodega que se está construyendo será un activo de propiedad planta y equipo, pero la persona que ayuda con el aseo debe ir al gasto en el estado de resultados.

\section{COSTOS DEL PROYECTO}

\section{FIJOS}

Los costos fijos son aquellos que por ser inherentes al proyecto son obligados, tales como el arrendamiento, pago de impuestos prediales, servicios públicos, materiales de oficina, servicios de internet, vigilancia, transporte, o que por decisión de los encargados se generen para lograr propósitos, pero que son fijos como publicidad, promoción, contratos de mantenimiento o de capacitación.

\section{VARIABLES}

Los costos variables guardan directa relación con la repartición del costo del producto o servicio; en esta categoría podemos encontrar los costos directos que son aquellos que tienen relación directa; por ejemplo: para la fabricación de una silla, se requiere madera y metal, los costos directos serian estos materiales más la mano de obra utilizada, es decir materiales directos, como insumos, materia prima que es requerida para el producto o servicio que se fabrique o se preste. El pegante sería un costo indirecto. En definitiva, los costos variables fluctúan en relación con el volumen de fabricación que se realice. 


\section{MUERTOS}

Los costos muertos son aquellos en los que se incurre antes de empezar la operación del negocio y que son inevitables, ejemplo de estos costos son los estudios previos a la realización de un proyecto o la pintura y pago de honorarios al pintor de una bodega antes de ponerla en punto para abrir el negocio.

A nivel contable, estos "costos" se deben tener plenamente identificados y reconocerlos en el momento oportuno para proceder a aplicar una amortización y /o transferirlos. De no ser así, estos costos serán gastos y no se podrán recuperar desde el precio de venta.

En el mismo sentido, hay diferencia entre si finalmente se realiza el proyecto o no. En caso de que el inversionista tome la decisión de llevar a cabo el proyecto, los costos muertos se podrán amortizar dentro de lo que sea permitido a nivel fiscal, si el proyecto se demora, se detiene en el tiempo o no se identifican y se reconocen oportunamente, serán gastos que impacten los resultados.

\section{FINANCIEROS}

En relación con el financiamiento del proyecto es necesario evaluar diferentes alternativas de inversión que permitan escoger la fuente de financiación en relación con el plazo, condiciones del crédito, costo de intereses; estos a su vez tienen costos asociados como son el estudio de crédito, los seguros, las comisiones bancarias, estos costos se deben tener en cuenta a la hora de analizar la mejor opción para el proyecto.

\section{Flujo de caja}

Es un registro de egresos y de ingresos, teniendo presente que en el momento cero, se espera tener una salida de dinero "egreso" representado como la inversión inicial, la cual tendrá un tratamiento especial a la hora de evaluar financieramente el proyecto. 


\section{TABLA 7}

\section{FLUJO DE CAJA PROYECTADO}

Fuente: Elaboración propia.

$\begin{array}{lllll}\text { Ingresos del periodo } & \text { Periodo } 1 & \text { Periodo } 2 & \text { Periodo } 3 & \text { Periodo n }\end{array}$

(+) Ingresos Ingresos Ingresos Ingresos

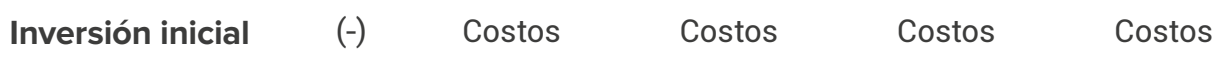

(-) Gastos Gastos Gastos Gastos

Es necesario tener en cuenta aquellos rubros que tienen efecto tributario gracias a que se registran como gastos, es decir disminuyen la utilidad y por lo tanto la base de impuestos, sin embargo, constituyen una salida real de efectivo. Estos son:

>La depreciación, que es la pérdida de valor de la propiedad, planta y equipo a través del tiempo.
La amortización de activos intangibles o diferidos, que corresponde a activos inmateriales o derechos adquiridos por la empresa.

" Gastos preoperativos, que son todos los gastos incurridos antes de empezar la operación de una empresa o proyecto.

A continuación, se listan los rubros más usuales para cada uno: 


\section{ILUSTRACIÓN 3}

\section{RUBROS QUE NO REPRESENTAN SALIDAS DE EFECTIVO}

Fuente: Elaboración propia.

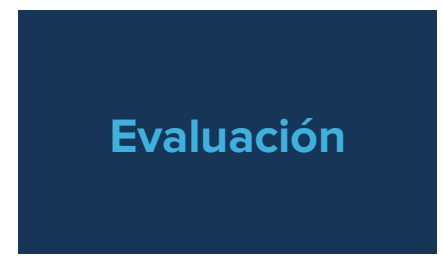

Construcciones

Maquinaria y equipo

Muebles y enseres

Equipos de

tecnología

Vehículos

Infraestructura

Recursos

naturales: mineros, petroliferos, agropecuarios

\section{Amortización} intangibles / diferidos

\section{Amortización} de gastos preoperativos
Trabajos de

investigación

en desarrollo

de productos, servicios, procesos

Trabajos de ingeniería, tecnología o legales

Organización y administración

\section{Patentes}

Gastos de constitución 
Es importante mencionar que la depreciación, y las amortizaciones de los intangibles, diferidos y gastos preoperativos, es preciso calcularlos para elaborar el flujo de caja por el método indirecto. Los métodos de elaboración del flujo de caja se estudiarán más adelante en este capítulo.

Por su parte, se debe considerar el valor residual del proyecto, que corresponde al valor de los activos al final del horizonte de inversión; cuando se habla de activos, se hace referencia a la propiedad planta y equipo y al capital de trabajo invertido.

En el último periodo de la proyección, se debe incluir el valor estimado de venta de dichos activos en ese momento, en algunos casos puede ocurrir que el valor residual no se tenga en cuenta si se espera que al final de la proyección estos activos no se puedan vender. Si se trata de una empresa de transporte, con un horizonte de inversión de 5 años, puede estimar el precio de venta de los vehículos al cabo de este periodo. Caso contrario sería para una empresa de servicios, donde la mayoría de sus activos pueden estar representados en muebles, enseres y equipos de tecnología, que al cabo de unos años serían obsoletos. 


\section{TABLA 8}

FLUJO DE CAJA PROYECTADO

\section{TENIENDO EN CUENTA EL}

\section{VALOR RESIDUAL}

Fuente: Elaboración propia.

(+) Ingresos Ingresos Ingresos Ingresos

Inversión inicial

$(-) \quad$ Costos

Costos

Costos

Costos

(-) Gastos

Gastos

Gastos

Gastos 


\section{FLUJO DE CAJA LIBRE}

El flujo de caja libre se refiere a todos los ingresos y egresos que tienen relación directa con el objeto social. Indica el dinero que le queda disponible a una empresa, después de tener en cuenta los siguientes rubros:

»Pago de todos sus costos y gastos operacionales

»Impuestos operacionales (calculados a partir de la utilidad operacional)

»Incremento o disminución de la inversión en capital de trabajo a empresa.

»Incremento o disminución de la inversión en propiedad, planta y equipo.

Dicho lo anterior, el flujo de caja libre significa la capacidad financiera o capacidad de generar efectivo para un negocio.
MÉTODOS PARA

\section{CONSTRUIR EL FLUJO DE}

\section{CAJA LIBRE}

Existen dos métodos para el desarrollo del flujo de caja libre, el método directo y el método indirecto. En la estructura que se verá a continuación para cada método, solo se tiene en cuenta las partidas que corresponden a la operación del negocio, es decir no se incluyen movimientos en la deuda o el pago de dividendos a los accionistas, dado que estos corresponden al flujo de caja de la deuda y al flujo de caja del accionista.

\section{FLUJO DE CAJA POR EL MÉTODO DIRECTO:}

Con este método se deben registrar los rubros que significaron entrada $o$ salida real de efectivo durante un periodo. La información que se debe tener a la mano es la siguiente: 


\section{TABLA 9}

\section{INGRESO Y SALIDAS \\ REALES DE EFECTIVO}

Fuente: Elaboración propia

Ventas de contado

" Cobro de cartera en el periodo

»Otros cobros derivados de la operación
»Compras a proveedores pagadas de contado

»Pagos a proveedores

»Pagos en efectivo de impuestos

»Pagos en efectivo relacionados con gastos operativos 


\section{TABLA 10}

\section{ESQUEMA FLUJO DE CAJA POR MÉTODO DIRECTO}

Fuente: Elaboración propia
La estructura del flujo de caja por el método directo es la siguiente:

\section{Periodo Periodo \\ XXX1 XXX2}

(+) Ingresos del Periodo en efectivo

$(+) \quad$ Cobro de cartera en el periodo

$(-) \quad$ Compras en efectivo

$(-) \quad$ Pago a proveedores

$(-) \quad$ costos y gastos operacionales en efectivo

$(-) \quad$ Impuesto de renta

$(=)$

Flujo de caja bruto

$(+/-) \quad$ Incremento/Decremento capital de trabajo

(+/-) Incremento/Decremento activos fijos

(-) Inversión en activos intangibles

$\Leftrightarrow \quad$ Flujo de caja de los accionistas 


\section{FLUJO DE CAJA POR EL MÉTODO INDIRECTO}

El flujo de caja por el método indirecto inicia con la utilidad operacional que se toma del estado de resultados, por lo tanto, hay que recordar que en este punto ya se han descontado los costos y gastos operacionales, entre los que se incluye la depreciación de los activos fijos y la amortización de los activos intangibles y diferidos.

El tratamiento de las depreciaciones y amortizaciones de los intangibles en el flujo de caja es muy importante dado que estos dos rubros no son una salida de efectivo, sino una partida contable.

La estructura del flujo de caja por el método indirecto es la siguiente:

\section{TABLA 11}

\section{MODELO DE ESTADO DE}

RESULTADOS Y FLUJO DE CAJA POR MÉTODO INDIRECTO

Fuente: Elaboración propia

Estado de resultados

Periodo XXXO

$(+)$

Ingresos del periodo

$(-) \quad$ costo de ventas y gastos operacionales

$(=)$

EBITDA

Depreciaciones y Amortizaciones

$(=)$

Utilidad Operativa UAll

Intereses

$(=)$

Utilidad antes de Impuestos UAI Impuestos 
Flujo de Caja Método Indirecto

Periodo XXXO

Utilidad Operativa UAll

$(-)$

Impuesto de Renta

$(+)$

Depreciaciones y amortizaciones

(=)

Flujo de caja Bruto

(+/-) Incremento/Decremento capital de trabajo

(+/-) Incremento/Decremento activos fijos

Inversión en Intangibles

(=)

Flujo de caja libre

\section{DEPRECIACIONES Y AMORTIZACIONES}

Las depreciaciones se registran como costo o como un gasto en el estado de resultados integral. Dado que estos activos ya han sido pagados, bien sea de contado o financiados; es un movimiento contable, NO caja, lo que quiere decir que se registra, pero no se gira. Por esto es un factor importante a la hora de calcular el flujo de caja libre.
Con respecto a las amortizaciones de intangibles, diferidos o gastos preoperativos; recordemos que los primeros corresponden a derechos adquiridos previamente, por ejemplo una franquicia o una patente, y los segundos corresponden a gastos pagados por anticipado, por ejemplo seguros, afiliaciones o impuestos diferidos, y los gastos preoperativos son todos aquellos en que se incurrió antes de entrar en operación. En estos casos, la empresa debe esti- 
mar el tiempo de amortización, que puede ser en meses en el caso de un seguro, o años si por ejemplo se adquiere una licencia de un software por 5 años, si los gastos preoperativos son elevados y requiere que se amorticen entre 3 y 5 años para no generar pérdidas al registrarlos en el estado de resultados integral.

\section{VARIACIÓN EN LA \\ INVERSIÓN EN ACTIVOS FIJOS Y EN CAPITAL DE TRABAJO CAPEX Y OPEX}

A continuación, veremos la forma de registrar las variaciones entre un periodo y otro en el flujo de caja libre. De acuerdo con la estructura del flujo de caja para estos dos rubros debemos registrar:

»(+/-) incremento/decremento activo fijo y

»(+/-) incremento/decremento de capital de trabajo.

En el caso de los activos fijos, debemos tener en cuenta si hay compra o venta de estos activos entre un perio- do y otro. Por ejemplo, una empresa realiza una inversión inicial de $\$ 500$ millones de pesos en activos fijos y durante los primeros tres años de operación se mantiene esta inversión, debido a que con la capacidad instalada actual puede atender su mercado. Sin embargo, para el cuarto año se plantea la compra de maquinaria adicional por $\$ 100$ millones debido a que ha ingresado a nuevos mercados y necesita producir más. Para el año 5 la misma empresa vende un vehículo por $\$ 40$ millones que utilizaba para la entrega de pedidos, dado que se toma la decisión de tercerizar el servicio de transporte.

Según lo anterior tenemos los siguientes movimientos: 


\section{TABLA 12}

\section{EJEMPLO DE CÁLCULO DE \\ VARIACIÓN EN LOS ACTIVOS FIJOS}

Fuente: Elaboración propia

$\begin{array}{lllllll}\text { Periodo } & \text { Año0 } & \text { Año1 } & \text { Año2 } & \text { Año3 } & \text { Año4 Año5 }\end{array}$

Activo fijo bruto

(sin depreciaciones) 
Encontramos que durante los primeros tres años no existe ninguna variación en los activos, por lo tanto, al flujo de caja no se lleva ningún movimiento, sin embargo, para el quinto año el activo fijo se incrementa en $\$ 100$ millones, este incremento del activo significa que debió salir efectivo de la empresa, por lo tanto, estos $\$ 100$ millones se llevan al flujo de caja de forma negativa (lo que correspondería al pago del activo). De otro lado, al vender activos fijos, situación que se presenta en el año quinto, encontramos una disminución del activo fijo en $\$ 50$ millones. Al llevar este dinero al flujo de caja se debe registrar con un ingreso de efectivo, dado que producto de la venta del vehículo ingresó dinero a la empresa.

Al vender activos fijos se pueden producir ganancias ocasionales, esto ocurre cuando el valor de venta del activo es superior al costo fiscal, es decir el valor por el que ha sido declarado el activo. Por ejemplo, al vender un inmueble en $\$ 130$ millones, que se registra con un costo fiscal de $\$ 100$ millones, se tendría una ganancia ocasional de $\$ 30$ millones.
Según el estatuto tributario la tasa del impuesto ocasional es del $10 \%$ siempre que el bien haya estado en propiedad de la empresa mínimo dos años, de lo contrario se aplica el impuesto de renta.

Para nuestro ejemplo, la variación en el flujo de caja libre sería el siguiente: 


\section{TABLA 13}

\section{REGISTRO DE LA VARIACIÓN DEL ACTIVO FIJO EN EL \\ FLUJO DE CAJA LIBRE}

Fuente: Elaboración propia

\section{$\begin{array}{llllll}\text { Año0 } & \text { Año1 Año2 Año3 } & \text { Año4 Año5 }\end{array}$}

(+/-) Incremento/Decremento activos fijos

$\begin{array}{llll}0 & 0 & 0 & -100\end{array}$

En la tabla 8, se observa que, en el cuarto año los $\$ 100$ millones se restan, debido a que al incrementar o comprar activo fijo, necesariamente disminuye la caja, en el año 5 se genera un ingreso por $\$ 45$ millones por la venta del activo, en este caso ya se ha descontado el impuesto pagado por ganancia ocasional de $\$ 5$ millones.

En cuanto al capital de trabajo, también se debe tener en cuenta la variación que se presenta entre un periodo y otro, con el fin de determinar si hay una mayor inversión en este ru- bro; por ejemplo, si entre un periodo y otro se tiene un mayor stock de inventarios, la variación generaría un movimiento positivo, donde el inventario se incrementa, sin embargo, esto obedece a una salida de efectivo de parte de la empresa. Por el contrario, si la empresa es más eficiente en el manejo de sus recursos de corto plazo y logra registrar una menor inversión en estos rubros, se entiende que libera caja y por tanto tiene un ingreso de efectivo en su flujo de caja.

Una empresa posee la siguiente proyección de su activo y su pasivo corrientes: 


\section{TABLA 14}

\section{EJEMPLO ACTIVOS Y PASIVOS CORRIENTES PROYECTADOS}

Fuente: Elaboración propia

\section{Estado de Situación Financiera}

\begin{tabular}{|c|c|c|c|c|}
\hline Activos Corrientes & Año0 & Añol & Año2 & Año3 \\
\hline Efectivo (efectivo y equivalente al efectivo) & & 552 & 458 & 267 \\
\hline Deudores comerciales - clientes & & 1.520 & 1.670 & 3.456 \\
\hline Otras cuentas por cobrar & & 42 & 87 & 31 \\
\hline Inventarios & & 680 & 1.932 & 2.278 \\
\hline Créditos de impuestos & & 485 & 745 & 1.146 \\
\hline Total Activos Corrientes & & 3.279 & 4.892 & 7.178 \\
\hline Pasivos Corrientes & Año0 & Añol & Año2 & Año3 \\
\hline Obligaciones financieras de corto plazo & & 1.039 & 1.266 & 1.205 \\
\hline Acreedores comerciales - proveedores & & 1.275 & 1.180 & 1.420 \\
\hline Impuestos por pagar & & 48 & 19 & 16 \\
\hline Otros pasivos corrientes & & 457 & 628 & 547 \\
\hline Total pasivos corrientes & & 2.819 & 3.093 & 3.187 \\
\hline Inversión en capital de trabajo & 5.000 & & & \\
\hline
\end{tabular}




\section{TABLA 15}

\section{CÁLCULO DEL KTNO Y SU VARIACIÓN}

Fuente: Elaboración propia

\section{Cálculo del KTNO}

$\begin{array}{llll}\text { Año0 } & \text { Año1 } & \text { Año2 } & \text { Año3 }\end{array}$

Deudores comerciales - clientes

1.520

1.670

3.456

Inventarios

680

1.932

2.278

Acreedores comerciales

- proveedores

1.275

1.180

1.420

KTNO

5.000

925

2.422

4.314

\section{Cálculo de la variación del KTNO}


En la tabla 9 se muestran los activos y pasivos corrientes proyectados, y se puede determinar el capital de trabajo y su variación entre un periodo y otro. Se requiere para este cálculo conocer la inversión inicial en capital de trabajo.

\section{TABLA 16}

\section{REGISTRO DE LA VARIACIÓN \\ DEL ACTIVO FIJO EN EL \\ FLUJO DE CAJA LIBRE}

Fuente: Elaboración propia

$\begin{array}{llll}\text { Año0 } & \text { Año1 } & \text { Año2 } & \text { Año3 }\end{array}$

(+/-) Incremento/Decremento

activos fijos

4075

$-1497$

$-1892$

Finalmente se lleva la variación al flujo de caja, que para el año 1 es positiva, dado que al disminuir la inversión en capital de trabajo en $\$ 4.075$ millones se entiende como liberación de dinero que se tenía invertido en capital trabajo. Para los años 2 y 3 se observa que el movimiento es negativo, dado que se requiere mayor inversión en capital de trabajo, bien sea para financiar un mayor inventario o la cartera, por lo que se efectúa salida de dinero.

\section{FLUJO DE CAJA DE LA DEUDA}

El flujo de caja de la deuda registra los desembolsos realizados por concepto de créditos o préstamos provenientes de entidades financieras $u$ otras fuentes de financiación y también registra los pagos realizados, tanto de capital como de intereses en cada periodo; en el flujo de caja de la deuda se deben considerar otros gastos relacionados con el financiamiento, ta- 
les como gastos de honorarios, comisiones o estudios de crédito.

En términos generales, se debe tener claridad sobre el sistema de amortización de la deuda, para determinar los intereses pagados en cada periodo y los abonos a capital. Otro factor importante para considerar es que la deuda contratada por la empresa ofrece un escudo fiscal, debido a que los costos financieros son deducibles del impuesto de renta, así, el efecto que tiene es generar un ahorro en el pago de los impuestos. Veamos los estados financieros de una empresa sin deuda y otra que adquiere una deuda por $\$ 17.000$, en ambos casos la inversión inicial es de \$22.000.

En la tabla 12. Se evidencia un menor pago de impuestos gracias a que los gastos financieros pagados por parte de la empresa disminuyen en $\$ 1.000$ la utilidad antes de impuestos, significando una reducción en la utilidad neta de $\$ 670$.

En la tabla 13 se observa que el flujo de caja libre es igual tanto para la empresa sin deuda como para la em- presa con deuda; sin embargo, al realizar el flujo de caja de la deuda se encuentra el efecto que tiene el pago de intereses, como un ahorro en el pago de impuestos. Finalmente, se observa que el flujo de caja de los accionistas es menor debido a que se deben pagar los intereses (registrados en el estado de resultados) y el capital de la obligación financiera. Este último análisis se direcciona a la rentabilidad del accionista, ya que si bien la empresa que adquiere deuda presenta un flujo de caja del accionista de $\$ 540$, la inversión inicial de los socios fue de $\$ 5.000$ y el resto se financió con deuda. Por su parte, la empresa sin deuda obtiene un flujo del accionista de \$2.010, sin embargo, la inversión total de los socios fue de $\$ 22.000$. 


\section{TABLA 17}

\section{ESTADO DE RESULTADOS INTEGRAL CON DEUDA Y SIN DEUDA}

Fuente: Elaboración propia

\section{Empresa Empresa sin deuda con deuda}

Ventas

10.000

10.000

costos

$5.000 \quad 5.000$

gastos

$2.000 \quad 2.000$

Utilidad operacional

$3.000 \quad 3.000$

gastos financieros

1.000

utilidad antes de impuestos

$3.000 \quad 2.000$

impuesto de renta

990

660

Utilidad neta 


\section{TABLA 18}

\section{FLUJO DE CAJA CON \\ DEUDA Y SIN DEUDA}

Fuente: Elaboración propia

\section{Empresa Empresa \\ sin deuda con deuda}

Utilidad operacional

Impuestos operacionales

Flujo de caja libre

Flujo de caja de la deuda
3000

990

2010
3000

990

2010
Intereses

Capital

Ahorro en impuestos

Flujo de caja del accionista
1000

800

$0 \quad 330$

2010 540 
FLUJO DE CAJA DEL ACCIONISTA

El flujo de caja del accionista es el resultado de restar el resultado del flu- jo de caja libre con el flujo de caja de la deuda. El valor resultante corresponde al dinero disponible que tiene la empresa para pagar dividendos a los socios.

\section{ILUSTRACIÓN 4}

\section{FLUJO DE CAJA DEL ACCIONISTA}

Fuente: Elaboración Propia

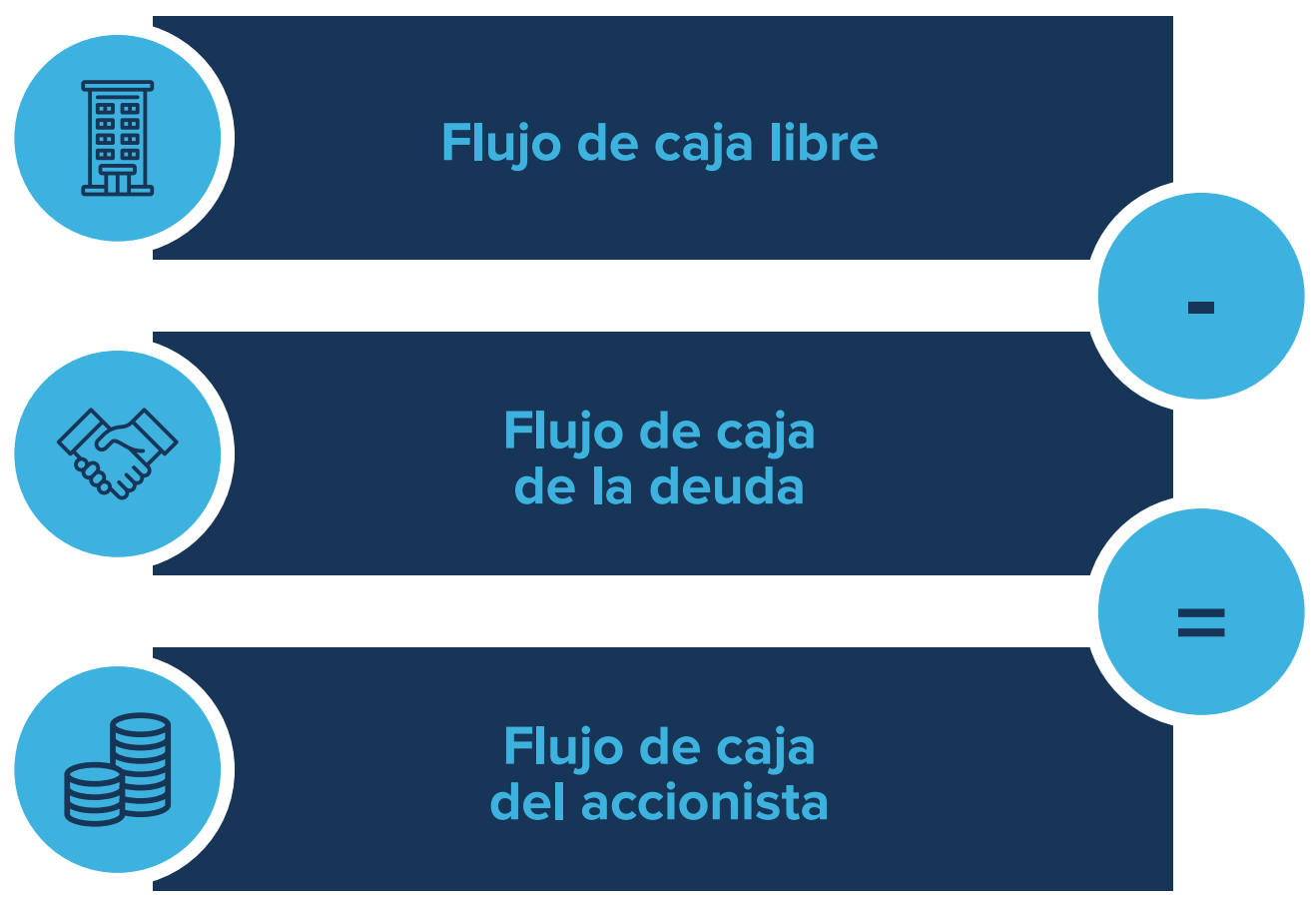




\section{ANÁLISIS APLICADO DE LA TEORÍA}

Para un mayor entendimiento de los conceptos vistos, a continuación, se presenta un ejemplo.

La empresa la Felicidad, desea iniciar una nueva línea de negocio que manejará dos productos. Para tal fin contratan un asesor financiero que determine a través del flujo de caja libre y el flujo de caja para el accionista la viabilidad de este proyecto. De acuerdo con la dinámica del sector económico, se fija un horizonte de inversión de 5 años y se obtiene la siguiente información:

Se proyecta vender 700 unidades del producto 1 (Monkey), y 950 unidades del producto (Leopard), el precio del primero será de $\$ 60.0000$ y de $\$ 45.0000$ para el segundo producto. Para el año 3 se espera que se incremente el número de unidades vendidas en $10 \%$ con respecto al año 2 , y para los años 4 y 5 en $6 \%$ con respecto al año anterior. Los Costos Fijos del proyecto para el primer año son de $\$ 13.000 .000$ y los Costos Variables por Unidad (CVu), que se incrementarán por inflación, así como los costos variables.

» Los gastos operacionales (de administración y ventas) corresponden al $15 \%$ de los ingresos. También afectados por la inflación.

"La deuda de la empresa se compone de la siguiente manera:

» Inversión inicial es de \$110 Millones el 60\% es aportado por los socios y el saldo es deuda con el BANCO XYZ.

»El banco hace un préstamo con las siguientes condiciones: $14 \%$ Efectivo anual con un plazo de 4 años. Se amortiza con abonos iguales a capital en todos los periodos, es decir, con el sistema de amortización alemán.

"En el año 0 se realiza inversión en activos fijos por $\$ 80$ Millones y en el año 3 se espera realizar una ampliación de capacidad invirtiendo $\$ 20$ millones adicio- 
nales. La depreciación es del $10 \%$ del total de los activos fijos.

»El capital de trabajo para cada año corresponde al 7\% de los ingresos y en el periodo inicial se destinan $\$ 20 \mathrm{Mi}$ llones para capital de trabajo.

»Los activos intangibles corresponden a \$10 Millones que se amortizan en el primer año.

»Impuesto de renta del 33\%

El primer paso consiste en organizar la información obtenida (esta información, se debe tomar de los estudios de mercado, técnico, organizacional y los demás que se consideren necesarios). De acuerdo con los datos obtenidos, a continuación se presentan los supuestos para proyectar el estado de resultados: (Ver tabla 19).

En la tabla 19 se estiman los datos de acuerdo con los crecimientos proyectados. El precio se incrementa de acuerdo con el IPC, y el número de unidades con un porcentaje dado, derivado de un estudio de mercado hecho previamente por la compañía. Tam- bién se estima el comportamiento de los activos fijos, teniendo en cuenta la compra de nuevos activos; así, podemos ver que en el año 3 se presenta un cambio en la depreciación.

»El segundo paso es calcular el estado de resultados: (Ver tabla 16).

Según los precios y las unidades de venta proyectadas, se determinan las ventas de cada periodo, de igual manera, con los costos variables por unidad afectados por inflación y el número de unidades proyectadas de ventas, se determinan los costos variables totales. Los costos fijos se incrementan por inflación, así como los gastos operacionales.

La estructura del estado de resultados deja los rubros de depreciación y amortización de forma independiente, con el fin de verificar su efecto en el flujo de caja.

En el estado de resultados se deben registrar los intereses pagados por concepto de deudas con costos financieros y los demás costos financieros que pueda tener la empresa debido a sus productos con las entidades financieras y otras entidades de financiación. 


\section{TABLA 19}

\section{SUPUESTOS PARA ESTIMACIÓN \\ DEL FLUJO DE CAJA POR \\ MÉTODO INDIRECTO}

Fuente: Elaboración propia

\begin{tabular}{|c|c|c|c|c|c|c|}
\hline & 0 & 1 & 2 & 3 & 4 & 5 \\
\hline $\begin{array}{c}\text { IPC } \\
\text { Proyectado }\end{array}$ & $3,50 \%$ & $3,50 \%$ & $3,50 \%$ & $3,50 \%$ & $3,50 \%$ & $3,50 \%$ \\
\hline \multirow[t]{2}{*}{$\begin{array}{l}\text { Incremento } \\
\text { Unidades }\end{array}$} & $0,00 \%$ & 0 & $0 \%$ & $10 \%$ & $6 \%$ & $6 \%$ \\
\hline & 1 & & & & & \\
\hline $\begin{array}{l}\text { Unidades } \\
\text { Monkey }\end{array}$ & 700 & 700 & 700 & 770 & 816 & 865 \\
\hline $\begin{array}{c}\text { Precio } \\
\text { Monkey }\end{array}$ & 60.000 & $60.000,00$ & $62.100,00$ & $64.273,50$ & $66.523,07$ & $68.851,38$ \\
\hline $\begin{array}{l}\text { Unidades } \\
\text { Leopard }\end{array}$ & 950 & 950 & 950 & 1.045 & 1.108 & 1.174 \\
\hline $\begin{array}{c}\text { Precio } \\
\text { Leopard }\end{array}$ & 45.000 & 45.000 & 46.575 & 48.205 & 49.892 & 51.639 \\
\hline $\begin{array}{c}\text { CVu } \\
\text { Monkey }\end{array}$ & 18.000 & 18.000 & 18.630 & 19.282 & 19.957 & 20.655 \\
\hline $\begin{array}{c}\text { CVu } \\
\text { Leopard }\end{array}$ & 12.800 & 12.800 & 13.248 & 13.712 & 14.192 & 14.688 \\
\hline $\begin{array}{l}\text { Ventas } \\
\text { Totales }\end{array}$ & 84.750 .000 & 84.750 .000 & 87.716 .250 & 99.864 .951 & 109.561 .837 & 120.200 .292 \\
\hline $\begin{array}{l}\text { Costos } \\
\text { Variables } \\
\text { totales }\end{array}$ & 24.760 .000 & 24.760 .000 & 25.626 .600 & 29.175 .884 & 32.008 .862 & 35.116 .923 \\
\hline $\begin{array}{l}\text { Activos } \\
\text { Fijos }\end{array}$ & & 110.000 .000 & 110.000 .000 & 130.000 .000 & 130.000 .000 & 130.000 .000 \\
\hline Depreciación & & 11.000 .000 & 11.000 .000 & 13.000 .000 & 13.000 .000 & 13.000 .000 \\
\hline
\end{tabular}




\section{TABLA 20}

\section{CÁLCULO DE VENTAS, COSTOS VARIABLES Y GASTOS OPERACIONALES PARA EL AÑO 1}

Fuente: Elaboración propia

Ventas

Unidades Monkey

700

60.000

Precio Monkey

18.000

\begin{tabular}{cccr} 
Precio Monkey & 60.000 & Precio Monkey & 18.000 \\
\hline $\begin{array}{c}\text { Ventas Producto 1 } \\
(P * Q)\end{array}$ & 42.000 .000 & Ventas Producto 1 & 12.600 .000
\end{tabular}

Unidades Leopard

950

Unidades Leopard

950

Precio Leopard

45.000

Precio Leopard

12.800

Ventas Producto 2

$(P * Q)$

42.750 .000

Ventas Producto 2

$(P \star Q)$

12.160 .000

Ventas Totales

84.750 .000

Ventas Totales

24.760 .000

Gastos operacionales para el año 1 (15\% de las ventas) 


\section{TABLA 21}

\section{ESTADO DE RESULTADOS PROYECTADO}

Fuente: Elaboración propia

\begin{tabular}{|c|c|c|c|c|c|c|}
\hline & & \multicolumn{5}{|c|}{ Periodo } \\
\hline & & 1 & 2 & 3 & 4 & 5 \\
\hline$(+)$ & $\begin{array}{c}\text { Ventas } \\
\text { del periodo }\end{array}$ & 84.750 .000 & 87.716 .250 & 99.864 .951 & 109.561 .837 & 120.200 .292 \\
\hline$(-)$ & $\begin{array}{c}\text { Costos variables } \\
\text { totales }\end{array}$ & 24.760 .000 & 25.626 .600 & 29.175 .884 & 32.008 .862 & 35.116 .923 \\
\hline$(-)$ & Costos Fijos & 13.000 .000 & 13.455 .000 & 13.925 .925 & 14.413 .332 & 14.917 .799 \\
\hline$(-)$ & $\begin{array}{c}\text { Gastos } \\
\text { operacionales }\end{array}$ & 12.712 .500 & 13.157 .438 & 14.979 .743 & 16.434 .276 & 18.030 .044 \\
\hline$\Leftrightarrow$ & EBITDA & 34.277 .500 & 35.477 .213 & 41.783 .399 & 46.705 .367 & 52.135 .526 \\
\hline$(-)$ & $\begin{array}{c}\text { Depreciaciones y } \\
\text { Amortizaciones }\end{array}$ & 21.000 .000 & 11.000 .000 & 13.000 .000 & 13.000 .000 & 13.000 .000 \\
\hline$\Leftrightarrow$ & $\begin{array}{c}\text { Utilidad } \\
\text { Operativa UAll }\end{array}$ & 13.277 .500 & 24.477 .213 & 28.783.399 & 33.705 .367 & 39.135 .526 \\
\hline$(-)$ & Intereses & 6.160 .000 & 4.620 .000 & 3.080 .000 & 1.540 .000 & 0 \\
\hline$\Leftrightarrow$ & $\begin{array}{l}\text { Utilidad antes de } \\
\text { Impuestos UAI }\end{array}$ & 7.117 .500 & 19.857 .213 & 25.703 .399 & 32.165 .367 & 39.135 .526 \\
\hline$(-)$ & Impuestos (33\%) & 2.348 .775 & 6.552 .880 & 8.482 .122 & 10.614 .571 & 12.914 .724 \\
\hline$(\Leftrightarrow)$ & Utilidad Neta & 4.768 .725 & 13.304 .332 & 17.221 .277 & 21.550 .796 & 26.220 .802 \\
\hline
\end{tabular}


A continuación, se presenta la amortización de la deuda con el sistema alemán; este sistema genera abonos iguales a capital en todos los periodos, y los intereses van decreciendo a través del tiempo ya que se calculan sobre un saldo que disminuye en una suma fija, esto permite que la cuota sea decreciente, como se observa en la tabla 22:

\section{TABLA 22}

\section{TABLA DE AMORTIZACIÓN DEL CRÉDITO}

Fuente: Elaboración propia

\section{Préstamo para inversión inicial}

Valor - 44.000.000

i - $14,00 \%$ EA

Plazo - 4 Años
Periodo

Cuota

Intereses

Capital

Saldo

44.000 .000

0

1

17.160 .000

6.160 .000

11.000 .000

33.000 .000

2

15.620 .000

4.620 .000

11.000 .000

22.000 .000

3

14.080 .000

3.080 .000

11.000 .000

11.000 .000 
Según la tabla de amortización, se puede ver el registro de los intereses en el estado de resultados.

»El tercer paso es determinar las variaciones en la inversión en activos fijos y en la inversión en capital de trabajo: (Ver tabla 23)

"El siguiente paso es realizar el flujo de caja. A continuación, veremos la elaboración del flujo de caja según los dos métodos enunciados anteriormente: (Ver tabla 24)

En la tabla 19 se elabora el flujo de caja por el método directo, donde se evidencia que en el flujo de caja de la deuda se registra tanto el valor de los intereses, como el valor de abono a capital, lo que suma el valor de la cuota para cada periodo, que es el valor de efectivo que sale del flujo de caja de la empresa. Además, se observa el ahorro obtenido por el pago de intereses.

\section{NOTA:}

OTROS SISTEMAS DEAMORTIZACIÓN SON EL FRANCÉS

Y EL AMERICANO, EL PRIMERO CORRESPONDE AL

PAGO DE CUOTAS FIJAS, DONDE EL ABONO A CAPITAL

ES CRECIENTE, ES DECIR AL COMIENZO SE PAGA

POCO CAPITAL Y MUCHOS INTERESES Y DESPUÉS

DE LA MITAD DEL CRÉDITO ESTE COMPORTAMIENTO

SE INVIERTE. EL SEGUNDO ES UN SISTEMA DE

AMORTIZACIÓN MENOS FRECUENTE EN NUESTRO

PAÍS, DONDE SE PAGA EXCLUSIVAMENTE INTERESES Y

AL FINAL DEL PLAZO, ES DECIR CON LA ÚLTIMA CUOTA

SE PAGA TODO EL CAPITAL. 


\section{TABLA 23}

\section{CÁLCULO DE VARIACIONES \\ EN CAPITAL DE TRABAJO \\ Y EN ACTIVOS FIJOS}

Fuente: Elaboración propia

\section{Capital de trabajo}

\begin{tabular}{lllllll} 
Periodo 0 & Periodo 1 & Periodo 2 & Periodo 3 & Periodo 4 & Periodo 5 \\
\hline & 5.932 .500 & 6.140 .138 & 6.990 .547 & 7.669 .329 & 8.414 .020 \\
\hline & -14.067 .500 & 207.638 & 850.409 & 678.782 & 744.692 \\
\hline
\end{tabular}

Activos Fijos

\begin{tabular}{|c|c|c|c|c|c|}
\hline Periodo 0 & Periodo 1 & Periodo 2 & Periodo 3 & Periodo 4 & Periodo 5 \\
\hline \multirow[t]{2}{*}{80.000 .000} & 80.000 .000 & 80.000 .000 & 80.000 .000 & 80.000 .000 & 80.000 .000 \\
\hline & & & 20.000 .000 & 20.000 .000 & 20.000 .000 \\
\hline \multirow[t]{2}{*}{80.000 .000} & 80.000 .000 & 80.000 .000 & 100.000 .000 & 100.000 .000 & 100.000 .000 \\
\hline & \multicolumn{4}{|c|}{ Variación de los activos fijos } & \\
\hline \multirow[t]{2}{*}{ Periodo 0} & Periodo 1 & Periodo 2 & Periodo 3 & Periodo 4 & Periodo 5 \\
\hline & & - & 20.000 .000 & & \\
\hline
\end{tabular}




\section{TABLA 24}

\section{FLUJO DE CAJA PROYECTADO POR MÉTODO DIRECTO}

Fuente: Elaboración Propia

\begin{tabular}{|c|c|c|c|c|c|c|c|c|}
\hline & $\begin{array}{l}\text { Ingresos } \\
\text { del Periodo }\end{array}$ & & 84.750 .000 & 87.716 .250 & 99.864 .951 & 109.561 .837 & 120.200 .292 & 120.200 .292 \\
\hline$(-)$ & Costos & & 37.760 .000 & 39.081 .600 & 43.101 .809 & 46.422 .195 & 50.034 .722 & 35.116 .923 \\
\hline$(-)$ & Gastos & & 12.712 .500 & 13.157 .438 & 14.979 .743 & 16.434 .276 & 18.030 .044 & 14.917.799 \\
\hline$\Leftrightarrow$ & Total & & 34.277 .500 & 35.477 .213 & 41.783 .399 & 46.705 .367 & 52.135 .526 & 18.030 .044 \\
\hline$(-)$ & $\begin{array}{l}\text { Impuesto } \\
\text { de Renta }\end{array}$ & & 4.381 .575 & 11.707 .480 & 13.788 .522 & 15.412 .771 & 17.204 .724 & 52.135 .526 \\
\hline$(+/-)$ & $\begin{array}{l}\text { Incremento } \\
\text { /Decremento } \\
\text { capital de trabajo }\end{array}$ & 20.000 .000 & 14.067 .500 & $\begin{array}{c}- \\
207.638\end{array}$ & $\begin{array}{c}- \\
850.409\end{array}$ & $\begin{array}{c}- \\
678.782\end{array}$ & $\begin{array}{c}- \\
744.692\end{array}$ & 13.000 .000 \\
\hline$(+/-)$ & $\begin{array}{l}\text { Incremento } \\
\text { /Decremento } \\
\text { activos fijos }\end{array}$ & 80.000 .000 & & & 20.000 .000 & & & 39.135 .526 \\
\hline$(-)$ & $\begin{array}{l}\text { Inversión en } \\
\text { Intangibles }\end{array}$ & 10.000 .000 & & & & & & 0 \\
\hline$\Leftrightarrow$ & Flujo de caja libre & & 43.963 .425 & 23.562 .095 & 7.144 .468 & 30.613 .814 & 34.186 .111 & 39.135 .526 \\
\hline$(-)$ & $\begin{array}{l}\text { Flujo de caja de } \\
\text { la deuda }\end{array}$ & & 43.560 .000 & 31.240 .000 & - & - & & 12.914 .724 \\
\hline$(+)$ & $\begin{array}{l}\text { Efecto de los } \\
\text { impuestos }\end{array}$ & & 2.032 .800 & 5.154 .600 & 5.306 .400 & 4.798 .200 & 4.290 .000 & 26.220 .802 \\
\hline$\Leftrightarrow$ & $\begin{array}{l}\text { Flujo de caja de } \\
\text { los accionistas }\end{array}$ & & 2.436 .225 & 2.523 .305 & 12.450 .868 & 35.412 .014 & 38.476 .111 & \\
\hline
\end{tabular}




\section{TABLA 25}

\section{FLUJO DE CAJA PROYECTADO POR MÉTODO INDIRECTO}

\section{Fuente: Elaboración Propia}

\begin{tabular}{|c|c|c|c|c|c|c|c|c|}
\hline & $\begin{array}{c}\text { Utilidad } \\
\text { Operativa UAll }\end{array}$ & & 13.277 .500 & 24.477 .213 & 28.783.399 & 33.705 .367 & 39.135 .526 & 120.200 .292 \\
\hline$(-)$ & $\begin{array}{l}\text { Impuesto de } \\
\text { Renta }\end{array}$ & & 4.381 .575 & 8.077 .480 & 9.498 .522 & 11.122 .771 & 12.914 .724 & 35.116 .923 \\
\hline$(+)$ & Depreciaciones & & 11.000 .000 & 11.000 .000 & 13.000 .000 & 13.000 .000 & 13.000 .000 & 14.917.799 \\
\hline$(+)$ & Amortizaciones & & 10.000 .000 & & & & & 18.030 .044 \\
\hline$\Leftrightarrow$ & $\begin{array}{l}\text { Flujo de caja } \\
\text { Bruto }\end{array}$ & & 29.895 .925 & 27.399 .732 & 32.284 .877 & 35.582 .596 & 39.220 .802 & 52.135 .526 \\
\hline$(+/-)$ & $\begin{array}{l}\text { Incremento/De- } \\
\text { cremento capital } \\
\text { de trabajo }\end{array}$ & 20.000 .000 & 14.067 .500 & $\begin{array}{c}- \\
207.638\end{array}$ & $\begin{array}{c}- \\
850.409\end{array}$ & $\begin{array}{c}- \\
678.782\end{array}$ & $\begin{array}{c}- \\
744.692\end{array}$ & 13.000 .000 \\
\hline$(+/-)$ & $\begin{array}{l}\text { Incremento/De- } \\
\text { cremento activos } \\
\text { fijos }\end{array}$ & 80.000 .000 & & & 20.000 .000 & & & 39.135 .526 \\
\hline$(-)$ & $\begin{array}{l}\text { Inversión en } \\
\text { Intangibles }\end{array}$ & 10.000 .000 & & & & & & 0 \\
\hline$\Leftrightarrow$ & Flujo de caja libre & & 43.963 .425 & 27.192 .095 & 11.434 .468 & 34.903 .814 & 38.476 .111 & 39.135 .526 \\
\hline$(-)$ & $\begin{array}{l}\text { Flujo de caja de } \\
\text { la deuda }\end{array}$ & & 43.560 .000 & 31.240 .000 & - & - & & 12.914 .724 \\
\hline$(+)$ & $\begin{array}{l}\text { Efecto de los } \\
\text { impuestos }\end{array}$ & & 2.032 .800 & 1.524 .600 & 1.016 .400 & 508.200 & - & 26.220 .802 \\
\hline$\Leftrightarrow$ & $\begin{array}{l}\text { Flujo de caja de } \\
\text { los accionistas }\end{array}$ & 110.000 .000 & 2.436 .225 & 2.523 .305 & 12.450 .868 & 35.412 .014 & 38.476 .111 & \\
\hline
\end{tabular}


La diferencia entre ambos métodos de elaboración del flujo de caja radica en la primera sección; en el primero se registran los rubros de ingresos, costos y gastos directamente y en el segundo se inicia a partir de la utilidad operacional. Como se puede observar, en ambos casos el resultado debe ser el mismo.

\section{MÉTODOS DE DECISIÓN FINANCIERA PARA VALORACIÓN DE PROYECTOS}

Después de haber realizado la proyección de los flujos futuros, la pregunta que debemos realizarnos es si la inversión es la conveniente y si será rentable. En este apartado veremos cuáles métodos de evaluación nos ayudan en la toma de la decisión final.

Como se presentó en el anterior capítulo de este libro, el inversionista debe tener la tasa de descuento o WACC, la cual será la tasa máxima a la que el inversionista decide invertir.

\section{VALOR PRESENTE NETO}

En el momento en el que se realizará la inversión en un proyecto, se debe evaluar antes si el proyecto es viable o no, el VPN es un indicador que es el resultado de comparar el valor presente de los ingresos con el de los egresos futuros de un flujo de caja a pesos de hoy. Es de recordar que estos flujos han sido resultado de la proyección de ingresos, gastos y costos que se ha venido trabajando.

El inversionista no solamente se puede fiar de las utilidades que eventualmente genere el negocio, dado que no se está teniendo en cuenta la inversión que se tuvo que hacer para generarlas. Una empresa requiere ser rentable además de líquida, y es rentable cuando se comparan las utilidades del periodo con la inversión que se ha realizado para generarlas. Finalmente, el VPN es el índice que compara en la misma fecha, la inversión con los flujos de caja netos.

A continuación se presenta un flujo de caja donde se aprecia de forma gráfica los valores que se traerán a valor presente neto. 


\section{ILUSTRACIÓN 5}

\section{VALOR PRESENTE NETO}

Fuente: Elaboración propia

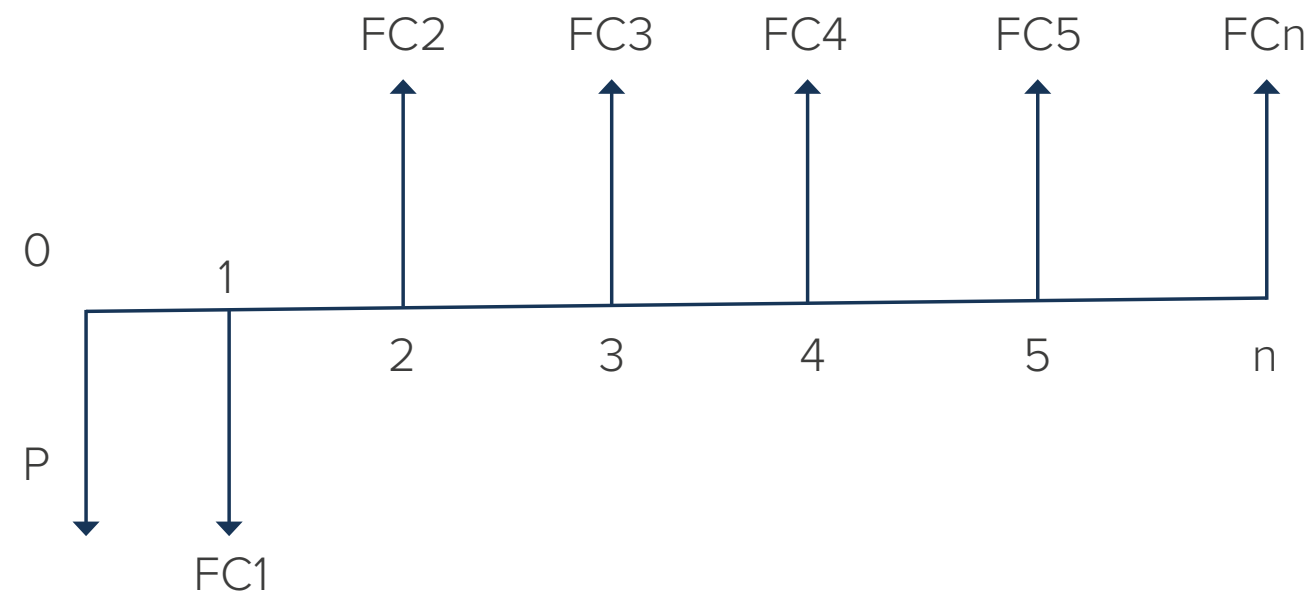

Como se aprecia en la gráfica anterior podemos deducir que este proyecto tiene una inversión inicial P que se da en el periodo 0 , al ser inversión hacia abajo y para el periodo 1 se evidencia que el flujo de este periodo es negativo, suponiendo que los ingresos son menores que los egresos, pero este es un ejemplo, así que existe también la posibilidad de tener un flujo 1 positivo. Para este ejemplo el resto de los flujos son positivos a partir del año 2. Podemos concluir que el valor presente neto compara en el presente el valor de la inversión inicial, frente a los valores del flujo de caja proyectados, teniendo en cuenta el costo de los recursos invertidos. 
ILUSTRACIÓN 6.

FÓRMULA DE VPN
La fórmula de Valor presente Neto es la siguiente:

Fuente: Elaboración propia

\section{$V P N=-P+F N E_{1}+F E_{2}+F_{3}+\ldots+F N E_{n}$ \\ $\begin{array}{lll}(1+i)^{1} & (1+i)^{2} \quad(1+i)^{3}\end{array}$ \\ $(1+i)^{n}$}

Los criterios para aceptar o rechazar el proyecto según el VPN son los siguientes:

» Si el VPN es mayor que 0, el proyecto se debe aceptar. Indica que se está ganando más de lo que se pretendía luego de recuperar la inversión.

» Si el VPN es igual a 0, es indiferente si se rechaza o se acepta. Indica que se está ganando lo que se pretendía luego de recuperar la inversión.
Si el VPN es menor que 0, el proyecto se debe rechazar. Indica que la cantidad en pesos que se muestra es lo que falta para llegar a lo que el inversionista quería ganar.

»Un ejemplo sencillo de valor presente neto es el siguiente:

» Un inversionista tiene la posibilidad de emprender. La inversión inicial es de $\$ 12.000$ y se tienen los siguientes flujos de caja: 


\section{ILUSTRACIÓN 7}

\section{EJEMPLO VPN}

Fuente: Elaboración Propia

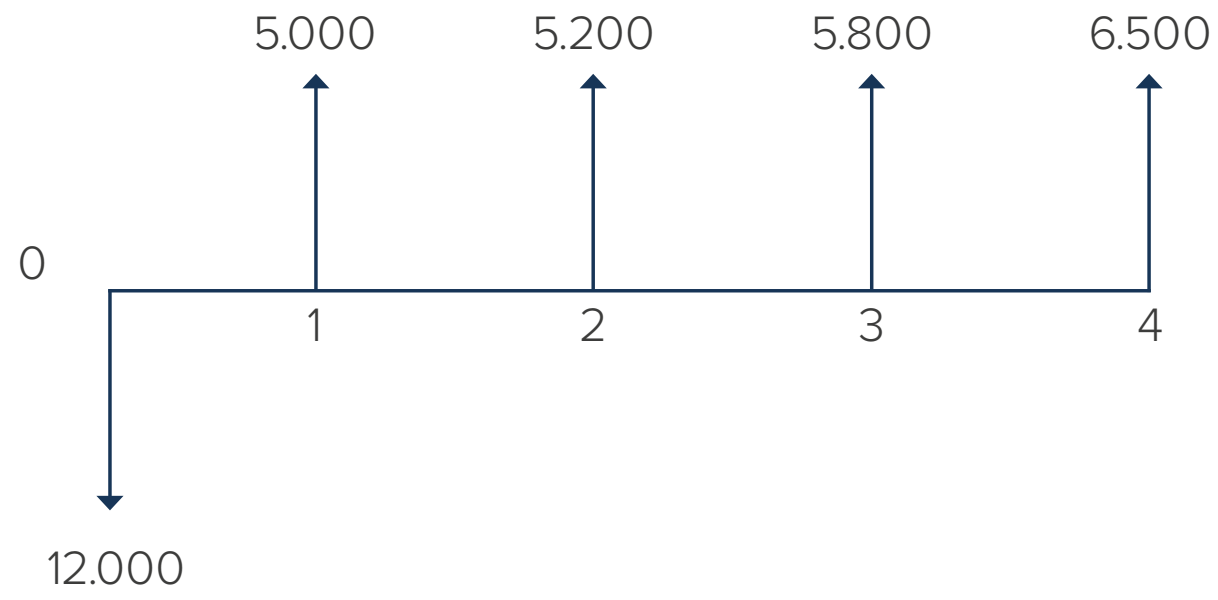

»La tasa de oportunidad del inversionista es del $30 \%$, es decir que está dispuesto a seguir con el negocio siempre y cuando dé un mínimo rendimiento de 30\% anual.

»Solo a modo de ejemplo, si el inversionista se guiara por los flujos sin descontar, este sería el resultado:
» Flujos de caja: $(5.000+5.200$

$+5.800+6.500)-$

$12.000=10.500$

»En este caso el proyecto debería ser aceptado porque se obtiene una utilidad de $\$ 10.500$.

»Si lo realizamos con la fórmula de VPN: 
VPN $(30 \%)=$

$-12.000+5.000 /(1+0.30)^{1}$

$+5.200 /(1+0.30)^{2}$

$+5.800 /(1+0.30)^{3}$

$+6.500 /(1+0.30)^{4}$

VPN $=-12.000+11.838,87$

VPN $=-161,13$

Con la fórmula de VPN el proyecto se rechaza.

\section{TASA INTERNA DE RETORNO TIR}

La TIR indica cuál tasa mínima de rentabilidad debe tener el proyecto en el tiempo estimado de ejecución o que se acepte por el inversionista y en el cual el VPN sea cero. Mientras más baja sea esa tasa, más fácil será estar por encima en la ejecución del negocio y por ende más atractiva la inversión.

Podemos decir también que la TIR es una tasa máxima a la cual el inversionista está dispuesto a endeudarse para poder financiar el proyecto, entendiendo que con los flujos que genere se pagarán el capital y los intereses sin que implique ninguna pérdida.
La TIR se debe comparar con la tasa de descuento, que es la tasa mínima que se requiere, si la TIR es mayor, el proyecto se acepta ya que se entiende que el rendimiento es mayor al mínimo que se requiere.

De forma matemática la TIR es el promedio algebraico de los flujos futuros de un proyecto. Sin embargo, la TIR solo representa la rentabilidad de un flujo de caja, pero no tiene en cuenta la rentabilidad asociada al riesgo de este. Es una tasa cruda de rentabilidad sobre la cual se podría realizar un análisis más profundo.

Hay varias formas de calcular la TIR, se recomienda utilizar el programa Excel, ya que es el método más sencillo. Una forma de cálculo es a través del método analítico:

\section{EJEMPLO:}

Se invierten $\$ 300.000$ y después de un año se reciben $\$ 320.000$, con estos datos procedamos a calcular la TIR.

Se construye el flujo de caja: 


\section{ILUSTRACIÓN 8}

\section{EJEMPLO TIR}

Fuente: Elaboración Propia

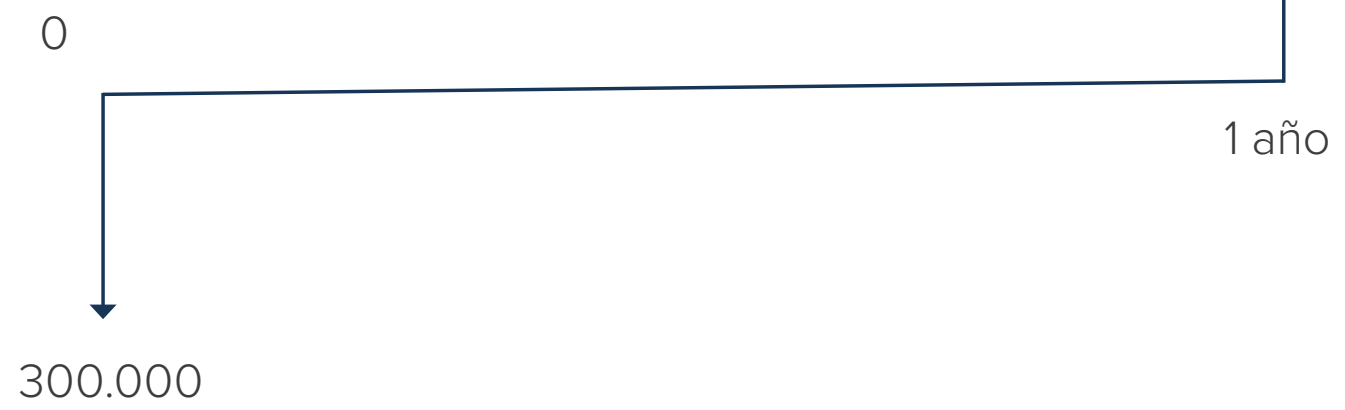

La TIR es la tasa de interés donde el $\quad 300.000=320.000 /(1+i)^{1}$ VPN es igual a 0.

$$
(1+i)=320.000 / 300.000
$$

$\operatorname{VPN}(30 \%)=$

$$
-300.000+320.000 /(1+i)^{1} \quad I=7 \% \text { anual }=\text { TIR }
$$

Haciendo el VPN = 0, entonces, $\quad$ Elaborado con el programa Excel: 


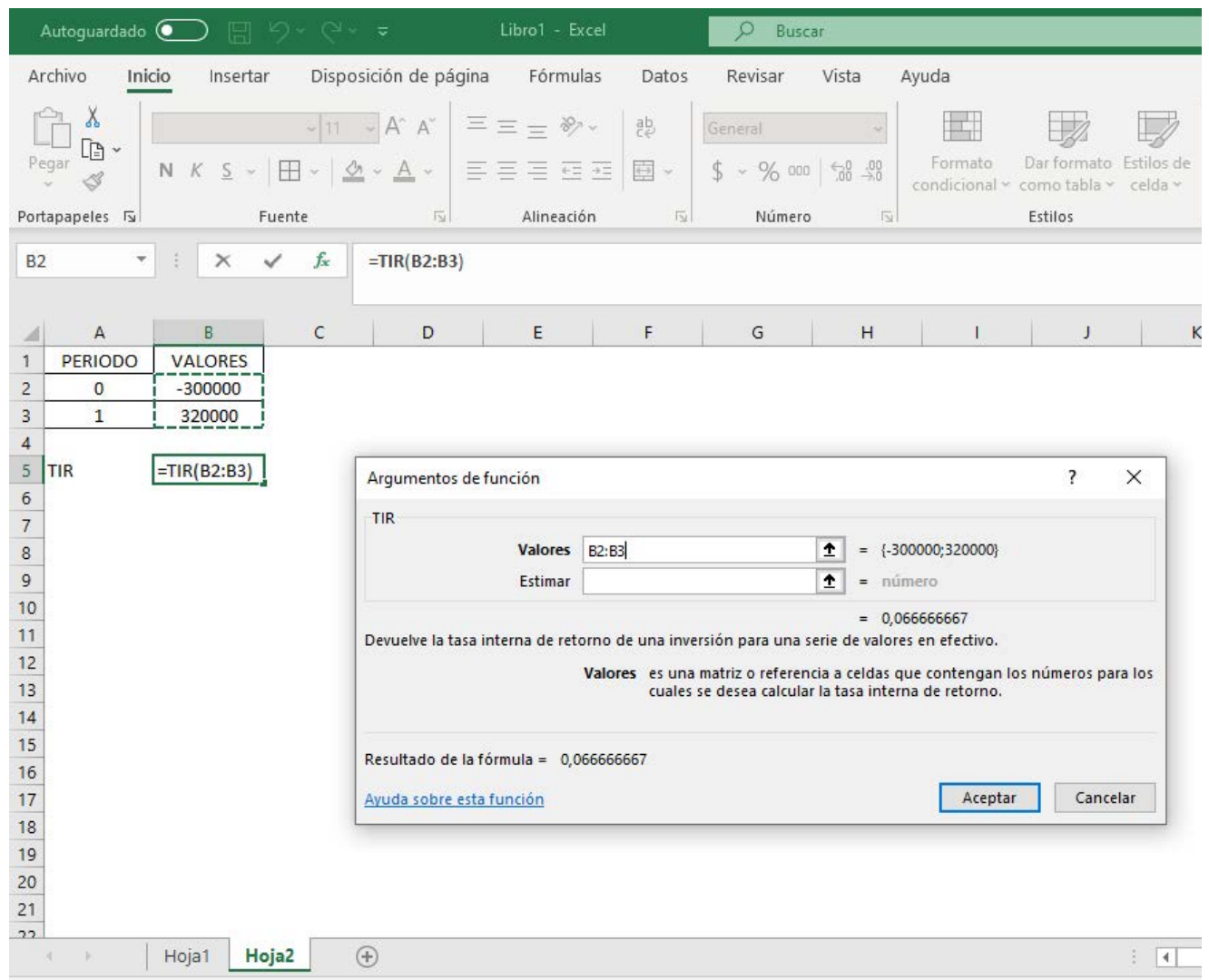

$\mathrm{TIR}=7 \%$

Los criterios para aceptar o rechazar el $\mathrm{Si}$ la TIR $=r$ entonces el proyecto es proyecto según la TIR son los siguientes: indiferente

Si la TIR > r entonces se rechazará el Si la TIR $<$ r entonces se aprobará el proyecto. proyecto. 
Donde $r$ es el costo de oportunidad de realizar el proyecto. Este costo de oportunidad es el valor máximo que el inversionista ha sacrificado por una inversión alterna.

\section{RELACIÓN BENEFICIO COSTO}

En valoración de proyectos de inversión la relación beneficios costos o RBC, es una razón que divide la inversión inicial o costos del proyecto a valor presente con los beneficios del proyecto, es decir, con la suma de los flujos de caja futuros, que se deben descontar o traer a valor presente. De esta manera, se compara la suma de inversión o costos con la suma de los ingresos o beneficios que se esperan recibir del proyecto en el horizonte de inversión.

Esta relación permite identificar los pesos (\$) recibidos por cada peso invertido en el proyecto.

Los criterios para aceptar o rechazar el proyecto según la RBC son los siguientes:
RBC $>1$ El proyecto se acepta - por cada peso invertido retorna más de un peso,

$\mathrm{RBC}=1 \mathrm{El}$ proyecto es indiferente - por cada peso invertido retorna un peso

RBC $<1$ El proyecto es se rechaza por cada peso invertido, retorna menos de un peso

\section{ILUSTRACIÓN 9}

FORMULA DE LA RBC

Fuente: Elaboración Propia

$\mathbf{R B C}=$

$\Sigma$ FNE a valor presente / INVERSION INICIAL 
Tomando el ejemplo usado para explicar el valor presente neto, tenemos la siguiente información:

$\operatorname{VPN}(30 \%)=$

$-12.000+5.000 /(1+0.30)^{1}$

$+5.200 /(1+0.30)^{2}$

$+5.800 /(1+0.30)^{3}$

$+6.500(1+0.30)^{4}$

$V P N=-12.000+11.838,87$

Donde:

Inversión Inicial = 12.000

Suma de los FNE a va-

lor presente $=11.838,87$

Aplicando la fórmula

$R B C=11.838,87 / 12.000$

$\mathrm{RBC}=0,99$ Con este resultado se rechazaría el proyecto dado que no se alcanza a recuperar la Inversión inicial.

\section{PAYBACK DESCONTADO}

El payback o periodo de recuperación de la inversión es una herra- mienta de toma de decisiones de inversión, con la cual se determina el tiempo en el que se recupera la inversión realizada en un proyecto. Es muy útil como criterio de decisión cuando existen dos alternativas de inversión con resultados de TIR y VPN similares. El elemento fundamental de decisión es el tiempo, a menor tiempo de recuperación de la inversión, menor incertidumbre, menor riesgo y por lo tanto mayor viabilidad del proyecto. Su forma de cálculo es mediante la suma de los flujos de caja descontados el costo de recurso del proyecto, como se muestra a continuación: 


\section{TABLA 26}

\section{EJEMPLO DE CÁLCULO DE PAYBACK}

Fuente: Elaboración propia

\begin{tabular}{|c|c|c|c|c|c|}
\hline Concepto & Año 0 & Año 1 & Año 2 & Año 3 & Año 4 \\
\hline $\begin{array}{c}\text { FCLO } \\
\text { descontados }\end{array}$ & -30.000 & -10.000 & 20.000 & 20.000 & 5.000 \\
\hline $\begin{array}{c}\text { Suma } \\
\text { de Flujos }\end{array}$ & -30.000 & -40.000 & -20.000 & 0 & \\
\hline
\end{tabular}

Como se observa en la tabla anterior se van acumulando los flujos de caja a medida que avanzan los periodos, en el periodo 0 se tiene una inversión inicial de $\$ 30.000$, luego en el periodo uno hay un flujo de caja negativo de $\$ 10.000$ con lo cual la suma de flujos para el año uno es igual a $-\$ 40.000$ y en los siguientes dos periodos hay un flujo de caja positivo de $\$ 20.000$, con lo cual al finalizar el año tres la suma de flujos es igual a cero, es decir, que el periodo de recuperación de la inversión correspondería a tres años para este ejemplo. La ventaja de este método es que es fácil de calcular y su resultado fácil de interpretar.

\section{ILUSTRACIÓN 10}

FORMULA DE PAYBACK

Fuente: Elaboración Propia

Payback $=$

$\mathrm{n}+(\mathrm{ii}-\Sigma$ FNE $) / \mathrm{FCr}$ 
$\mathrm{n}$ = periodo anterior a la recuperación de la inversión

II = Inversión inicial

$\sum$ fne = Suma de los flujos de efectivo hasta el periodo $n$

$\mathrm{FCr}=$ Flujo de caja $\mathrm{n}+1$ es decir en el que se recupera el total de la inversión

Al iniciar la ejemplificación del tema, se expuso un caso que presentaba variables de entrada tales como el precio, los costos variables, los costos fijos, la tasa de interés de la deuda y la tasa de descuento, por mencionar las principales. También se dijo que estos datos se derivan de estudios previos realizados en cada una de las áreas que le competen al proyecto. Por lo tanto, estás son consideradas variables independientes.

Se recomienda al lector que, a partir de la construcción de un escenario probable, como el desarrollado en el ejemplo, realice un análisis de sensibilidad con el objetivo de medir el riesgo o la variabilidad que se puede presentar en cualquiera de los datos de entrada, lo que en últimas afecta la rentabilidad del proyecto.

Si bien los estudios de factibilidad se deben hacer con rigurosidad, debemos entender que los mercados son cambiantes, y no se puede predecir el futuro con certeza, dado que un hecho político, económico, social, etc., puede afectar las proyecciones.

Existen métodos como el análisis de sensibilidad por variables y por escenarios que pretenden analizar el comportamiento de la rentabilidad al cambiar una a una las variables de entrada o cambiando varias a la vez. También se pueden consultar otras técnicas más avanzadas que corresponden a métodos probabilísticos, como los árboles de decisión o la simulación de Montecarlo que se realizan en softwares especializados tales como Crystal Ball o Risk Simulator. La simulación es una técnica que permite determinar la probabilidad de ocurrencia, por ejemplo, de la rentabilidad del proyecto, realizando entre 1.000 y 10.000 variaciones en los principales supuestos de entrada, aquellos que sean más sensibles. 


\section{CASO RESTAURANTE COMIDA DE MAR}

Este caso está sustentado en datos reales sobre una idea de emprendimiento de creación de un restaurante de comida de mar. Antes de comenzar con la evaluación financiera del proyecto de inversión se deben responder como mínimo las siguientes preguntas:

» ¿Realmente tengo un producto diferente que será capaz de cautivar a los clientes potenciales?

» ¿Quiénes son mis clientes potenciales y dónde están ubicados?

» ¿Dónde debo poner mi restaurante para llegar a mi nicho de mercado?

» ¿Quiénes serán mis competidores directos y cuáles son sus diferenciales?

» ¿Cuáles son los recursos físicos $y$ financieros que requiero para el montaje y puesta en marcha del restaurante?
Si se tienen claros estos elementos es posible desarrollar las estimaciones financieras y aplicar los métodos de decisión para determinar la viabilidad financiera del proyecto.

En respuesta a estas preguntas, el equipo emprendedor llegó a las siguientes conclusiones: se venderá comida de mar, en un local ubicado en el barrio Restrepo en Bogotá, donde se venderán dos tipos de almuerzo: Menú a la carta y Menú económico, ambos con precios similares a los del sector, pero de acuerdo con los emprendedores con diferenciadores claros en el sabor y variedad de los platos ofrecidos por el restaurante. Así mismo, el restaurante tendrá servicio de domicilios y tendrá capacidad máxima de 50 personas. El precio de venta sería de $\$ 25.000$ para los platos a la carta y de $\$ 8.000$ para el plato del día en el primer año. 


\section{TABLA 27}

\section{PRESUPUESTO DE VENTAS}

Fuente: elaboración propia

\begin{tabular}{|c|c|c|c|c|c|}
\hline & AÑO 1 & AÑO 2 & AÑO 3 & AÑO 4 & AÑO 5 \\
\hline $\begin{array}{c}\text { PLATOS A LA CARTA } \\
\text { (CANTIDAD) }\end{array}$ & 2.198 & 2.418 & 2.660 & 2.926 & 3.219 \\
\hline PRECIO & 25.000 & 26.750 & 28.623 & 30.626 & 32.770 \\
\hline SUBTOTAL & 54.959 .675 & 64.687 .538 & 76.137 .232 & 89.613 .522 & 105.475 .115 \\
\hline $\begin{array}{l}\text { PLATO DEL DIA } \\
\text { (CANTIDAD) }\end{array}$ & 11.164 & 12.838 & 14.764 & 16.979 & 19.525 \\
\hline PRECIO & 8.000 & 8.560 & 9.159 & 9.800 & 10.486 \\
\hline SUBTOTAL & 89.309 .451 & 109.895 .280 & 135.226 .142 & 166.395 .768 & 204.749 .992 \\
\hline TOTAL INGRESOS & 144.269 .127 & 174.582 .818 & 211.363 .374 & 256.009 .290 & 310.225 .108 \\
\hline
\end{tabular}


Como se observa en la tabla anterior, durante el primer año se estimó un total de ventas de 2.198 platos a la carta y de 11.164 platos del día. Lo cual equivale a un promedio diario de 7,37 platos a la carta y 37,46 platos del día. De esta estimación se observan varias situaciones. La primera de ellas, es completamente coherente con la capacidad proyectada del restaurante, la segunda que busca apuntarle a una estimación de ventas conservadora y la tercera y más importante, que la estimación en realidad no responde a ningún modelo estadístico o proyección de demanda sofisticada, esto se debe entre otras cosas, a la baja probabilidad que existe de acertar en una proyección ventas de un nuevo negocio. En este sentido lo más importante al momento de estimar las ventas en un negocio nuevo, es haber realizado pruebas de producto con clientes potenciales para así ser capaces de determinar su viabilidad comercial.

La estimación de ventas es fundamental, y si bien existen diversas técnicas para la proyección de ventas como la regresión lineal, la suavización exponencial o método Holts entre otros, en proyectos de inversión donde por lo general no existe una fuente de ingresos asegurada y no existen datos históricos de ventas, estas estimaciones no tienen validez y lo mejor que se puede hacer es realizar pruebas de validación de producto que den la confianza de que el producto o servicio va a tener una buena aceptación en el mercado y una buena caracterización del tipo de cliente que se espera, para asegurar una coherencia entre producto, nicho de mercado y ubicación geográfica. A partir de la definición clara de los aspectos anteriores, las estimaciones de ventas deben estar alineadas con la capacidad instalada, que se estima en una capacidad máxima de atención de 50 personas y también deben estar alineadas con la estructura organizacional que se requiere para atender adecuadamente la demanda.

En cuanto a la capacidad instalada se estima que la empresa debe realizar una inversión inicial compuesta por activos, por preoperativos y por capital de trabajo. Estas inversiones son fundamentales para la buena implementación del proyecto y su esti- 
mación debe ser lo más cercana a la realidad, teniendo como premisa que la inversión inicial ejecutada no supere a la inversión inicial proyectada. Esto debido a que una inversión inicial que supere las estimaciones realizadas generaría un déficit de recursos que en la etapa de inversión podría, incluso, llevar a la quiebra al proyecto, antes de que este llegue a una etapa operativa. Para el proyecto del restaurante de comida de mar se estima la siguiente inversión en activos fijos.

Como se observa en la tabla 22 , no se contempla compra de inmuebles para el funcionamiento del negocio, con lo cual la inversión inicial en activos fijos asciende a ocho millones treinta $y$ tres mil doscientos ocho pesos. Sin embargo, esta no es la única inversión que se debe tener en cuenta. En la fase preoperativa del proyecto que sería la etapa que iría desde la concepción de la idea hasta el día anterior a la apertura al público del local comercial, hay una serie de gastos que se deben contemplar para que el proyecto pueda llegar a feliz término, estos gastos preoperativos están relacionados con gastos de constitución, estudios de factibilidad, adecuación de instalaciones, capacitación de personal (antes de la fase operativa), entre otros. Para el proyecto restaurante de comida de mar que se está desarrollando se estiman los siguientes gastos preoperativos: (Ver tabla 29). 


\section{TABLA 28}

\section{PRESUPUESTO DE INVERSIÓN EN ACTIVOS FIJOS}

Fuente: Elaboración propia

\begin{tabular}{|c|c|c|c|}
\hline Activo & Cantidad & Valor Unitario & Total \\
\hline Congeladores y refrigeradores & 1 & $\$ 1.500 .000$ & $\$ 1.500 .000$ \\
\hline Estufas y planchas, hornos y freidoras & 2 & $\$ 1.550 .000$ & $\$ 3.100 .000$ \\
\hline Licuadoras, Sanducheras y microondas & 1 & $\$ 200.000$ & $\$ 200.000$ \\
\hline Copas y Vasos & 24 & $\$ 3.350$ & $\$ 80.400$ \\
\hline Ollas y Sartenes & 10 & $\$ 50.000$ & $\$ 500.000$ \\
\hline Utensilios de Cocina & 5 & $\$ 30.000$ & $\$ 150.000$ \\
\hline Vajillas Loza y Melamina & 24 & $\$ 10.417$ & $\$ 250.008$ \\
\hline Cubiertos & 72 & $\$ 1.150$ & $\$ 82.800$ \\
\hline Sillas y Mesas para Restaurantes & 7 & $\$ 200.000$ & $\$ 1.400 .000$ \\
\hline Otros Muebles & 1 & $\$ 100.000$ & $\$ 100.000$ \\
\hline Mueble para Caja & 1 & $\$ 100.000$ & $\$ 100.000$ \\
\hline Caja Registradora & 1 & $\$ 470.000$ & $\$ 470.000$ \\
\hline Bicicleta & 1 & $\$ 100.000$ & $\$ 100.000$ \\
\hline \multicolumn{3}{|c|}{ TOTAL } & $\$ 8.033 .208$ \\
\hline
\end{tabular}




\section{TABLA 29}

\section{PRESUPUESTO DE GASTOS PREOPERATIVOS}

Fuente: Elaboración propia

Concepto

Registro Mercantil (CCB)
Valor

$\$ 112.000$ 


\section{TABLA 30}

\section{PRESUPUESTO DE INVERSIÓN \\ EN CAPITAL DE TRABAJO}

Fuente: Elaboración propia

\section{Mes}

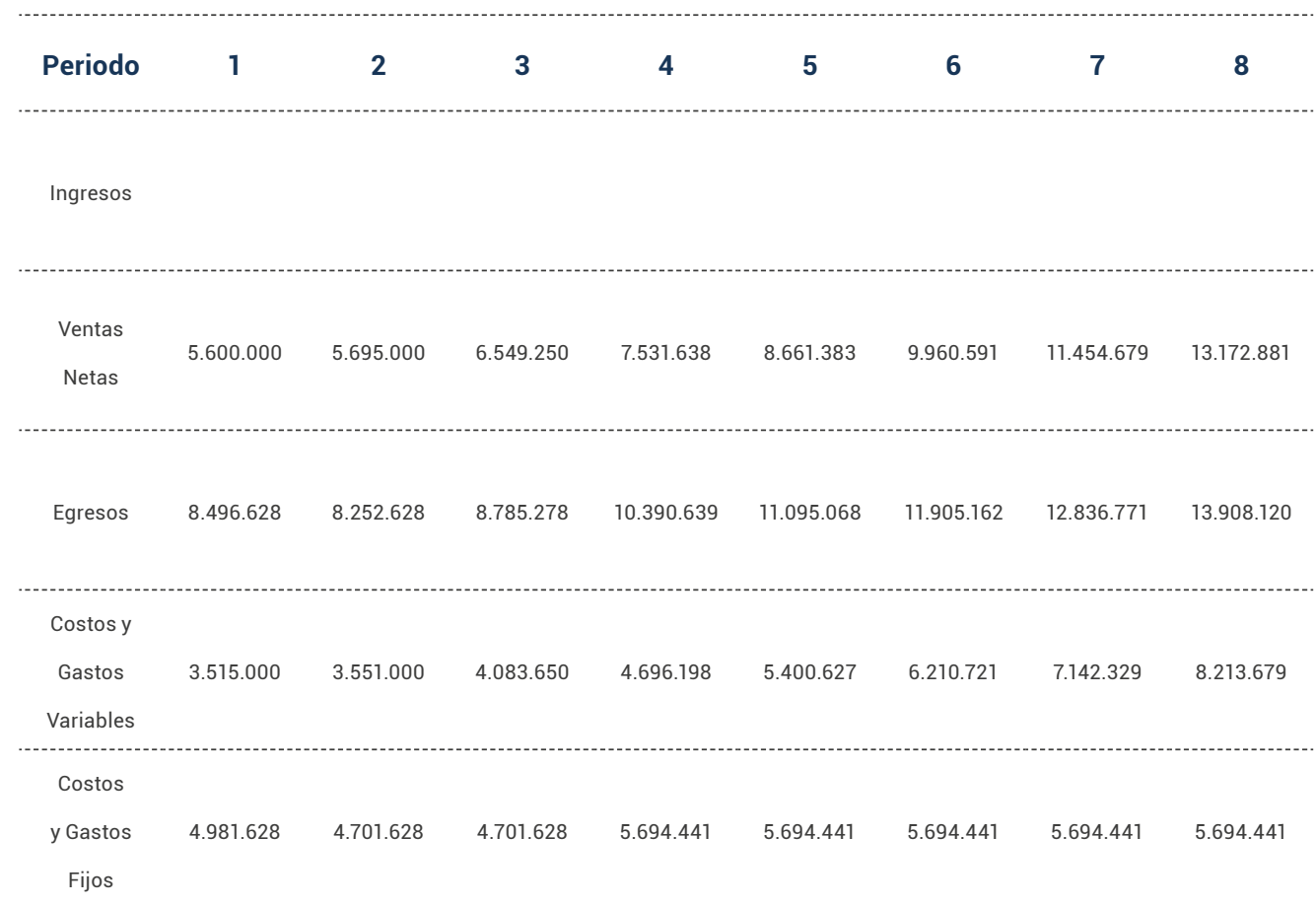

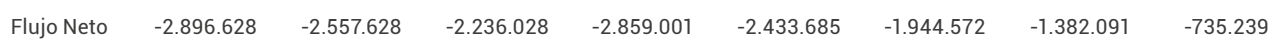


Adicionalmente, se debe contemplar otro elemento que es la inversión en capital de trabajo, ya que su omisión representa uno de los mayores errores al momento de evaluar un proyecto de inversión. El capital de trabajo representa los recursos monetarios que requiere el proyecto desde el momento de su puesta en marcha, hasta el momento en el cual es capaz de ser auto sostenible. $Y$ en este caso se debe ser muy realista con las estimaciones iniciales de ventas. Lo normal en un proyecto de inversión es que los primeros meses o incluso los primeros años tengan un bajo nivel de ventas en comparación con el punto de equilibrio de la empresa. Por ejemplo, si se estima que el punto de equilibrio se puede alcanzar en tres meses, pero este se lograra pasados doce meses, estaríamos ante una situación de falta de recursos financieros de nueve meses, con la consecuencia de poner en riesgo la continuidad del negocio. Inclusive, puede llegar a suceder que, dependiendo del tipo de negocio, se requieran más recursos de inversión en capital de trabajo que en activos fijos.
En la tabla 24 se observa cómo con los parámetros establecidos para el proyecto del restaurante de comida de mar se estima una inversión de \$17.044.871, que corresponden a ocho meses de flujo de caja negativo, ya que a partir del noveno mes se estima que los ingresos del proyecto superen a los gastos. Al hacer la sumatoria de la inversión en activos, los gastos preoperativos y la inversión en capital de trabajo, la puesta en marcha del restaurante tendría una inversión estimada de \$26.790.079. Esta inversión estimada a su vez correspondería al estado de situación financiera inicial con el que arrancaría el proyecto.

Ahora bien, además de la inversión proyectada se deben estimar los costos y gastos que generará el proyecto y para ello se deben diferenciar estos dos conceptos; los costos hacen referencia a las salidas de recursos financieros que son necesarias para que se pueda fabricar el producto de forma adecuada. En este sentido, los costos dentro del proyecto estarían dados principalmente por proteínas, legumbres, abarrotes, frutas, entre otros insumos requeridos para la 
preparación de los almuerzos. Mientras que los gastos operacionales corresponden a las salidas de recursos financieros destinados a las actividades de apoyo requeridas para que el producto pueda ser vendido y los recursos provenientes de la venta sean administrados de forma adecuada. Dentro de estos gastos operacionales se encontrarían los salarios del administrador y de los meseros, los gastos en publicidad como volantes, tarjetas, almanaques entre otros.

En este sentido, es importante diferenciar entre costos y gastos fijos y costos y gastos variables, ya que los primeros son independientes del nivel de ventas que se logren, mientras que los segundos, tienen una relación directa con el nivel de ventas de la empresa. En otras palabras, la empresa debe procurar generar ingresos que por lo menos cubran sus costos (y gastos) fijos y sus costos (y gastos) variables.

Luego de que el emprendedor ha determinado sus inversiones, sus costos y sus gastos, debe tomar la siguiente decisión que tiene que ver con la forma de financiar el proyecto.
¿ ¿Tiene los recursos propios para hacerlo?

¿ ¿Requiere financiación?

¿ ¿Tiene acceso a crédito bancario?

¿Tiene la posibilidad de asociarse con un inversionista?

Las respuestas a estas preguntas darán como resultado la estructura de capital del proyecto, entendiéndose como la forma de financiación del mismo. Esta estructura de capital estará dividida en dos partes, la financiación propia o con socios y la inversión con terceros o entidades financieras. La estructura de capital propuesta para el proyecto del restaurante seria la siguiente:

Luego de tener claridad sobre la estructura del capital, es necesario proyectar el flujo de caja de la deuda. Ya que si bien, la deuda representa un ingreso en el momento inicial para poder poner en marcha el proyecto, luego de esto representará un egreso equivalente al valor de las cuotas periódicas. Adicionalmente, es importante conocer la porción de interés 
pagado (gastos financieros) dentro de la cuota estimada y que porción corresponde a amortización de pasivos (abono a capital de la deuda).

Esta diferenciación es importante debido a que los intereses afectan el Estado de Resultados, mientras que la amortización de pasivos afec- ta el Estado de Situación Financiera. Para el caso planteado, teniendo en cuenta una tasa de interés del $37 \%$ EA (muy cercana a la tasa de interés corriente para microcréditos) y un plazo de cinco años la tabla de amortización con el sistema de amortización francés seria la siguiente: (Ver tabla 32).

\section{TABLA 31}

\section{ESTRUCTURA DE CAPITAL}

Fuente: Elaboración propia

Fuente de Financiación

Financiación propia
13.290 .079

Monto

13.500 .000 


\section{TABLA 32}

\section{TABLA DE AMORTIZACIÓN}

\section{DEL CRÉDITO}

Fuente: Elaboración propia

\begin{tabular}{|c|c|c|c|c|c|c|}
\hline & & Año 1 & Año 2 & Año 3 & Año 4 & Año 5 \\
\hline Capital & & 1.312 .201 & 1.794 .173 & 2.453 .173 & 3.354 .223 & 4.586 .229 \\
\hline Intereses & & 4.958 .550 & 4.476 .578 & 3.817 .579 & 2.916 .528 & 1.684 .522 \\
\hline Cuota & & 6.270 .751 & 6.270 .751 & 6.270 .751 & 6.270 .751 & 6.270 .751 \\
\hline Saldo & 13.500 .000 & 12.187.799 & 10.393 .625 & 7.940 .453 & 4.586 .229 & 0 \\
\hline
\end{tabular}

Ya en este punto, donde se han realizado las proyecciones de ventas, se ha estimado la inversión inicial, los costos y los gastos operativos, la estructura de capital y los gastos financieros, es posible hacer la proyección de estados financieros y en especial la proyección del flujo de caja con el método indirecto explicado previamente. Con esta metodología se llega al resultado que se observa en la siguiente tabla. 


\section{TABLA 33}

\section{FLUJO DE CAJA LIBRE OPERACIONAL}

Fuente: Elaboración propia

\begin{tabular}{|c|c|c|c|c|c|c|}
\hline & Año 0 & Año 1 & Año 2 & Año 3 & Año 4 & Año 5 \\
\hline $\begin{array}{c}\text { Utilidad } \\
\text { Operacional }\end{array}$ & & -13.302 .185 & 7.830 .517 & 32.955 .574 & 65.130 .107 & 106.001 .544 \\
\hline $\begin{array}{l}\text { (-) Impuestos } \\
\text { Operacionales }\end{array}$ & & - & 2.349 .155 & 9.886 .672 & 19.539 .032 & 31.800 .463 \\
\hline $\begin{array}{l}\text { Utilidad Opera- } \\
\text { tiva después de } \\
\text { Impuestos }\end{array}$ & & -13.302 .185 & 5.481 .362 & 23.068 .902 & 45.591 .075 & 74.201 .081 \\
\hline $\begin{array}{c}(+) \\
\text { Depreciaciones }\end{array}$ & & 931.814 & 931.814 & 931.814 & 616.012 & 616.012 \\
\hline$\stackrel{(+)}{\text { Amortizaciones }}$ & & 1.712 .000 & & & & \\
\hline $\begin{array}{l}(-) \text { Incremen- } \\
\text { to en Capital de } \\
\text { Trabajo }\end{array}$ & & - & & & & \\
\hline $\begin{array}{l}\text { (-) Inversión en } \\
\text { Activos Fijos }\end{array}$ & & & & & & \\
\hline $\begin{array}{l}\text { FLUJO DE } \\
\text { CAJA LIBRE } \\
\text { OPERACIONAL }\end{array}$ & -26.790 .079 & -10.658 .371 & 6.413 .176 & 24.000 .716 & 46.207 .087 & 74.817 .093 \\
\hline
\end{tabular}


A este flujo de caja libre operacional se le tendría que colocar un valor de salvamento en el periodo final, correspondiente al valor que quedaría de liquidar los activos y pasivos en el año final de la vida útil del proyecto, que para este caso sería el año cinco. Sin embargo, por el tipo de activos que componen el proyecto de inversión del restaurante se asume un valor de salvamento de cero pesos. Ahora bien, también se podría estimar que el restaurante tiene una vida útil infinita con lo cual el valor de salvamento sería igual al valor presente de los flujos de caja proyectados a perpetuidad. Sin embargo, con la dinámica actual de los negocios y un mundo altamente cambiante no sería una estimación realista.

Como siguiente etapa, se calcula el costo de capital de acuerdo con la metodología explicada en el capítulo anterior, de tal modo que este representa la tasa de interés de oportunidad. Es decir, la tasa de interés mínima ante la cual el proyecto de inversión sería considerado viable; para el caso del proyecto analizado, esta tasa de interés se estima en 18,19\% EA.
A partir de estos supuestos, el flujo de caja libre operacional arrojaría un valor presente neto de 39.430 .418 y una tasa interna de retorno de $43,74 \%$ EA.

Ahora bien, éste sería el flujo de caja del proyecto, sin embargo, una cosa es el flujo de caja del proyecto y otra distinta es el flujo de caja del accionista, ya que si el emprendedor ha financiado parte de su proyecto con deuda con terceros hay cambios en los flujos de caja que genera el proyecto, y a su vez, en la tasa de interés de oportunidad que en este caso solo contemplaría el costo de la deuda con accionistas (Ke) que para el caso analizado seria del 5,83\% EA. 
TABLA 34

FLUJO DE CAJA DEL ACCIONISTA

Fuente: Elaboración propia

\begin{tabular}{|c|c|c|c|c|c|c|}
\hline & Año 0 & Año 1 & Año 2 & Año 3 & Año 4 & Año 5 \\
\hline $\begin{array}{l}\text { FLUJO DE } \\
\text { CAJA LIBRE } \\
\text { OPERACIONAL }\end{array}$ & & -10.658 .371 & 6.413 .176 & 24.000 .716 & 46.207 .087 & 74.817 .093 \\
\hline $\begin{array}{l}\text { (-) Gastos de } \\
\text { Intereses }\end{array}$ & & 4.958 .550 & 4.476 .578 & 3.817 .579 & 2.916 .528 & 1.684 .522 \\
\hline $\begin{array}{l}\text { (-) Amortización } \\
\text { de la deuda }\end{array}$ & & 1.312 .201 & 1.794 .173 & 2.453 .173 & 3.354 .223 & 4.586 .229 \\
\hline \multicolumn{7}{|l|}{$\begin{array}{l}\text { (+) Créditos } \\
\text { Recibidos }\end{array}$} \\
\hline \multicolumn{7}{|l|}{$\begin{array}{c}(+) \text { Otros } \\
\text { Ingresos no } \\
\text { Operacionales }\end{array}$} \\
\hline \multicolumn{7}{|l|}{$\begin{array}{c}\text { (-) Otros } \\
\text { Egresos no } \\
\text { operacionales }\end{array}$} \\
\hline $\begin{array}{l}\text { (+) Efecto } \\
\text { Impuestos }\end{array}$ & & - & 1.342 .974 & 1.145 .274 & 874.958 & 505.357 \\
\hline $\begin{array}{l}\text { FLUJO DE CAJA } \\
\text { DISPONIBLE } \\
\text { PARA EL } \\
\text { ACCIONISTA }\end{array}$ & -13.290 .000 & -16.929 .123 & 1.485 .398 & 18.875 .238 & 40.811 .294 & 69.051 .698 \\
\hline
\end{tabular}


Con estos parámetros, el accionista obtendría un valor presente neto de 68.532 .725 y una tasa interna de retorno de $48 \% \mathrm{EA}$, es decir, que, a mayor financiación con terceros, también habría una mayor rentabilidad, pero al mismo tiempo el proyecto está expuesto a un mayor riesgo.

Sin embargo, en el caso expuesto, como en todo proyecto de inversión, hay un último elemento a evaluar que tiene que ver con el riesgo del proyecto, teniendo en cuenta que las estimaciones realizadas a lo largo del caso son solo eso, simples estimaciones, y como tales están sujetas a múltiples variaciones.

Estas variaciones pueden ser, por ejemplo, en el precio de venta. Puede suceder que el precio de venta estimado haya sido muy alto y se tenga que ajustar a la baja, o que los costos tengan mucha variabilidad y esto afecte negativamente las estimaciones financieras. También podría pasar, por ejemplo, que se hubiera proyectado un nivel de ventas inferior al que realmente se alcance, y en este punto se hace necesario el análisis de sensibilidad, que no es otra cosa que la evaluación de lo que sucede financieramente, si uno o varios de los supuestos utilizados no se cumplen. Para ello, el programa Excel cuenta con diversas herramientas de análisis que se encuentran dentro del menú datos, submenú herramientas de hipótesis como, por ejemplo, administrador de escenarios, tablas de datos y buscar objetivo. Del mismo modo, existen aplicativos de simulación de Montecarlo como Risk Simulator, que permiten hacer análisis estocásticos de los resultados encontrados en los métodos de decisión aplicados en la evaluación financiera de los proyectos de inversión. A modo de ejemplo, se va a hacer un análisis de sensibilidad donde se evalúa qué pasaría si las ventas de platos a la carta del año uno, fueran inferiores a las proyectadas. 


\section{TABLA 35}

\section{ANÁLISIS DE SENSIBILIDAD}

Fuente: Elaboración propia

\begin{tabular}{ccc} 
Unidades & VPN & TIR \\
\hline 2.198 & 39.430 .418 & $43,74 \%$ \\
\hline 1.945 & 27.634 .175 & $34,71 \%$ \\
\hline 1.691 & 15.342 .866 & $26,29 \%$ \\
\hline 1.408 & 1 & $16,70 \%$ \\
\hline 931 & -12.537 .279 & $9,47 \%$ \\
\hline
\end{tabular}

En esta tabla se observa, que si se vende menos de 1.408 platos a la carta en el primer año, el valor presente neto pasaría a ser negativo, con lo cual el proyecto dejaría de ser viable. $Y$ en este punto cabría la pregunta ¿Qué tan probable es que las ventas de platos a la carta estén por debajo de 1.408 unidades? Y si se da este escenario, ¿valdría la pena continuar con el negocio?
Nótese que, aunque el proyecto no es viable por debajo de 1.408 platos a la carta, no significa que no sea rentable, de hecho, con ventas de platos a la carta de 931 unidades alcanza a darse una Tasa Interna de Retorno (TIR) de 1,51\%. Entonces, lo que sucede en niveles de ventas entre 931 y 1.408 platos es que a pesar de que hay una rentabilidad positiva, ésta no es suficiente para generar valor en el 
proyecto. Es así como, ante escenarios en los cuales el proyecto no esté dando los resultados esperados cual será mi decisión como emprendedor:

» ¿Cerraría el negocio si las ventas son inferiores a 1.408 unidades siendo que hay utilidades, aunque no se genera valor?

» ¿Cerraría el negocio con ventas por debajo de 931 unidades donde no habría ni utilidades ni generación de valor?;

A través del análisis de escenarios la respuesta a esa pregunta se puede dar incluso antes de haber comenzado la etapa preoperativa del proyecto.

Sin embargo, no todos los escenarios son negativos, también existen escenarios positivos, para lo cual la decisión será ¿Qué voy a hacer con los excedentes de liquidez que no tenía contemplados? Es decir, que con los análisis de sensibilidad puedo tener respuesta a esta pregunta desde antes de darle inicio al proyecto de inversión.

De este modo, hemos hecho un recorrido por la evaluación de un proyecto de inversión desde sus fundamentos conceptuales, pasando por la metodología que contempla la estimación de ingresos, inversiones, costos, gastos, estados financieros, flujos de caja; la evaluación de proyectos con el apoyo de métodos de decisión como la Tasa Interna de Retorno (TIR), el Valor Presente Neto (VPN) y los análisis de sensibilidad y escenario que permiten la toma de decisiones de forma anticipada a la ocurrencia de los hechos. 



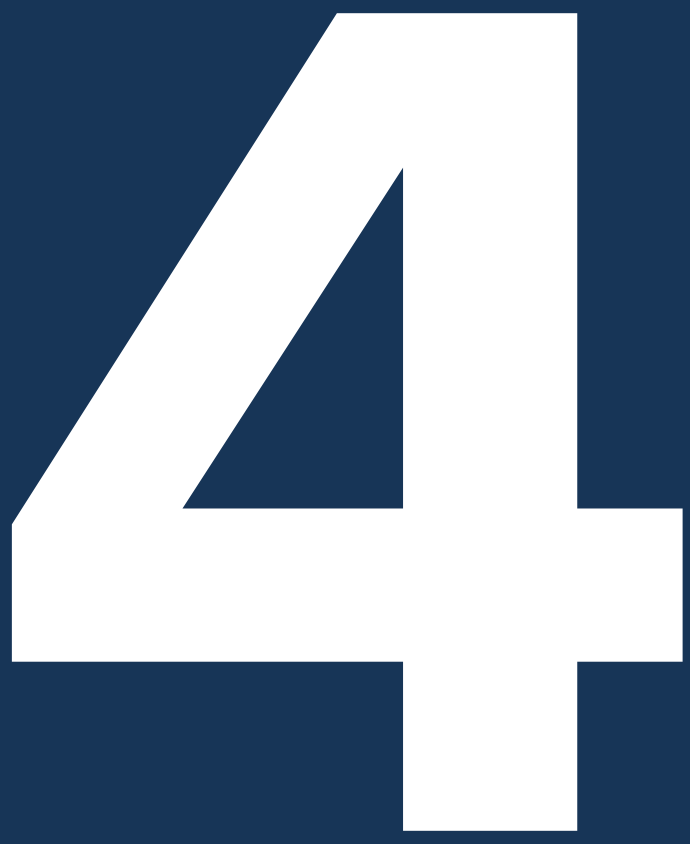

- -

CAPÍTULO

GESTIÓN CONTINUA DE NEGOCIO,

INDICADORES PARA LA TOMA DE DECISIONES 


\section{¿Cuál es la importancia de los indicadores financieros como: EBITDA y Margen EBITDA, ROA, ROE, Costo promedio ponderado de capital y EVA? y ¿cómo éstos influyen en las decisiones de un empresario consciente de sus finanzas?}

Tunjano, Iván

\section{INDICADORES FINANCIEROS Y TOMA DE DECISIONES}

¿Cuál es la importancia de los indicadores financieros como: EBITDA y Margen EBITDA, ROA, ROE, Costo promedio ponderado de capital y EVA?, y ¿cómo estos influyen en las decisiones de un empresario consciente de sus finanzas?

Las empresas constituidas legalmente llevan un proceso de contabilidad que les permite, entre otras cosas, identificar el valor de sus activos y registrar hechos económicos, como ingresos y salidas de dinero. A pesar de que en algunos casos esta información solo se lleva con fines tributarios, es útil para hacer un diagnóstico financiero que le puede ayudar a las organizaciones a enfrentar importantes retos que condicionan su supervivencia. Es decir, así como las personas con ayuda de su médico detectan y superan dificultades de salud con la observancia de una serie de signos, las empresas pueden detectar distintas "enfermedades" que puedan estar padeciendo, con ayuda de la información financiera. Un médico al ordenar un examen de sangre de un paciente busca identificar efectos negativos en su salud y 
bienestar que no son visibles a simple vista. De esta misma forma, los exámenes médicos en las empresas son los estados financieros que deben ser preparados cada mes, cada trimestre y cada año, pero no solo hace falta tener los estados financieros, hay que realizar un análisis y lectura de los mismos desde una perspectiva financiera.

Una persona capaz de leer estos signos (un profesional en finanzas) resulta entonces fundamental en la estrategia de toda organización, sin embargo, el tamaño de algunas empresas no permite contar con este elemento. Para muchas, los recursos económicos son muy limitados y es imposible acudir a un lector especialista de estos datos o un "medico de empresas" que les brinde información acerca de la existencia factores de alarma o de si existe algún tratamiento óptimo para afrontar las dolencias que se puedan estar sufriendo a tiempo y no terminar con un paciente en cuidados intensivos o que deba ser intervenido de urgencia.

Un proceso de diagnóstico financiero requiere la revisión de todos los es- tados financieros históricos para poder entender cómo ha evolucionado la compañía y poder identificar cuáles pueden ser sus mayores fortalezas o mayores problemas desde el punto de vista de su situación financiera. Procesos como el análisis horizontal y el análisis vertical permiten identificar comportamientos y mayores cambios en las diferentes cuentas contables en el estado de situación financiera y estado de resultados integral, pero que pueden no ser suficientes. En el desarrollo de este capítulo se describirán otros indicadores que permiten generar hipótesis con algún grado de precisión y de esta forma poder entender el comportamiento de la empresa, identificando oportunidades de mejora o amenazas que se puedan tener o que se puedan estar formando o incubando en la empresa.

\section{EBITDA Y MARGEN EBITDA}

El primer elemento de análisis será el EBITDA, que pareciera ser un sofisticado indicador financiero con un difícil proceso para su cálculo, aunque nada más alejado de la realidad. Este indicador corresponde al ingreso ope- 
racional menos el costo de ventas y los gastos administrativos, excluyendo del cálculo los gastos financieros, los impuestos y el valor de las depreciaciones y amortizaciones. En esencia, es un indicador de utilidad que no tiene en cuenta las decisiones de financiamiento (intereses por créditos), el efecto de tener activos (depreciaciones y amortizaciones), ni el efecto de los impuestos. Se puede calcular de dos formas:

\section{TABLA 36}

\section{ESTADO DE RESULTADOS INTEGRAL}

Fuente: Elaboración propia

\section{ERI $^{12}$ (MiPyme)}

(+) Ingresos Operacionales

(-) Costo de ventas

(=) Utilidad bruta

(-) Gastos Administrativos

(-) Depreciaciones y amortizaciones

$(=)$ UAll O EBIT

(+) Depreciaciones y amortizaciones

(=) EBITDA
8.000

4.500

3.500

2.430

980

90

980

1.070 
Forma 1: EBITDA = UAll + Depreciaciones y amortizaciones

Forma 2: EBITDA = Ingresos operacionales - Costo de ventas - Gastos Administrativos $^{13}$

La información que ofrece este indicador hablándose relaciona únicamente con la capacidad que tiene la empresa de generar caja en sus operaciones. Es decir, solo está mencionando que el flujo de caja de la empresa MiPyme es de 1.070 , pero no muestra qué tan eficiente es en la administración de sus recursos para generar dicho flujo de caja. Por tanto, es necesario agregar otros elementos de análisis para darle más profundidad y llegar a conclusiones más acertadas; con este fin observemos el siguiente caso:

Ejemplo: suponga dos empresas que se encuentran en el mismo sector, que fabrican el mismo producto o prestan el mismo servicio, o comercializan el mismo producto, pero tienen la siguiente información de estado de resultados integral: (Ver tabla 37).

Si solo nos fijamos en las ventas y en el EBITDA, se podría llegar a la conclusión de que la empresa B está en una posición más favorable que la empresa $\mathrm{A}$. Sin embargo, un análisis más detallado permite señalar lo siguiente:

»La empresa A Vende 12.000 y genera 1.980 de EBITDA. Es decir, convierte el $16,5 \%$ de sus ventas en flujo de caja. Mientras que,

》La empresa B vende 24.000 y genera 2.500 de EBITDA, es decir el $10,42 \%$ de sus ventas. 


\section{TABLA 37}

\section{COMPARATIVO DE EMPRESA}

Fuente: Elaboración propia

\begin{tabular}{|c|c|c|c|}
\hline \multicolumn{2}{|c|}{ ERI (Empresa A) } & \multicolumn{2}{|c|}{ ERI (Empresa B) } \\
\hline (+) Ingresos Operacionales & 12.000 & (+) Ingresos Operacionales & 24.000 \\
\hline (-) Costo de ventas & 6.480 & (-) Costo de ventas & 15.600 \\
\hline$\Leftrightarrow$ Utilidad bruta & 5.520 & (=) Utilidad bruta & 8.400 \\
\hline (-) Gastos Administrativos & 3.540 & (-) Gastos Administrativos & 5.900 \\
\hline $\begin{array}{c}\text { (-) Depreciaciones y amor- } \\
\text { tizaciones }\end{array}$ & 1.540 & $\begin{array}{c}\text { (-) Depreciaciones y amorti- } \\
\text { zaciones }\end{array}$ & 1.200 \\
\hline$(=)$ UAII (EBIT) & 440 & $(=)$ UAII (EBIT) & 1.300 \\
\hline (=) EBITDA & 1.980 & (=) EBITDA & 2.500 \\
\hline Margen EBITDA & $16,50 \%$ & Margen EBITDA & $10,42 \%$ \\
\hline
\end{tabular}


El porcentaje calculado resulta de dividir el EBITDA de 1.980 sobre 12.000 para la empresa A y 2.500 sobre 24.000 para la empresa B. Este indicador es conocido como el margen EBITDA, y nos permite hacer supuestos como:

»La empresa $A$ es más eficiente que la empresa B.

»Aunque la empresa $\mathrm{B}$ tiene mayores ventas y mayor EBITDA, relativamente tiene mayores erogaciones (Costos de ventas o Gastos Administrativos) que la empresa $\mathrm{A}$.

Cuando una empresa tiene menos erogaciones en cuanto a costo de ventas o gastos administrativos relativamente, significa que tiene procesos más eficientes que le permiten hacer las tareas a un menor costo que otra empresa. Tan solo revisando el margen EBITDA de una empresa y comparándolo con los de sus principales competidores, es posible reconocer cuál es más o menos eficiente. Entonces, para un empresario es de vital importancia revisar su margen EBITDA y estar informado del margen EBITDA que están presentando sus competidores.

\section{¿Qué acciones se pueden tomar para mejorar el margen EBITDA?}

»Innovaciones tecnológicas que permiten producir las mismas cantidades, pero a un menor costo, sin afectar la calidad

»Subir precios de venta, sin afectar el volumen de ventas

" Generar una gestión administrativa más eficiente

»Profesionales con mayor preparación y habilidades, capaces de realizar labores que tendrían que desarrollar con más de dos empleados.

»Manejo de paquetes tecnológicos para la gestión administrativa, siempre y cuando se parametricen de forma correcta con las necesidades y condiciones del negocio (CRM, Paquete contable, POS, entre otros).

» Generar menores costos por arrendamientos, siempre y cuando no implique au- 
mentar costos en otras áreas como logística o afectar la generación de ingresos.

» Mejorar procesos de logística, para que consuman menos recursos económicos

»Potencializar las líneas de producto o servicios que mayor contribución unitaria generan ${ }^{14}$.

Estas acciones son algunas de las muchas alternativas que se pueden implementar para mejorar el margen EBITDA. Sin embargo, cada compañía tiene sus propias cualidades y cada negocio tiene su propia dinámica, por lo que existirán más alternativas dependiendo del negocio que se desarrolla. Si usted espera hacer un análisis de eficiencia operativa desde el punto de vista financiero, lo que debe hacer es calcular el Margen EBITDA y en lo posible compararlo con el margen EBITDA que tiene el sector o algunos de sus principales competidores.

\section{ROA}

Es conocida como la rentabilidad económica, y se calcula al dividir los beneficios operativos sobre los activos totales utilizados para generar dicho beneficio. Para una compañía es de vital importancia calcular cuál es el beneficio económico generado con los activos que tienen en uso.

Supongamos que una empresa tiene la siguiente información en sus estados financieros: 


\section{TABLA 38}

\section{ESTADOS FINANCIEROS (EMPRESA X)}

Fuente: Elaboración propia

\section{$\operatorname{ESF}^{15}($ Empresa X)}

\begin{tabular}{|c|c|c|c|}
\hline Disponible & 700 & Deuda CP & 8.900 \\
\hline Inversiones & 450 & Hacienda & 1.200 \\
\hline Bancos & 720 & Cuentas por Pagar & 3.500 \\
\hline $\begin{array}{c}\text { Inventarios } \\
\text { (Materia prima) }\end{array}$ & 650 & Obligaciones Laborales & 970 \\
\hline $\begin{array}{c}\text { Inventario } \\
\text { (Producto terminado) }\end{array}$ & 3.120 & Deuda LP & 7.300 \\
\hline Cuentas por cobrar & 1.200 & Total & 21.870 \\
\hline $\begin{array}{c}\text { Propiedad planta } \\
\text { y equipo }\end{array}$ & 19.500 & Capital & 11.950 \\
\hline $\begin{array}{l}\text { Flota y equipo } \\
\text { de transporte }\end{array}$ & 9.000 & Utilidades Acumuladas & 1.520 \\
\hline Total & 35.340 & Total Patrimonio & 13.470 \\
\hline
\end{tabular}

15. Estado de situación financiera. 


\section{TABLA 39}

\section{ESTADO DE RESULTADOS \\ INTEGRAL (EMPRESA $X$ )}

Fuente: Elaboración propia

\section{ERI (Empresa X)}

(+) Ingresos Operacionales

(-) Costo de Ventas

(=) Utilidad Bruta

(-) Gastos Administrativos

(-) Depreciaciones y Amortizaciones

(=) UAII (EBIT)

(+) Otros Ingresos

(-) Otros Egresos

(-) Gastos Financieros

(=) UAI (EBT)

(-) Impuestos (30\%)

( $\Rightarrow$ Utilidad Neta Final (UNF)
49.000

34.300

14.700

6.300

2.850

5.550

0

0

2.446

3.104

931

2.173 
Para este caso, la rentabilidad económica se ubicaría en $15,70 \%$, resultante de dividir 5.550 de UAll sobre 35.340 de valor de activos. Esto quiere decir que con estos activos se logra un beneficio económico de $15,70 \%$, antes de tener en cuenta las decisiones de financiamiento (créditos) o el efecto de los impuestos.
La rentabilidad económica, también puede ser calculada, teniendo en cuenta el efecto de los impuestos, para lo cual se sustituye la utilidad operativa (UAIl) por la utilidad operativa después de impuestos (UODI), y las fórmulas quedarían de la siguiente forma:

\section{TABLA 40}

\section{FORMULAS PARA EL \\ CÁLCULO DE ROA}

Fuente: Elaboración propia

\begin{tabular}{|c|c|}
\hline $\begin{array}{l}\text { Rentabilidad económica } \\
\text { antes de impuestos }\end{array}$ & $\begin{array}{l}\text { Rentabilidad económica } \\
\text { después de impuestos }\end{array}$ \\
\hline ROA $=($ UAll $(E B I T)) /($ Activos Totales) & $\mathrm{ROA}=\mathrm{UODI} /$ (Activos totales) \\
\hline $\begin{array}{l}\text { Por su parte el UODI (Utilidad opera- } \\
\text { tiva después de impuestos) se calcula } \\
\text { de la siguiente forma: } \\
\text { ODI=EBIT*(1-Tasa de impuestos }{ }^{16} \text { ) }\end{array}$ & $\begin{array}{l}\text { De esta forma, la rentabilidad eco- } \\
\text { nómica después de impuestos es de } \\
10,99 \% \text { resultante de dividir el resulta- } \\
\text { do de } 14.700^{*}(1-30 \%) \text {, la UODI, entre el } \\
\text { valor del activo total de } 35.340 \text {. }\end{array}$ \\
\hline
\end{tabular}

16. Impuesto sobre la renta. Corresponde al impuesto que se aplica sobre las ganancias generadas por las empresas. 
El ROA brinda información importante a la hora de conocer la rentabilidad que puede ofrecer un negocio antes de tener en cuenta su situación de apalancamiento, es decir, permite evaluar un negocio antes de involucrar su endeudamiento. Teniendo en cuenta esto, dos empresas pertenecientes a un mismo sector y que desarrollen el mismo negocio deberían tener medidas de ROA similares, suponiendo que manejan la misma eficiencia operativa. Este indicador tiene en cuenta todas las erogaciones de costo de ventas y gastos administrativos, reconoce el desgaste de los activos que se registra en las depreciaciones y las cuentas que se estén amortizando. Permite, además, como se verá más adelante, formular hipótesis precisas al ser comparado con otros indicadores como el ROE.

Pero si solo se trata de analizar cuánta utilidad operativa -antes de impuestos y después de impuestos- la empresa es capaz de generar con los activos que tiene en uso, entonces la mejor forma es calculando el ROA. Recuerde que este indicador le está diciendo cuánto es capaz de producir con los activos que posee, antes de pagar intereses e impuestos, y si quiere mejorarlo debe disminuir activos, y/o aumentar la utilidad operativa, la cual podrá mejorar, vendiendo más o disminuyendo los costos y/o mejorando la gestión administrativa. En resumen, siendo más eficientes.

\section{ROE}

Es conocida como la rentabilidad financiera, y se calcula al dividir el beneficio neto (utilidad neta final) sobre el patrimonio. Este indicador sí tiene en cuenta las decisiones de apalancamiento que puedan tomar las empresas.

Supongamos la misma empresa del ejercicio anterior. Para ese caso la rentabilidad financiera se ubicaría en $16,13 \%$, la cual resulta de dividir 2.173 de UNF sobre 13.470 de valor del patrimonio. Esto quiere decir que el patrimonio le genera al accionista una rentabilidad del $16,13 \%$.

\section{ROE= UNF/(Patrimonio Total)}

Para este caso, el ROE es superior al $\mathrm{ROA}$, lo que se interpreta como un 
efecto positivo generado por la deuda. Es decir, que la deuda además de generar recursos para crecer, también está promoviendo que los accionistas tengan mayor rentabilidad en un negocio que como está estructurado renta un $15,70 \%$ antes de impuestos, y que debido al apalancamiento renta para el accionista un $16,13 \%$, es decir un poco más.

\section{¿Cómo entender el efecto de la deuda en el ROE?}

EI ROE es calculado con la utilidad neta final, la cual ya tiene descontado los valores de intereses y de impuestos, por lo que ya es una utilidad libre para el accionista (en términos contables). Entonces, cuando la tasa de intereses es inferior a la rentabilidad económica ROA, los excedentes quedarán disponibles para ser distribuidos entre los accionistas. Para entender este efecto de la deuda en el $\mathrm{ROE}$, observe el siguiente ejemplo:

Ejemplo: una empresa tiene $\$ 200 \mathrm{Mi}$ llones de activos, y su utilidad operativa está en $\$ 40$ Millones, lo cual quiere decir que obtiene el $20 \%$ de rentabilidad económica ROA. Maneja una deuda de $\$ 100$ Millones con una tasa de interés del $14 \%$, es decir que los intereses se ubican en \$14 Millones (gastos financieros), para este ejercicio no tendremos "otros ingresos" ni "otros egresos", únicamente el efecto de los impuestos, por esta razón el estado de resultados integral quedaría así: (Ver tabla 41).

En este ejemplo tenemos un ROA antes de impuestos de $20,00 \%$ resultante de dividir la utilidad operativa de 40 sobre los activos que son 200 , y un ROA después de impuestos de $14 \%$ resultante de dividir el resultado de $40 *(1-30 \%)$, la UODI, sobre el valor del activo que es $\$ 200$ Millones.

En esencia, lo que podemos decir de este cálculo es que el negocio renta un 20\% antes de impuestos y un $14 \%$ después de impuestos en el escenario en que no se tiene deuda. Pero se mencionó que sí se tiene deuda, por lo que la rentabilidad financiera sería de $18,20 \%$, resultante de dividir 18,2 millones de la utilidad neta entre el valor del patrimonio que es $\$ 100$ Millones. 


\section{TABLA 41}

\section{ESTADO DE RESULTADOS \\ (EMPRESA X)}

Fuente: Elaboración propia

\section{ERI (Empresa X)}

(+) Ingresos Operacionales

(-) Costo de Ventas

(=) Utilidad Bruta

(-) Gastos Administrativos

(-) Depreciaciones y Amortizaciones

(=) UAII (EBIT)

(+) Otros Ingresos

(-) Otros Egresos

(-) Gastos financieros

(=) UAI (EBT)

(-) Impuestos (30\%)

$(=)$ Utilidad Neta Final (UNF)
181,0

110,0

71,0

23,0

8,0

40,0

14,0

26,0

7,8

18,2 
Ahora, observe el estado de resulta- que no tiene deuda y compárelos con dos de la empresa bajo el supuesto de los de la empresa con financiamiento:

\section{TABLA 42}

\section{ESTADO RESULTADOS \\ INTEGRAL (EMPRESA $X)$}

Fuente: Elaboración propia

\section{ERI (Empresa X)}

$(+)$ Ingresos Operacionales

181,0

(-) Costo de Ventas

110,0

(=) Utilidad Bruta

71,0

(-) Gastos Administrativos

23,0

(-) Depreciaciones y Amortizaciones

8,0

(=) UAII (EBIT)

40,0

(+) Otros Ingresos

(-) Otros Egresos

(-) Gastos financieros

14,0

(=) UAI (EBT)

26,0

(-) Impuestos (30\%) 7,8

(=) Utilidad Neta Final (UNF) 
En este caso, tendremos una rentabilidad económica de $20 \%$ antes de impuestos y una rentabilidad económica después de impuestos del 14\%, la cual sería igual a la rentabilidad financiera ROE de $14 \%$

En resumen:

\section{TABLA 43}

\section{TABLA COMPARATIVA}

Fuente: Elaboración propia

Tabla comparativa

Activos

Pasivos

Patrimonio

ROA

ROA

ROE
Con Deuda

Sin deuda

$200 \mathrm{~m}$

$200 \mathrm{~m}$
$100 \mathrm{~m}$

$100 \mathrm{~m}$

$200 \mathrm{~m}$

$20,00 \%$

$20,00 \%$

$14,00 \%$

$14,00 \%$

$18,20 \%$ 
En este cuadro comparativo se aprecia el efecto positivo que tiene la deuda al incrementar la rentabilidad financiera, y en este caso podemos decir que la deuda es positiva para la empresa, es decir es un apalancamiento que está agregando valor.

\section{COSTO PROMEDIO PONDERADO DE CAPITAL}

¿Cuánto cuesta el dinero? Una pregunta axiomática, pero a la vez ambivalente. El dinero definitivamente tiene un costo, asociado al uso del mismo, en este sentido no renta igual en una inversión en el sector de finca raíz, que, en el sector agropecuario, y esto ocurre porque en cada sector se tienen diferentes riesgos, y la rentabilidad depende del riesgo. Por otro lado, es importante además entender el dinero como un recurso escaso. A continuación, se presenta una teoría que permite valorar el costo del dinero que es utilizado en una inversión, teniendo en cuenta además que parte del dinero se pueda conseguir mediante financiamiento de un tercero, como un banco.

En finanzas, cuando se habla de capital, se habla del dinero involucrado en un negocio o representado por un gasto o costo. Cuando se constituye una empresa es necesario colocar recursos económicos para la compra de activos y pueden ser de dos fuentes:

De recursos ajenos: representan los dineros que son prestados por terceros, se pueden dividir en recursos de largo y de corto plazo, en recursos con costo y sin costo, o en recursos sin costo explícito (con costo implícito ${ }^{17}$ ). $Y$ en general en todos los casos es obligatoria su devolución.

17. ¿Qué es un costo implícito? es lo contrario de costo explícito el cual se conoce con antelación como un crédito bancario que tiene una tasa de interés. Cuando se habla de costo implícito también se está hablando de "sin costo explícito" y se trata de aquel costo no mencionado por un tercero que ofrece crédito a la empresa sin una tasa de interés, pero que surge al momento de no aprovechar los descuentos por pago de contado; ejemplo: cuentas por pagar a proveedores. 
De recursos propios: son equivalentes a los recursos que pone el accionista, el dueño del negocio como capital de riesgo y sin garantías propias de su retorno en el corto plazo. Se trata del capital suscrito, autorizado y pagado (únicamente el pagado; a estos aportes se pueden sumar utilidades acumuladas en el escenario en que sea posible generarlas, ya que las utilidades también son propiedad del accionista.

Recuerde que en el capítulo 2 se mencionó lo que puede costar y como calcular el costo de capital propio, a través del modelo CAPM. Para el caso de los recursos ajenos, la empresa conocerá el costo pactado para cada obligación de crédito que tenga; a continuación, algunas opciones de recursos ajenos y su respectivo costo: (Ver tabla 44).

Como se observa, cada fuente cuesta, y cuando se habla de costo promedio ponderado de capital, se está hablando del promedio ponderado de los costos de recursos ajenos y de recursos propios (véase Capítulo 2).

\section{¿Cómo se calcula?}

El proceso para el cálculo es muy sencillo; en esencia se trata de ponderar de un $100 \%$ de recursos a diferentes niveles de costo, un costo promedio que tenga en cuenta la participación de cada fuente en el total de activos, así:

Ejemplo: Suponga que los activos de una empresa son financiados de la siguiente manera: (Ver tabla 39). 


\section{TABLA 44}

\section{CARACTERIZACIÓN DE FUENTES DE RECURSOS}

\section{Fuente: Elaboración propia}

Fuente

Deuda bancaría
Tipo de costo
Deuda con terceros

Costo explícito, tasa de interés establecida con la contraparte

Hacienda

Costo explícito, tasa de interés establecida con la contraparte

Sin costo explícito (Excepto por las cesantías)

Sin costo explícito (Excepto multas y sanciones, por exceder los plazos mínimos)

Obligaciones laborales

Deuda con accionistas
Con costo explícito (algunos accionistas financian sin costo sus empresas, pero lo correcto es cobrar un interés legal para poder obtener la ventaja tributaria derivada del pago de intereses) 


\section{TABLA 45}

\section{FUENTE DE RECURSOS}

Fuente: Elaboración propia 
En total los activos ascienden a 9.740, financiados en un $60,99 \%{ }^{18}$ con recursos ajenos (pasivo), y en un $39,01 \%$ con recursos propios $^{19}$.

Suponiendo que el costo de capital propio (KE) calculado por medio del modelo CAPM (Véase capítulo 2), fue de $22 \%$ $E A$, que el banco $(A)$ realizó el préstamo a una tasa de $15 \%$ EA y que el banco (B) realizó el préstamo a una tasa del $14 \%$ EA, entonces ¿Cuánto estamos pagando por el total de 9.740 en activos?

La respuesta no es $22 \%$, ni es $15 \%$, ni es $14 \%$, y tampoco es el $17 \%$ resultante del promedio simple de estas tres tasas, ya que estas no participan de manera equitativa en la financiación de los activos que necesita esta empresa para funcionar. Entonces, para resolver la pregunta de forma adecuada, es necesario ponderar cada fuente de recursos que tiene costo explícito, dependiendo de su participación relativa en la financiación de los activos (Valor de la fuente), así: (Ver tabla 46).
El valor de la ponderación de cada fuente se calcula dividiendo el valor de la cuenta sobre el total de los activos que es 9.740, entonces:

》Deuda con proveedores $(320 / 9.740)=3,29 \%$

»Deuda de corto plazo (Banco A) $(1.300 / 9.740)=13,35 \%$

» Hacienda (Impuestos por pagar) $(800 / 9.740)=8,21 \%$

»Obligaciones laborales $(520 / 9.740)=5,34 \%$

Anticipo de clientes $(700 / 9.740)=7,19 \%$

»Deuda de largo plazo (Banco B) $(2.300 / 9.740)=23,61 \%$

» Total patrimonio $(3.800 / 9.740)=39,01 \%$

18. Resultante de dividir 5.940 sobre 9.740 (total de la deuda sobre el total de activos)

19. Que resulta de dividir 3.800 sobre 9.740 (total del patrimonio sobre el total de activos) 


\section{TABLA 46}

\section{PONDERACIÓN Y CÁLCULO \\ DE COSTOS POR FUENTE \\ DE FINANCIAMIENTO}

Fuente: Elaboración propia

\begin{tabular}{|c|c|c|c|}
\hline \multicolumn{2}{|c|}{ Fuente de financiamiento } & \multirow{2}{*}{$\begin{array}{c}\text { Ponderación } \\
\text { 3,29\% }\end{array}$} & \multirow[t]{2}{*}{ Costo } \\
\hline $\begin{array}{l}\text { Deuda con } \\
\text { proveedores }\end{array}$ & 320 & & \\
\hline $\begin{array}{l}\text { Deuda de corto plazo } \\
\qquad(\text { Banco A) }\end{array}$ & 1.300 & $13,35 \%$ & $15,00 \%$ \\
\hline $\begin{array}{l}\text { Hacienda (Impuestos } \\
\text { por pagar) }\end{array}$ & 800 & $8,21 \%$ & \\
\hline Obligaciones laborales & 520 & $5,34 \%$ & \\
\hline Anticipos de clientes & 700 & $7,19 \%$ & \\
\hline $\begin{array}{c}\text { Deuda de largo plazo } \\
\text { (Banco B) }\end{array}$ & 2.300 & $23,61 \%$ & $14,00 \%$ \\
\hline Total deuda & 5.940 & $60,99 \%$ & \\
\hline Capital & 3.000 & $39,01 \%$ & $22,00 \%$ \\
\hline Utilidad acumuladas & 800 & & \\
\hline Total Patrimonio & 3.800 & $39,01 \%$ & \\
\hline
\end{tabular}


Nótese que las fuentes con costo explícito (Columna costo) son únicamente tres: Deuda de corto plazo (1.300), deuda de largo plazo (2.300) y patrimonio (3.800), por lo que solo sería necesario hacer el cálculo con estas fuentes, pero respetando los porcentajes de participación que tienen dentro del total activo, y el proceso se hace de la siguiente forma:

$\mathrm{CPPC}=$ (KD*(1-tx)*((Deuda 1) /Activos))+ (KD2*(1-tx)*((Deuda 2) /Activos)) $+($ KE*(Patrimonio/Activos))

Reemplazando tendríamos:

$$
\begin{aligned}
& 12,30 \%=(15 \% *(1-30 \%) * 13.35 \%)+ \\
& (14 \% *(1-30 \%) * 23,61 \%)+(22 \% * 39,01 \%)
\end{aligned}
$$

Este cálculo muestra que los activos están costando $13,92 \%$, que corresponde al interés promedio ponderado de las fuentes que tienen costo explícito dentro de nuestro ejemplo, sin olvidar que existen fuentes de capital que no tienen un costo explícito, pero podrían tener un costo implícito, lo cual para este cálculo únicamente se deja advertido.
Note como en esta fórmula se está incluyendo el efecto de la ventaja tributaria asociado al costo de la deuda (Ver siguiente explicación ventaja tributaria). Por lo que en la fórmula se multiplica el KD por (1-Tx), donde Tx=Tasa de impuestos.

De esta forma podemos describir con precisión el valor del costo del capital necesario para adquirir los activos utilizados por la empresa.

CPPC significa Costo promedio ponderado de capital, y también se conoce con el nombre de WACC por sus siglas en inglés Weighted Average Cost of Capital

\section{EXPLICACIÓN DE VENTAJA TRIBUTARIA:}

El efecto de los impuestos está relacionado con el costo real de las fuentes de capital de recursos ajenos, toda vez que el interés de estas obligaciones es cargado en el estado de resultados integral como un gasto antes de realizar el cálculo de la utilidad antes de impuestos, así: 


\section{TABLA 47}

\section{ESTADO DE RESULTADOS INTEGRAL (ESTRUCTURA GENERAL)}

Fuente: Elaboración propia

\section{ERI (Estructura General)}

(+) Ingresos Operacionales

(-) Costo de Ventas

(=) Utilidad Bruta

(-) Gastos Administrativos

(-) Depreciaciones y Amortizaciones

\section{(=) UAII (EBIT)}

(+) Otros Ingresos

(-) Otros Egresos

(-) Gastos financieros

(=) UAI (EBT)

(-) Impuestos (30\%)

(=) Utilidad Neta Final (UNF) 
El efecto en el estado de resultados integral de pagar intereses por una deuda, es una reducción en la utilidad antes de impuestos UAI ó EBT, lo cual genera una base menor para el cálculo de los impuestos, y esto nos lleva a tener que evaluar el efecto de los impuestos en el costo real de una deuda (recursos ájenos) para una empresa, como se puede observar en el siguiente ejemplo:

Ejemplo: A continuación se muestra una misma empresa con dos estructuras de capital diferentes (relación de deuda patrimonio), y el efecto en cuanto a estado de resultados integral, suponiendo que la deuda tiene un costo de $14 \%$ EA y que los estados financieros son anuales: (Ver tabla 42).

De esta situación podemos afirmar que:

»La estructura 2 es mejor en términos de generación de utilidad antes de impuestos (UAI) y utilidad neta final, sin embargo, también genera mayor pago de impuestos.

»En la estructura 1 solo se evidencia menor pago en impuestos, y es la estructura que menos utilidad antes de impuestos (UAl ó EBT) y menos utilidad neta final genera.

Estas dos afirmaciones son correctas, el ahorro en impuestos generado por el apalancamiento es de 168 y corresponde a lo que se conoce como ventaja tributaria, la cual se calcula mediante la siguiente fórmula:

\section{VT=Intereses*tasa de impuestos}

Para este caso la ventaja tributaria sería de:

\section{$168=560 * 30 \%$}

Y corresponde al ahorro en impuestos que supone el pago de intereses que para nuestro ejemplo es de 560 en la estructura de capital 1. 


\section{TABLA 48}

\section{COMPARATIVO DE ESTRUCTURAS}

CON DEUDA Y SIN DEUDA

Fuente: Elaboración propia

\begin{tabular}{|c|c|c|}
\hline ESF & Estructura 1 & Estructura 2 \\
\hline Deuda & 4.000 & - \\
\hline Patrimonio & 3.400 & 7.400 \\
\hline Activos & 7.400 & 7.400 \\
\hline ERI & Estructura 1 & Estructura 2 \\
\hline (=) UAII (EBIT) & 2.000 & 2.000 \\
\hline (+) Otros Ingresos & 0 & 0 \\
\hline (-) Otros Egresos & 0 & 0 \\
\hline (-) Intereses & 560 & - \\
\hline (=) UAI (EBT) & 1.440 & 2.000 \\
\hline (-) Impuestos (30\%) & 432 & 600 \\
\hline (=) Utilidad Neta Final (UNF) & 1.008 & 1.400 \\
\hline
\end{tabular}


En términos absolutos esta primera estructura supone un ahorro de impuestos de 168 más el apalancamiento que puede obtener la empresa, y en términos relativos el cálculo de ventaja tributaria se obtiene teniendo en cuenta el costo de la deuda que denominamos KD. Entonces se calcula el costo real de la deuda suponiendo el ahorro que significa el pago de intereses, mediante la siguiente fórmula:

Tasa real de la deuda $(K D T)=$ Tasa de itereses (KD)*(1-tasa de impuestos)

Que para nuestro ejemplo sería:

\section{$9,8 \%=14 \% *(1-30 \%)$}

En consecuencia, en este ejercicio el empresario realmente está pagando un costo de $9,8 \%$, y no un costo del $14 \%$, porque tiene un beneficio tributario por el descuento de intereses de la base para el pago de impuestos. Otra forma de verlo es

Intereses (+) 560

Ahorro en el pago de impuestos (-) 168
Interés real pagado (=) 392

Deuda 4.000

Tasa real 9,8\%

Tasa de interes real=(Interes tota pagado-ahorro en impuestos)/(Deuda Total)

Reemplazando:

\section{$9,8 \%=(560-168) / 4.000$}

Observación: En la estructura de capital 1 que tiene deuda de 4.000 se cuenta con una menor utilidad antes de impuestos (UAll) y también se tiene una menor utilidad neta final, sin embargo:

En términos de ROE la estructura 1 propone un ROE de $29,65 \%$ debido a que la porción de patrimonio necesaria es menor, y la utilidad neta final es relativamente mayor que en la estructura 2 en la que se genera un ROE de $18,92 \%$, teniendo las dos estructuras la misma rentabilidad económica (ROA). Esto hace referencia a los beneficios de un buen proceso de apalancamiento, que pueden ayudar a que el accionista de una empresa pueda tener un mejor ROE. 
Un buen proceso de apalancamiento, sirve para ampliar la capacidad de la empresa, y crea una ventaja tributaria que puede ayudar a generar mayor ROE. Sin embargo, el apalancamiento es un arma de doble filo ya que ejerce mayor presión sobre los resultados operativos de la compañía, por lo que requiere de un análisis objetivo, sustentado en un aumento de los ingresos para soportar los costos que conlleva.

\section{TEORÍA DE VALOR ECONÓMICO AGREGADO}

La teoría de valor económico agregado (VEA) ó (EVA) Economic value added por sus siglas en inglés, propone la comparación directa de los beneficios económicos obtenidos en un negocio, con los costos generados por la utilización de recursos para lograr dicho beneficio económico. En otras palabras, propone poner en una balanza el ingreso neto que se obtiene de un negocio, versus los costos de lograr dicho beneficio. Vale la pena observar el siguiente esquema: (Ver tabla 49).

El beneficio económico para este análisis está determinado por la utili- dad operativa después de impuestos UODI, que tiene en cuenta las ventas, los costos y gastos asociados, así como las depreciaciones y/o amortizaciones, y el efecto de los impuestos; sin embargo, no tiene en cuenta el gasto por intereses, debido a que este gasto se tiene en cuenta en el cálculo del WACC:

Se entiende que un negocio tiene buenos resultados en la medida que genera un EVA mayor que cero y tiene resultados aceptables en la medida que genera un EVA igual acero. Pero cuando un negocio, a pesar de ser rentable, no genera un EVA superior a cero, debe ser considerado como destrucción de valor. 


\section{TABLA 49}

\section{ELEMENTOS QUE COMPONEN EL EVA}

Fuente: Elaboración propia

Beneficio económico

(+) Ingresos

(-) Costo de ventas

$(=)$ Utilidad bruta

(-) Gastos administrativos

(-) Gastos de ventas

(-) Depreciaciones / Amortizaciones

(=) UAll ó EBIT

\section{Costo de los recursos utilizados}

2.000

0

0

560

1.440

432

1.008

El beneficio económico generado será la utilidad operativa después de impuestos (UODI), recuerde: 


\section{PARA TENER EN CUENTA:}

Se toma como beneficio económico la utilidad operativa (UAII/EBIT) menos los impuestos, desconociendo el valor de los intereses, debido a que la tasa WACC tiene en cuenta esta magnitud en términos porcentuales. Por lo tanto, si se descuentan los intereses del beneficio económico calculado, se estaría duplicando dicha magnitud.

A continuación, resolveremos un ejemplo, con el objetivo de integrar esta teoría a un análisis:

Suponga una empresa que tiene activos por $\$ 780$ Millones de pesos, y su tasa WACC es del 15\% EA. Su ERI muestra la siguiente información (cifras en millones).

Teniendo en cuenta que le aplica una tasa impositiva de 30\%. Entonces el valor del beneficio económico estaría dado por:
UODI=EBIT*(1-Tx)

UODI=390*(1-30\%)

\section{UODI=273}

En este sentido, se entiende como beneficio económico la utilidad operativa después de impuestos (UODI), la cual ahora se debe comparar con el costo de los activos utilizados para generar dicha utilidad.

\section{Costo del Capital Invertido= WACC*Activos}

\section{Costo del Capital Invertido= $15 \% * 780$}

\section{Costo del Capital Invertido $=117$}

El valor económico agregado será:

\section{EVA=UODI - (WACC*Activos)}

\section{$E V A=273-117$}

\section{$E V A=156$}

Para este caso la empresa, sí genera valor económico agregado. 


\section{ERI}

(+) Ingresos Operacionales

(-) Costo de Ventas

(=) Utilidad Bruta

(-) Gastos Administrativos

(-) Gasto de Ventas

(-) Depreciaciones / Amortizaciones

(=) UAII (EBIT)
1.800

1.000

800

300

80

30

390
En el ejemplo anterior se muestra de una forma sencilla el proceso de cálculo. Sin embargo, es importante tener en cuenta que los datos en las compañías no siempre están disponibles, o no lo están con el nivel de detalle necesario, por lo que se pueden presentar dificultades para la obtención del indicador. Por ejemplo, cuando se quiere calcular el valor económico agregado de una línea en específico que comparte diferentes actividades de apoyo con otras líneas, actividades como: administración, transporte, equipo de ventas, etc. En este senti- do, se deben estudiar metodologías de asignación de costos que permitan asignar los costos asociados a varias líneas, cuando solo se quiere estudiar el costo de una en específico.

A continuación, presentamos otro ejemplo que permite abordar la teoría desde otra perspectiva:

La empresa MPF SAS requiere actualizar un vehículo para su logística, ya que el actual presenta fallas de forma constante. En el mercado tiene dos opciones: 
Vehículo 1: con un costo de $\$ 80$ Millones y un promedio de recorrido de 32 kilómetros por galón.

Vehículo 2: con un costo de $\$ 75$ Millones y un promedio de recorrido de 30 kilómetros por galón.

Por otro lado, los activos de la empresa son de 400.000.000, donde 280.000.000 corresponden a pasivo con un costo KD de 15\% EA. El costo del patrimonio $\mathrm{KE}$ es de $18 \% \mathrm{EA}$, $\mathrm{T} x=30 \%$

Si el vehículo que actualmente tienen recorre 20 kilómetros por galón y en el año recorre en promedio 120.000 kilómetros, y el costo por galón de combustible es de 8.900 , cuál podría ser la mejor opción, teniendo en cuenta que la estructura de capital (relación deuda/patrimonio) se mantendría en todo caso al crecer los activos.

\section{Solución:}

Lo primero será determinar el costo de capital, es decir el WACC, que para este caso sería:

\section{CPPC ó WACC $=$ (15\%*(1-30\%)* (280/400)) $+\left(18 \%^{*}(120 / 400)\right.$}

\section{CPPC ó WACC $=12,75 \%$}

Suponiendo que la estructura de capital se mantenga, es decir que el costo de capital se mantiene para este ejercicio.

El segundo paso que se debe seguir es identificar el beneficio económico, que en este caso estaría asociado con el ahorro que se puede generar con el nuevo vehículo dependiendo de la opción que se escoja. El vehículo actual tiene un consumo de 6.000 galones, que resulta de dividir el recorrido anual sobre el rendimiento por galón, por lo que los gastos por rubro de combustible son de 53.400.000.

Ahora, con la opción 1: se necesitarían 3.570 galones, y esta cifra resulta de dividir los kilómetros recorridos en el año sobre el rendimiento de 32 kilómetros por galón. Es decir, se necesi$\tan 3.750$ galones, con un costo total de 33.375.000. 
Para la opción 2: se necesitarían 4.000 galones, y esta cifra resulta de dividir los kilómetros recorridos en el año sobre el rendimiento de 30 kilómetros por galón. Es decir, se necesi$\tan 4.000$ galones, con un costo total de 35.600 .000 .

En este análisis es fácil identificar el "ahorro" que produce cada una de las dos opciones, así:

Opción 1: 20.205.000

Opción 2: 18.800 .000

Sin tener en cuenta otros gastos asociados, como mantenimiento y otros asociados a administrar este activo, tendríamos que suponer que este ahorro se generaría en términos de utilidad operativa (UAll - EBIT), por lo que podríamos suponer entonces que a dicho ahorro sería conveniente descontarle los impuestos que debería generar una mayor utilidad operativa, es decir, calcular un OUDI proporcional:

UODI=

Beneficio Económico*(1-Tx)
UODI (Opción 1)= 20.025.000*(1-30\%)

\section{UODI (Opción 2)=} $17.800 .000 *(1-30 \%)$

Finalmente, tendríamos que calcular el costo del capital, para determinar lo que cuesta a esta empresa utilizar 80 millones para la opción 1, o utilizar 75 millones para la opción 2 , y posteriormente comparar este resultado con el beneficio económico calculado para cada una de las opciones, así:

\begin{tabular}{|c|c|c|}
\hline $\begin{array}{l}\text { Cuadro } \\
\text { Resumen }\end{array}$ & Opción 1 & Opción 3 \\
\hline $\begin{array}{c}\text { Costo } \\
\text { de capital }\end{array}$ & 10.200 .000 & 9.562 .500 \\
\hline $\begin{array}{l}\text { Beneficio } \\
\text { económico }\end{array}$ & 14.017 .500 & 12.460 .000 \\
\hline VEA / EVA & 3.817 .500 & 2.897 .500 \\
\hline \multicolumn{3}{|c|}{$\begin{array}{l}\text { De esta forma podremos concluir que } \\
\text { a empresa debería optar por la op- } \\
\text { ción } 1 \text {, con la que podrá tener mayor } \\
\text { /alor económico agregado. }\end{array}$} \\
\hline
\end{tabular}


LOS INDICADORES FINANCIEROS SON VALIOSOS EN LA MEDIDA QUE SE LES PUEDA HACER UN SEGUIMIENTO QUE PERMITA LA TOMA DE DECISIONES, POR LO QUE ES CONVENIENTE PARA CUALQUIER EMPRESA

DISEÑAR UN ENTORNO DE MONITOREO PARA HACER EL SEGUIMIENTO ADECUADO. PARA ESTE PROCESO SE SUGIERE CREAR UN DASHBOARD, QUE LE PERMITA MONITOREAR

LOS PRINCIPALES INDICADORES

UN DASHBOARD HACE PARTE DE LAS HERRAMIENTAS DIGÍTALES QUE SE TIENEN A DISPOSICIÓN POR EL HECHO DE TENER EL PAQUETE DE OFFICE, Y PERMITE HACER

UNA REPRESENTACIÓN GRÁFICA DE LOS PRINCIPALES INDICADORES QUE DEBEN SER MONITOREADOS PARA HACER UNA GESTIÓN EFICIENTE. ESTAS HERRAMIENTAS DIGITALES PUEDEN SER UTILIZADAS EN DIFERENTES DISCIPLINAS, Y EN EL ÁREA DE FINANZAS ES CONVENIENTE UTILIZARLAS PARA LLEVAR EL REGISTRO Y CONTROL DE LOS INDICADORES QUE PRESENTAMOS EN ESTE CAPÍTULO. 

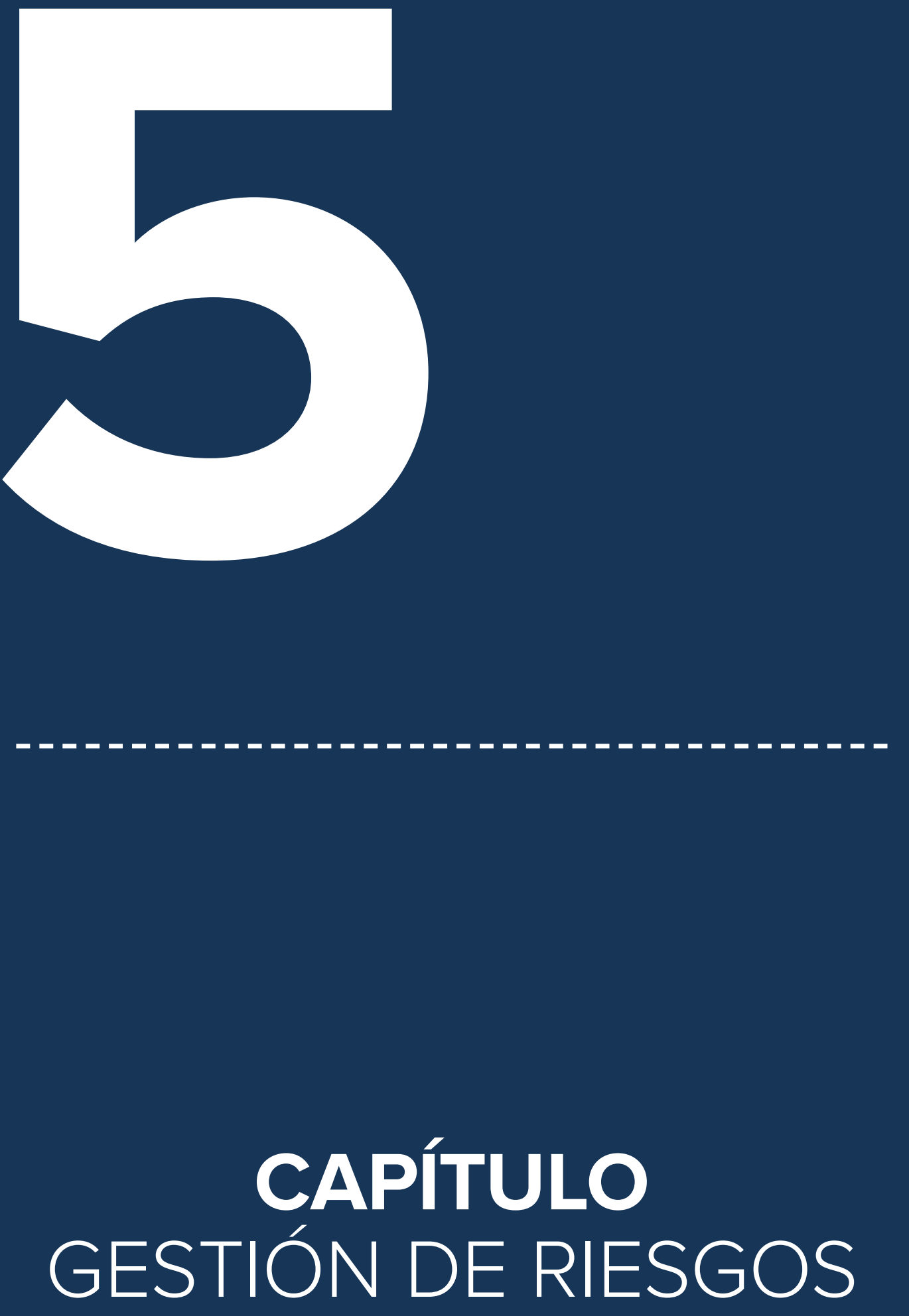


\section{Este capítulo busca caracterizar algunos riesgos que día a día deben enfrentar sus líderes para el cumplimiento de los objetivos estratégicos organizacionales, e incluye recomendaciones de cómo tratarlos usando pólizas de seguros.}

Guzmán, Hugo \& Álvarez, Aníbal \& Morales, María

\section{RESUMEN:}

El capítulo busca caracterizar algunos riesgos presentes en los procesos productivos y de servicio que enfrentan las organizaciones, para alcanzar la satisfacción de sus clientes. Ha sido desarrollado a manera de guía, con la intención de ayudar al empresario a saber qué riesgos existen y qué maneras hay para tratarlos y monitorearlos.

Este apartado contiene definiciones para la palabra riesgo y para su tratamiento, así como aspectos técnicos sobre pólizas de seguros. Se encontrará también una clasificación sugerida de los riesgos dentro de la organización, un listado de riesgos asociados a los bienes dentro de la empresa, un procedimiento básico para gestionar riesgos no asegurables y otro complementario para gestionar los asegurables. Contiene además cómo deben describirse los riesgos, para su posterior tratamiento y recomendaciones para el correcto aseguramiento de sus bienes mediante pólizas de seguros. Por último, a partir de una entrevista con un experto, se explican algunas estrategias basadas en el análisis estratégico FODA y el ciclo PHVA, para la planificación estratégica del riesgo y la contratación de pólizas de seguros.

Palabras claves: gestión de riesgos, administración de riesgos, pólizas de seguros, continuidad de negocio, asegurabilidad. 


\section{INTRODUCCIÓN}

\section{QUE UN SINIESTRO NO AFECTE SUS FINANZAS}

El flujo de caja que genera una empresa tiene finalidades específicas que garantizan la operatividad del negocio: pago de sus deudas, inversión, mantenimiento y expansión de las operaciones, y proporcionar un remanente adecuado para repartir como dividendos entre sus propietarios, pero ¿qué pasaría si ese dinero tuviera que ser usado para pagar las consecuencias de un hecho súbito e imprevisto, que impactara directamente la operación principal de la empresa?

Existen diversos eventos que pueden afectar a una empresa, así como siniestros derivados de estos eventos, por ejemplo, ¿Cuánto cuesta la reparación de una máquina en comparación con realizar su mantenimiento con la periodicidad requerida, o garantizarle sus protecciones eléctricas? ¿Cómo este daño puede afectar la utilidad de la empresa? ¿Qué pasa si hace un inadecuado proceso de reclutamiento de personal $y$, por un error involuntario, este nuevo empleado comete un error que le cuesta a la empresa el pago de alguna indemnización, por el incumplimiento tal vez de un contrato? ¿Cuánto le cuesta a la empresa reemplazar a un empleado que ha debido ausentarse de su lugar de trabajo por incapacidad o muerte? ¿Genera esto algún reproceso, parálisis o desarticulación de la empresa?

Así como las mencionadas, suceden en las empresas diversas situaciones perjudiciales, que resultan ser muy onerosas, obligándolas a invertir sumas de dinero -que estaban destinadas a su crecimiento y fortalecimiento-, en acciones para sobreponerse a la pérdida y seguir operando. Así mismo, se encuentran en el mercado alternativas que cubren a las empresas ante estas situaciones, mediante contratos conocidos como "pólizas de seguros", que amparan riesgos llamados asegurables; el incendio, la sustracción, las inundaciones, la responsabilidad civil, el incumplimiento de contratos, son apenas algunos ejemplos de estos riesgos dentro de las organizaciones. 


\section{EL RIESGO Y SU PRESENCIA EN LA ORGANIZACIÓN}

En un mundo globalizado, las empresas tienen mayores exigencias por el número de competidores existentes en los mercados, lo que implica asumir mayores riesgos y la necesidad de adoptar acciones para mitigarlos, proteger su patrimonio y garantizar la continuidad del negocio. Estas nuevas exigencias requieren de las organizaciones innovación y creatividad para poder competir, y por ello deben vincular nuevos recursos representados en nuevas tecnologías, capital humano con un mayor grado de cualificación, inversiones en propiedad, planta y equipo, alinearse a las nuevas regulaciones, entre otros requerimientos que le permitan responder con rapidez a las exigencias del mercado.

Los recursos necesarios para sacar adelante los procesos empresariales traen consigo un costo para el empresario: para el personal estará el salario, para la infraestructura y la tecnología estarán los costos de instalación y mantenimiento $y$, para el recurso financiero estará el dinero; que exige a cambio una devolución al inversionista que busca el rendimiento propio según su nivel de riesgo.

El recurso financiero se inyecta en la empresa para aumentar la capacidad de producir y/o prestar servicios, incrementar la cuota de mercado, mejorar la relación con los clientes, y en otras actividades propias de cada negocio. ¿A cuántos empresarios se les escucha que han tenido que usar ese dinero en la reposición o reparación de bienes que se dañan, con ocasión de hechos súbitos e imprevistos, o para responder civilmente por pérdidas ocasionadas por sus empleados, o por ocasionar daños a terceros? Eventos que dificultan alcanzar sus objetivos y posiblemente los hace perder competitividad en el mercado.

Los incendios, las explosiones, la infidelidad de los empleados, la responsabilidad civil, daños eléctricos como corto circuitos, terremotos, inundaciones, fuertes lluvias, vendavales, el incumplimiento de contratos, entre otros muchos eventos denominados "ries- 
gos", son causantes de diversos daños a los bienes de una empresa, o a su buen nombre, que para ser reparados o renovados afectan las finanzas de la organización, especialmente cuando no se han tomado precauciones y las protecciones no se han previsto.

A continuación, se definirá la palabra riesgo desde diferentes puntos de vista. Luján, J \& Echeverría, J (2004); Vila, J (2005); Hincapié, J (2007); Ballesteros, J \& López, D (2009) y Herrera Soler (2011), consideran un riesgo como una combinación probabilística asociada a un evento y sus consecuencias.

Para Mejía, la palabra "riesgo" tiene su origen etimológico en el latín resecu, que significa "riesgo en el mar, roca o risco", y se relaciona con el peligro que representaban los riscos en la Antigüedad (pág. 100, 2006).

Para Diz, "El concepto de riesgo se comprende como todo aquello que puede ocasionar la ocurrencia de un evento no deseado y producir, como consecuencia, pérdidas o daños" (Diz, 2004, pág. 1).
Para la Norma técnica NTC-ISO 31000 , el riesgo es el efecto de la incertidumbre sobre los objetivos (Instituto Colombiano de Normas Técnicas ICONTEC, 2011).

De igual forma, los riesgos desde el punto de vista económico pueden ser de dos tipos: asegurables y no asegurables. Los primeros son aquellos que pueden afectar financieramente a la empresa, que solo le causan pérdidas. Los segundos pueden generarle pérdidas financieras a la organización, y también ganancias. Es decir, al materializarse pueden causar consecuencias tanto negativas como positivas.

Entre los ejemplos de riesgos asegurables más generales están los riesgos de la naturaleza, los asociados a la tecnología, a la infidelidad de los empleados, los riesgos de personas, la interrupción del negocio y algunos eventos ocurridos producto del uso de internet. Entre los no asegurables encontramos los riesgos financieros (distintos a los que se negocian en un mercado de derivados financieros: swaps, forwards, futuros), los riesgos asociados a la dirección de empresas, la reputación, el riesgo antrópico, entre otros. 
La siguiente tabla presenta una cla- riesgos que se pueden considerar sificación general dividida en 4 gran- relevantes para la pequeña, micro y des grupos, elaborada sobre los mediana empresa.

\section{TABLA 50}

\section{CLASIFICACIÓN DE LOS RIESGOS.}

Fuente: Elaboración propia

Tipo de riesgo

Aspecto asociado al riesgo

Desde lo financiero

Desde lo económico
Rentabilidad, liquidez, crédito, mercado y legal

Asegurables, de daños, patrimoniales y de personas, y no asegurables.
No financiero
Lavado de activos, financiación del terrorismo,

Operativo y Cibernético. 
La pregunta siguiente sería: ¿Existe algún procedimiento que permita identificar posibles pérdidas financieras a consecuencia de ciertos hechos dañinos, llamados riesgos? Y la respuesta es sí. El procedimiento se conoce como Gestión de Riesgos, y permite su identificación y tratamiento, de tal modo que, al ocurrir, la empresa se encuentre preparada y actúe de manera prevista, para disminuir al máximo las pérdidas financieras.

Para la gestión de riesgos existen normas internacionales muy utilizadas, como la ISO ${ }^{20} 31000$ o COSO $^{21}$ ERM $^{22}$, que guían a las personas en el camino de identificación, tratamiento y monitoreo de riesgos dentro de las organizaciones. Estas metodologías son generales, especialmente ISO 31000 , que guía al empresario desde el conocimiento de su contexto empresa- rial, o del proceso que desea analizar, pasando por la construcción de planes de identificación, control de riesgos, su tratamiento y seguimiento.

Si usted está en proceso de certificación ISO 9001, o planea certificarse, encontrará que existe un capítulo dedicado a la Gestión de Riesgos, y si profundiza un poco más encontrará que dicho capítulo hace referencia a la aplicación de la norma ISO 31000 dentro del proceso que será certificado.

COSO es una metodología empleada especialmente por auditores internos, para hacer seguimiento también a los procesos y validar que se encuentran cumpliendo los manuales de procedimiento establecidos por la empresa. ERM es la metodología desarrollada por COSO, para el análisis de riesgos de cualquier tipo en la organización. 


\section{LA GESTIÓN DE RIESGOS}

La palabra gestión se refiere a la dirección y control de los procesos empresariales. Al aplicar este concepto a la gestión de riesgos se hace referencia a cómo la organización se encarga de ellos, cuáles le importan, su capacidad para asumirlos, las personas dentro de la organización encargados de monitorearlos, los procedimientos para tratarlos eliminándolos y/o mitigándolos.

Para una adecuada gestión de riesgos se deben revisar, primero, los objetivos de la organización, sus estrategias, planes estratégicos y procesos misionales para alcanzarlos; y segundo, determinar los riesgos asociados a estos, que podrían ayudar, demorar o impedir su cumplimiento. Desde el punto de vista financiero, los objetivos pueden estar orientados hacia el crecimiento de ventas en el mercado y/o a conseguir rentabilidad sobre el capital invertido, mediante el aumento y mejora de la capacidad operativa y lograr la satisfacción de los clientes.

Cada proceso inevitablemente involucra bienes y activos expuestos a riesgos. La capacidad operativa, por ejemplo, puede asociarse a conseguir más recursos humanos que podrían accidentarse, enfermar o morir. Otra opción puede ser el comprar locaciones e invertir en tecnología para la producción, lo que involucra maquinaria y equipos eléctricos y electrónicos que podrían quemarse en un incendio, ser afectados por un terremoto, dañarse por un corto circuito, o ser atacados por el mismo personal de la empresa. Además, se requiere de capital para la inversión, que podría desviarse para el pago de siniestros y disminuir así la liquidez de la empresa.

Desde el análisis financiero se recomienda partir de la revisión de los riesgos asegurables, los que generan solo pérdidas a la organización, asociados a las personas, las materias primas, la infraestructura y la tecnología, y que tienen relación con el proceso misional de la empresa. En la siguiente tabla se citan varios ejemplos de riesgos asegurables comunes a los bienes y activos de las organizaciones, y que pueden ser compartidos con compañías aseguradoras, trate de identificar cuáles de ellos son cercanos a la empresa a la que pertenece y busque luego intervenirlos. 


\section{TABLA 51}

\section{EJEMPLOS DE RIESGOS}

ASEGURABLES ASOCIADOS A BIENES

Y ACTIVOS DE UNA EMPRESA.

Fuente: Elaboración propia

\section{Bienes $\mathbf{y}$ activos comunes asociados al proceso misional}

Inmuebles

Comercio e industria extractiva, manufacturera, agropecuaria, entre otras.

Mercancías, materias primas, envases y embalajes

Mobiliario, enseres de oficina, útiles.

Maquinaria de naturaleza eléctrica, mecánica o electromecánica

Equipos electrónicos, como computadores portátiles y de escritorio

Dineros y títulos valores

Obras de arte

Empleados

Información y datos 


\section{Algunos ejemplos de riesgos asegurables asociados a los bienes y activos del proceso misional}

Terremoto, incendio, inundación, fuga de agua de tubería interna, deslizamiento de tierra, terrorismo, caída de aeronaves, vientos fuertes, tornados, impacto de vehículos, erupción volcánica, maremoto, tsunami, granizo, humedad, actos mal intencionados de terceros.

Incendio, terremoto, inundación, fuga de agua de tubería interna, infidelidad del empleado, actos mal intencionados de terceros, sustracción, responsabilidad civil.

Incendio, terremoto, inundación, agua de tubería interna, infidelidad del empleado, actos mal intencionados de terceros, sustracción.

Incendio, terremoto, rayo, corto circuito, sobre voltaje, inundación, fuga de agua de tubería interna, infidelidad del empleado, actos mal intencionados de terceros, sustracción, impericia, responsabilidad civil, riesgo cibernético.

Corto circuito, sobre voltaje, incendio, rayo, terremoto, sustracción, impericia, responsabilidad civil, riesgo cibernético.

Incendio, infidelidad de los empleados, robo; robo o falta de entrega durante su transporte, riesgo cibernético.

Incendio, terremoto, robo.

Responsabilidad civil contractual, extracontractual, extrapatrimonial, profesional, alteración al medio ambiente, infidelidad, actos deshonestos, fraude, muerte, accidentes, enfermedad.

Riesgo cibernético.

Información y datos 
Los riesgos pueden compartirse con compañías aseguradoras porque éstas han generado productos llamados pólizas de seguros, donde el tomador de la póliza, y/o el asegurado, mantienen la responsabilidad sobre un porcentaje del riesgo asegurado, este porcentaje se reconoce como deducible y se pacta con la compañía aseguradora desde el mismo momento en que se contrata la póliza de seguros.

El artículo 1037 del Código de Comercio define a la aseguradora como la persona jurídica que asume el riesgo, $\mathrm{y}$ al tomador como la persona que, actuando por cuenta propia, o ajena, traslada el riesgo (Superfinanciera , 2020). El seguro cubre a quien lo contrata, buscando compartir el riesgo con el fondo común, el cual es administrado por expertos (aseguradoras), quienes serán los encargados de responder financieramente ante un siniestro, de acuerdo con la cobertura contratada mediante la póliza.

Es importante tener en cuenta que los riesgos no son excluyentes, puede materializarse el riesgo de rayo que, al golpear las instalaciones eléctricas del inmueble genere un corto circuito, que afecte equipos electrónicos y cause una explosión en la maquinaria, que a su vez produce un incendio que quema parte de la empresa. Cuando el riesgo se materializa pueden presentarse consecuencias desde leves hasta catastróficas, donde no solo se expone la continuidad del negocio sino también todo el patrimonio de la empresa. Por ello se hace necesario también listar o inventariar todos los bienes y activos que podrían verse expuestos a la acción de los riesgos.

Los riesgos se miden teniendo en cuenta tres variables: la posibilidad de que ocurra, el impacto que causan y los controles existentes para monitorearlos y hacerles seguimiento. La posibilidad de ocurrencia puede describirse, partiendo de la experiencia de los dueños del proceso, del conocimiento que la empresa tenga del proceso, experiencias siniestrales pasadas, frecuencia, proyecciones, riesgos materializados en empresas de características similares a la analizada, entre otras.

Por ejemplo, se puede describir el riesgo de hurto desde la posibilidad 
de que ocurra, afirmando lo siguiente: "se puede producir un robo en la bodega de almacenamiento de celulares, ubicada en el barrio Desolación, un barrio residencial que presenta altos índices de criminalidad, sumado a las características constructivas del edificio, el cual consta de ventanales con vista a la calle que no gozan de elementos de protección, como rejas, y cierres adecuados; las instalaciones no cuentan con vigilancia privada en horario nocturno".

Recuerde que desde el punto de vista de un riesgo asegurable la consecuencia siempre será negativa, representará una pérdida financiera, moral, social, psicológica, etc., que dependerá, para su cálculo, del bien o activo afectado. Para que se haga a una idea de una consecuencia negativa, imagine una inundación o un incendio, que dañaron al edificio principal (donde se encuentra el proceso misional), a sus empleados, mobiliarios, maquinaria, equipos electrónicos, vehículos y demás bienes asociados al proceso analizado.

Desde la consecuencia, se puede relatar el mismo riesgo de hurto de la si- guiente forma: "Dentro de la bodega se almacenan teléfonos iPhone, Huawei y Samsung, todos de alta gama, valorados en un millón de dólares, valor costo". Es importante resaltar el valor de los bienes, pues una cosa es valorarlos contablemente y otra tener en cuenta su valor real, basados en condiciones de mercado. Contablemente todos los activos pueden ser depreciados, con las metodologías que su contador haya recomendado a la empresa, pero en el mercado sus bienes pueden subir de precio, piense en una casa (en condiciones normales), o bajar de precio, piense en vehículos. Este cambio de precio, por condiciones de mercado, es lo que denominaremos valor real o valor asegurable en una póliza de seguros.

Una responsabilidad civil puede generar una pérdida financiera, por la obligación que tendría la empresa de reparar los bienes dañados a consecuencia de un accidente de tránsito, donde estuvieran involucrados vehículos de su propiedad o bajo su responsabilidad, y/o resarcir con dinero las lesiones o la muerte de las personas que pudieran verse afectadas, teniendo en cuenta también el lucro cesante, cuan- 
do los bienes dañados producen algún valor para el afectado.

Pueden producirse pérdidas financieras derivadas de la infidelidad de un empleado, quien ha utilizado las cuentas bancarias de la empresa para beneficio propio, que valiéndose de la confianza sustraiga importantes sumas de dinero, de manera continuada o por una única vez.

En la tabla 46 se establece un procedimiento básico para gestionar riesgos asegurables. Lo invitamos a implementarlo en su organización, reconociendo los riesgos que tiene la empresa y trazar los planes para tratarlos.

Como controles para el riesgo de hurto, se puede citar: "la bodega cuenta con cámaras de vigilancia, circuito cerrado de televisión, DVR, sensores de movimiento y alarma". Así mismo, se pueden enumerar controles para el riesgo de incendio: detectores de humo, sensores de calor, brigada de emergencia que puedan reconocerlo al materializarse. Para casos de hurto se puede contar también con sistemas de vigilancia monitoreada, sen- sores de movimiento, controles de acceso y salida de las instalaciones. En caso de infidelidad de un empleado, pueden realizarse arqueos periódicos, manejo de topes para las transacciones electrónicas, seguimiento de las funciones del empleado. En general, los controles permiten monitorear y hacer seguimiento a los riesgos que pueden afectar los bienes y activos de la organización.

Siempre que se adelante la descripción de un riesgo es obligatorio abordar tres variables: posibilidad de que ocurra, impacto que causa y controles que existan para monitorear cada riesgo, con el fin de establecer tratamientos adecuados. Hablar de tratamientos para los riesgos organizacionales corresponde a eliminar o disminuir la posibilidad de ocurrencia, la consecuencia, o ambas variables. 


\title{
TABLA 52
}

\section{PROCEDIMIENTO BÁSICO PARA LA GESTIÓN DE RIESGOS ASEGURABLES}

\author{
Fuente: Elaboración propia
}

Implica Conocer

la organización

\author{
Establecer ¿cómo es y cómo \\ opera la organización?
}

Identifique sus procesos con los respectivos riesgos asociados
¿Cuáles son sus objetivos estratégicos?
¿Qué amenazas tiene la organización? ¿Es posible que se materialicen?
Identifique sus riesgos y descríbalos en términos de posibilidad de ocurrencia y consecuencia.
¿Qué peligros tienen relación con la organización? ¿Pueden afec-

¿Cuáles son sus procesos misionales? tar a la organización? ¿Cómo puede verse afectada la organización por estos peligros?
Evalúe y califique sus riesgos, clasifíquelos en orden de importancia para la empresa. En lo posible construya mapas de colores o matrices de riesgos.
¿Cuáles son los bienes

y activos asociados a sus procesos misionales?
¿Existen controles para los riesgos identificados?

Determine si el riesgo requiere tratamiento, en cuyo caso, haga prevención, proteja sus bienes, transfiera los riesgos o compre pólizas de seguros. 
Cuando la empresa opta por aplicar tratamientos a la posibilidad de ocurrencia del riesgo, se dice que está empleando medidas de prevención. Si lo que busca la empresa es disminuir las consecuencias, o que el perjuicio sea menor, se dice que está aplicando medidas de protección. Los manuales de funciones y de procedimientos son ejemplos de medidas preventivas que reducen el número de veces que una persona puede cometer un error durante sus labores, aunque no diluye los daños de una acción equivocada. Gracias a la repetición de los simulacros de emergencia, en caso por ejemplo de un incendio, disminuirá el posible número de víctimas, aunque una sola muerte pueda ser catastrófica para la organización.

El uso de elementos de protección personal dentro de obras civiles, como el casco o los guantes de acero, son ejemplos de medidas de protección que no impedirán que el ladrillo caiga del edificio sobre la cabeza o las manos, pero sí disminuirán el impacto o lesión que una persona pueda sufrir por esta causa. Otro ejem- plo puede ser que las instalaciones cuenten con vigilantes, que no necesariamente impedirán un hurto, pero si pueden disminuir la cantidad de bienes o dinero que puedan robarle. Las pólizas de seguro corresponden a una medida de protección muy conocida, y sirven para mitigar las pérdidas financieras ocurridas por la acción de riesgos asegurables.

A modo de resumen, la ilustración que se presenta a continuación llamada proceso básico de gestión de riesgos asegurables, muestra el paso a paso que se ha detallado, necesario para la adecuada gestión de sus riesgos desde el estudio de los objetivos organizacionales hasta la determinación de comprar una póliza de seguros, como alternativa de mitigación de pérdidas financieras. 


\section{ILUSTRACIÓN 11}

\section{PROCESO BÁSICO DE GESTIÓN DE RIESGOS ASEGURABLES}

Fuente: Elaboración propia

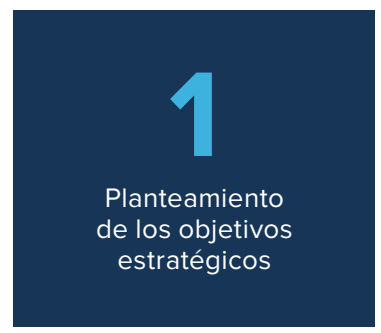

-

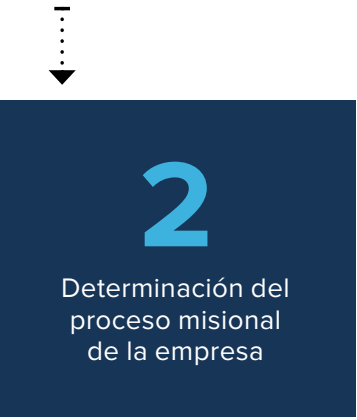

$\div$
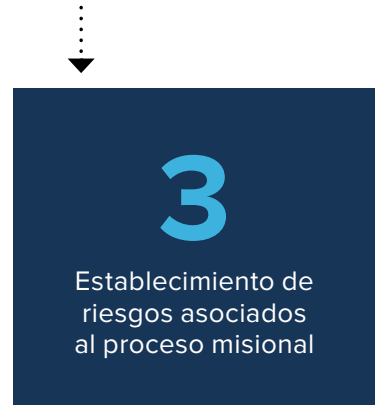

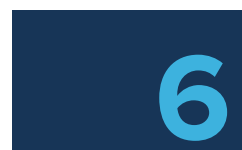

Descripción de

los riesgos según

posibilidad de ocurrencia, consecuencia y controles
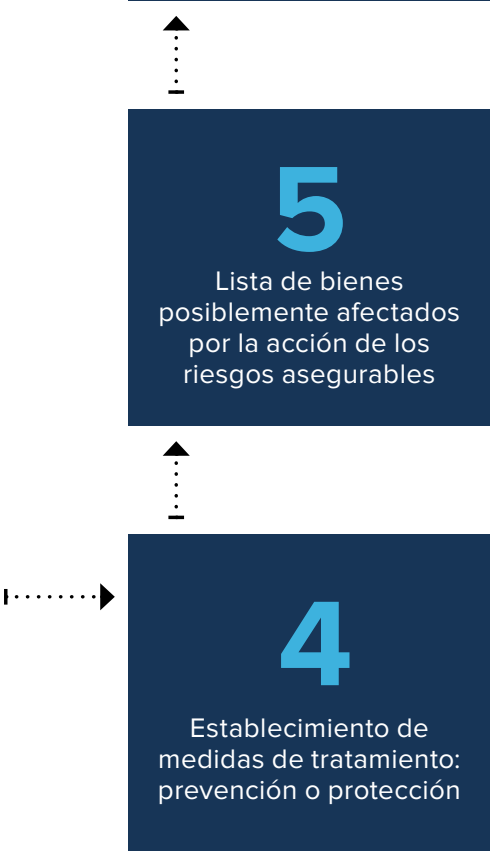

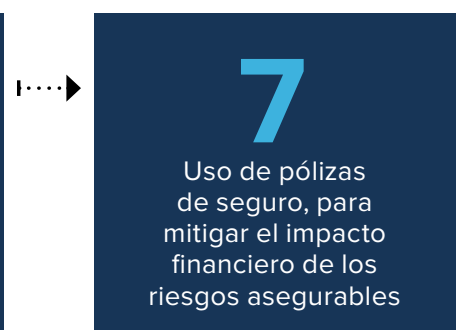




\section{EL SEGURO COMO UN INSTRUMENTO DE PROTECCIÓN}

Una póliza de seguros es una alternativa que tienen las empresas para compartir sus riesgos, que pretende una indemnización en caso de ocurrencia de un siniestro por la materialización de un riesgo asegurable. La caída de un rayo, por ejemplo, que afecta las instalaciones eléctricas de la empresa y saca de servicio el ascensor, requiere de una indemnización. Un incumplimiento de contrato que afecte al contratante del servicio contratado exige una indemnización. Enfermedades que pueda sufrir un operario derivadas de sus obligaciones para con la empresa, que lo lleven a una incapacidad total o permanente, se satisfacen mediante una indemnización.

Para Mecca R. 2006, citado por Mejía (2011) la palabra "seguro es un vocablo que proviene del latín "securus" que significa libre de peligro” (Mejía D., 2011).

Para Fasecolda (Federación de Aseguradoras Colombianas), los seguros se define como: "instrumentos finan- cieros diseñados para minimizar el impacto económico que puedan sufrir las personas como consecuencia de la ocurrencia de un suceso inesperado que pueda poner en peligro su vida o sus bienes. (Fasecolda, 2020).

El seguro se convierte en un instrumento para compartir el riesgo de manera efectiva, no es una forma de aumentar sus ingresos, pero sí es una herramienta que protege su patrimonio ante una eventual pérdida financiera por la acción de un riesgo asegurable. Si no existieran las pólizas de seguros no habría opción, las empresas tendrían que afectar sus finanzas para resarcir los daños que hayan acontecido por acción de los riesgos. 


\section{ILUSTRACIÓN 12}

\section{RECOMENDACIONES AL BUSCAR}

\section{UNA ALTERNATIVA DE COBERTURA.}

Fuente: Elaboración propia

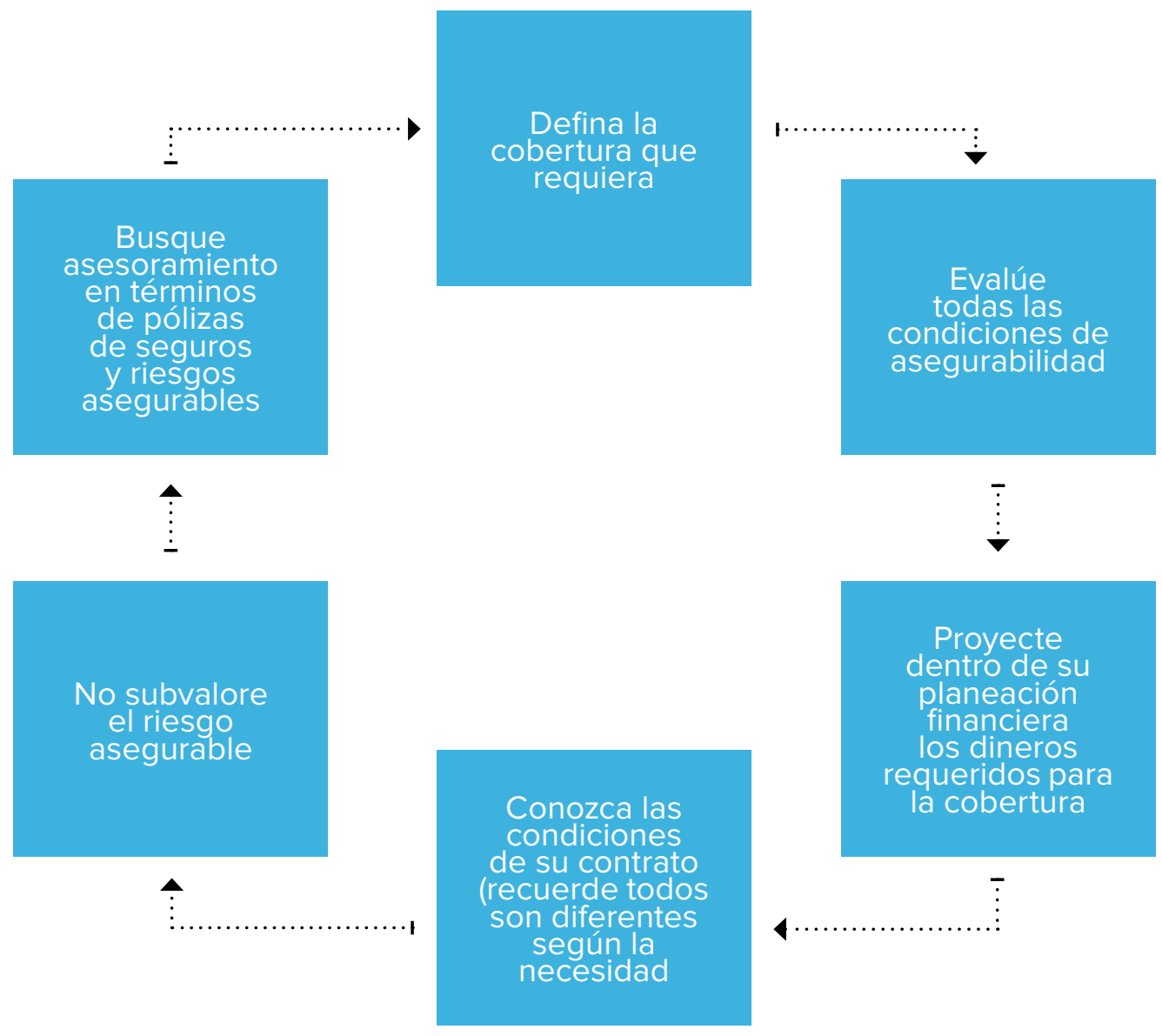


En caso de la materialización de un riesgo, el asegurado recibe a manera de reparación una compensación denominada indemnización, dinero que no constituye fuente de ingreso para él. Al contratar un seguro no se busca obtener un beneficio sino evitar una posible pérdida, la cual se puede generar de un riesgo futuro. Para que un riesgo pueda ser asegurable no puede haber ocurrido, debe partir del principio de buena fe, ser incierto, medible y cuantificable financieramente. Los contratos de seguros contienen graves sanciones para quien incurra en falsedad, omisión o imprecisiones que conduzcan a la cancelación de la póliza por parte del asegurador.

\section{»Recuerde:}

Al contratar un seguro no se busca obtener un beneficio sino evitar una posible pérdida que se genere de un riesgo futuro.
En la ilustración que se detalla a continuación, se presentan una serie de recomendaciones para tener en cuenta a la hora de revisar coberturas para riesgos asegurables.

\section{ASPECTOS PARA TENER EN CUENTA A LA HORA DE ADQUIRIR UNA PÓLIZA DE SEGUROS}

Con el fin de contribuir con los empresarios en el conocimiento acerca de la forma como se adquieren las pólizas de seguros, y en parte cambiar la percepción de las personas que opinan que "las compañías aseguradoras no indemnizan", a continuación, se presentan algunas recomendaciones importantes en la adecuada contratación de una póliza de seguros:

1. El bien asegurado debe ser de su propiedad o estar bajo su responsabilidad (lo tiene que demostrar), lo que en seguros se conoce como interés asegurable. No se pueden asegurar bienes que no le pertenezcan o sobre los cuales no pueda demostrar algún compromiso. 
2. Establezca claramente quién es el beneficiario de la póliza, especialmente en pólizas de vida.

3. No contrate dos pólizas para cubrir un mismo riesgo, por ejemplo, dos pólizas de incendio y terremoto para la misma locación, edificio, vivienda; podría perder el derecho a una indemnización por coexistencia de seguros. Esto no aplica para contratar pólizas de vida, donde la persona puede asegurar su muerte con más de una póliza de seguros.

4. Avalúe los bienes que pretende asegurar, asesórese de un experto. Por ejemplo, los bienes inmuebles deben ser valorados al menos cada 2 o 3 años, los vehículos al menos dos veces al año, ya sea para asegurarlos por primera vez, renovar la póliza de seguros y actualizar el valor asegurado, o para venderlos.

5. Los bienes tienen que estar asegurados a valor real o a valor de reposición, según sea el caso. De este valor dependerá el valor de la prima que pagará por la cobertura de cada riesgo contratado. Un valor asegurado correctamente calculado le evitará dolores de cabeza al momento de una indemnización. Si el valor asegurado es inferior al real podrían indemnizarle menos de lo esperado, por una condición que en seguros se conoce como infraseguro; si el valor asegurado es superior al valor real, una condición conocida como supraseguro, podría usted estar pagando mayor valor de prima de la que debería.

6. Tenga en cuenta que los bienes y activos de la empresa deben estar relacionados adecuadamente según la cobertura contratada. Se recomienda leer bien las coberturas aplicables a cada riesgo, para escoger adecuadamente dónde consignar los bienes a asegurar debidamente inventariados.

7. Evite la terminación automática del contrato de seguros por mora en el pago de la prima. Tiene que pagar la prima de su pó- 
liza según lo pactado con la compañía aseguradora, o en su defecto dentro del mes siguiente a la expedición de la póliza.

8. Brinde toda la información correspondiente al riesgo que pretende asegurar, en ninguna circunstancia permita la reticencia o inexactitud sobre los riesgos contratados, razón por la cual podrían objetarle una reclamación y perder el respectivo derecho a la indemnización.

9. Las pólizas de seguros se terminan cuando usted vende el bien asegurado. Usted no puede creer que un bien que ha comprado y que está asegurado, sigue asegurado, pues al cambiar el bien de propietario cambia el interés asegurable, las condiciones del riesgo asegurado y se hace necesaria la expedición de una nueva póliza de seguros. Los cambios de propietarios deben avisarse a la compañía aseguradora dentro de plazos estrictamente establecidos.

10.En caso de siniestro, para que una compañía aseguradora lo indem- nice, deberá demostrar dos condiciones: la ocurrencia del siniestro y la cuantía de la pérdida. Si uno de estos dos aspectos falta, o no puede demostrarlos, no podrá hacerse merecedor a la indemnización.

11. De su póliza de seguros lea al menos el capítulo de las "exclusiones", y tenga en cuenta las "garantías" exigidas por la compañía aseguradora, de esa manera sabrá dos cosas: que $\mathrm{NO}$ está cubierto por la póliza de seguros y CUÁLES son las obligaciones mínimas contractuales que tiene que cumplir para que sea indemnizado.

\section{BITÁCORA DE LA ASEGURABILIDAD Y EL RIESGO EN MICRO $Y$ PEQUEÑAS EMPRESAS}

Según Gustavo Adolfo Pérez Osorio, Gerente de la empresa PRIN Seguros, ubicada en la ciudad de Medellín (www. prinseguros.com), todo micro y pequeño empresario debe conocer los siguientes aspectos que, según él, darán claridad al momento de tomar una decisión de asegurabilidad y le ayudarán 
en el fomento de la cultura del seguro, como una verdadera apuesta al desarrollo corporativo, porque implica la protección y la recuperación del capital tras una perdida fruto de un siniestro.

\section{VENTAJAS}

1. Existe una amplia variedad de seguros que ajustados a la necesidad del empresario pueden coadyuvar en el sostenimiento de la empresa; ya que existen seguros para todo: seguros para los activos, patrimoniales en el caso de que exista daño a un tercero, una pérdida de lucro o que tenga que seguir pagando los gastos fijos en caso de un incendio. Existen seguros para el manejo de dinero, para bienes transportados, incumplimiento de contratos, y seguros para fraude o robo por parte de los empleados.

2. Fomenta la prevención y la cultura de la asegurabilidad, para estar siempre preparados y protegidos financieramente ante posibles siniestros, que a la luz de muchos es muy raro que suceda, pero cuando se materializa, afec- ta a una empresa hasta el punto de tener que cerrar la organización por la falta de recursos propios para atender un siniestro.

3. Tranquilidad para todos, al ver que todo el patrimonio está asegurado y el riesgo es compartido con las aseguradoras.

\section{BENEFICIOS}

1. Protección patrimonial en caso de un siniestro, daño o perjuicio; ya que, si no existe una protección, el dinero lo pierde directamente el empresario.

2. Al tomar la póliza de seguros las aseguradoras asumen un alto porcentaje de las pérdidas en un evento inesperado, brindando tranquilidad al empresario.

3. Contar con un capital financiero de respaldo al momento de una perdida, limitado solo por el valor de la cobertura y de prima pagado por su cobertura, da plena tranquilidad al empresario para continuar con su operación. 


\section{ERRORES COMUNES}

1. La gestión de los riesgos y la asegurabilidad no están contemplados dentro del proceso de planificación de las Micro y Pequeñas empresas.

2. El empresario considera que el costo de los seguros es muy elevado en relación con sus beneficios.

3. El entrevistado opina que el empresario colombiano, cuando inicia su negocio, está pensando principalmente en vender sin detenerse a pensar en los riesgos, en las posibilidades de pérdidas o daños que pueda sufrir su negocio.

4. Pensar que los seguros son para las grandes empresas, porque son quienes tienen los recursos financieros para acceder a ellos y no para aquellos que cuentan con recursos limitados, desconociendo de facto que las micro y pequeñas empresas, en general, no cuentan con los recursos para afrontar por cuenta propia un siniestro.
5. Ver el seguro como un gasto y no como una inversión para soportar un posible siniestro.

6. La creencia de que los seguros solo son adquiridos para cubrir eventos no muy comunes como incendios, asonadas etc., sin conocer que los seguros tienen múltiples coberturas que minimizan los riesgos de operación, como puede ser el robo continuo de empleados.

7. No conocer los derechos y deberes de las partes al momento de contratar las pólizas de seguros, ni estudiar los detalles del contrato, para cumplir garantías y acceder a las indemnizaciones.

8. No gestionar el vencimiento de las pólizas.

9. Adquirir pólizas con compañías de menor experiencia o reconocimiento en el mercado que puedan afectar el proceso ante una eventual reclamación. 


\section{RIESGOS MÁS COMUNES}

»Robo continuo de mercancías

» Impago

»Corto circuito, explosión, sobre voltaje

»Incendio

» Hurto

» Responsabilidad civil

\section{PÓLIZAS DE SEGUROS MÁS COMUNES}

» Todo riesgo daños materiales

» Todo riesgo incendio

» Equipo eléctrico y electrónico

» Maquinaria y equipo

»Responsabilidad civil contractual

» Responsabilidad civil extracontractual o póliza de automóviles.
» Infidelidad de empleados

» Lucro cesante

» Interrupción de actividades

\section{PLANIFICACIÓN ESTRATÉGICA DEL RIESGO Y EL SEGURO}

Una matriz de fortalezas, oportunidades, debilidades y amenazas frente a las posibles situaciones, le puede ayudar a diagnosticar su nivel de riesgo y el grado de preparación en la que se encuentra la organización para asumir los costos asociados a una calamidad, y el detrimento en el patrimonio que puede sufrir una micro o pequeña empresa en caso de no tener asegurados sus activos y/o sus procesos.

Este análisis permite a los empresarios obtener de manera eficiente información relacionada con los siniestros más comunes, los riesgos más importantes y el monto patrimonial que se puede ver afectado en una organización, en caso de no estar preparada y blindada ante cualquier 
eventualidad o siniestro. Por otra parte, se hace necesario conocer las pólizas de seguros existentes en el mercado y sus respectivas coberturas, en aras de entender en detalle los beneficios, coberturas, exclusiones, deducibles, y todo aquello que hace parte del área de los seguros, para reconocer cómo proteger activos de la empresa ante riesgos asegurables.

\section{VARIABLES INTERNAS}

»Planificación del riesgo y sus costos asociados

»Infraestructura física, tecnológica, de maquinaria y equipo amparados

»Capital de trabajo y asegurabilidad de los inventarios

» Recurso humano preparado y socializado frente a los posibles riesgos

»Proceso de toma de decisiones

» Fuerza financiera para asumir costos por siniestros y catástrofes

»Cultura de la asegurabilidad

»Riesgos más comunes
»Eventos más comunes que impliquen un detrimento patrimonial

Variables externas

»Certificaciones nacionales e internacionales

»Desarrollo e innovación tecnológica

»Seguros y micro seguros de bajo costo

»Desarrollo de nuevos segmentos de mercado

"Orden público y sus efectos en la economía del negocio

» Inestabilidad social existente en Colombia

» La extorsión

» Nuevas leyes y normas que reformen la actividad empresarial, sus activos y patrimonio

»Entornos hostiles

» Incertidumbre política 
A partir del ciclo PHVA: Planear, Hacer, Verificar y Actuar (PHVA), idea de Shewart (1891-1967), desarrollada por Deming (1900-1993), (Avalos, Vol.9 no1), se desarrolla la propuesta denominada Ciclo Deming de la asegurabilidad, cómo se muestra a continuación en la ilustración 13.

\section{ILUSTRACIÓN 13}

CICLO DEMING DE LA

ASEGURABILIDAD Y MANEJO

DEL RIESGO PARA MICRO $Y$

PEQUEÑOS EMPRESARIOS

Fuente: Elaboración propia
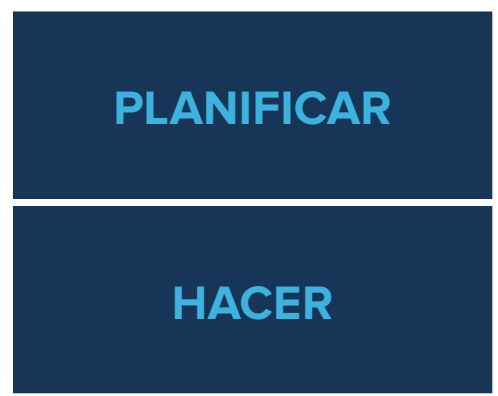

VERIFICAR

ACTUAR
PLANIFICACIÓN

DEL RIESGO Y LA

\section{ASEGURABILIDAD}

»Planificar los posibles ries-

gos y siniestros.

»Definir los objetivos de asegurabilidad y protección de operaciones, activos y patrimonio a corto, mediano y largo plazo.

»Establecer las coberturas más idóneas y de mayor trascendencia para la protección integral de la empresa y su patrimonio.

»Estructurar las estrategias de fortalecimiento de la cultura del seguro en la empresa y sus beneficios.

"Determinar los requerimientos de asegurabilidad en cada uno de los procesos productivos y de generación de valor, en pro de alcanzar altos estándares de calidad.

»Establecer los mecanismos de control preventivo, concurrente y posterior a la implementación del plan de asegurabilidad de la empresa. 
»Definir los indicadores que servirán como mecanismo de medición del costo beneficio de los seguros.

»Desarrollar políticas y valores que estimulen una cultura de prevención ante los posibles riesgos y siniestros, y mecanismos para socializar dicha cultura.

»Evaluar hasta qué punto la empresa puede asumir por cuenta propia los costos derivados de un siniestro y tomar decisiones.

\section{HACER}

»Revisar el portafolio de ofertas de seguros, sus alcances, coberturas y costos.

"Adquirir los seguros respectivos, a la luz de los riesgos que se tienen identificados. Al momento de la compra tenga en cuenta las condiciones expuestas en las pólizas, sus exclusiones y deducibles.

»Desarrollar un plan de capacitación para todos los emplea- dos de la organización para atender necesidades de información frente a los posibles riesgos y controles que se deben llevar a cabo en el cumplimiento de los objetivos de no ocurrencia de ciertos eventos o siniestros.

»Indicar a todos los colaboradores los riesgos a los cuales están expuestos y promover la cultura de prevención y comunicación de riesgos.

\section{VERIFICACIÓN}

»Realizar un seguimiento periódico del alcance de la política de asegurabilidad de la empresa.

»Diseñar y realizar encuestas de percepción, para identificar el nivel de aceptación del plan de asegurabilidad y nivel de apropiación de la cultura en cada una de las actividades que se realizan al interior de la empresa.

»Verificar si los objetivos en torno a los controles preventivos, 
de concurrencia y de retroalimentación se están cumpliendo conforme a lo planificado.

»Establecer, a través de indicadores, niveles de mejora o deterioro de procesos, activos y patrimonio de la empresa.

» Informar permanentemente a sus colaboradores sobre los resultados de la política de asegurabilidad y manejo de riesgos al interior de cada una de las áreas de la organización.

\section{ACCIONES}

» Realizar actividades encaminadas a la mejora continua del desempeño individual y colectivo en torno a la política del manejo de riesgos en la empresa y su impacto en la operación.

Ajustar los objetivos relacionados con el desarrollo de una cultura de responsabilidad frente a los riesgos y controles, si existen fallos.
"Comparar permanentemente los resultados propios con sus principales competidores en variables tales como: adquisición de seguros, niveles de cobertura, siniestros ocurridos vs planificados y asegurados.

»Evaluar el desempeño de los indicadores y establecer si es necesario proponer nuevas metas y parámetros. 


\section{CONCLUSIONES}

El gerente propietario tiene entre sus responsabilidades asegurar la continuidad de la empresa, por lo tanto, debe identificar los riesgos asociados y generar un tratamiento mediante una correcta gestión de riesgos.

Para la gestión del riesgo se hace necesario conocer con detalle la organización, aquellos factores internos y externos que pueden afectarla en el tiempo.

Trabajar en la cultura de asegurabilidad es una gran oportunidad para el país, en el sentido de invitar a las aseguradoras a diseñar productos al alcance de todas las Micro y Pequeñas empresas.

Contar con herramientas de cobertura como los seguros, le permite a la empresa ahorrar en gastos y mantener la operación sin afectar su rentabilidad, para continuar beneficiando al inversionista, luego de la materialización de algún riesgo asegurable.

\section{GLOSARIO}

Término

Amparo

\section{Anegación}

Asegurado

persona como beneficiaria.
persona como beneficiaria.
Es la forma como los aseguradores representan o describen los riesgos que asumen en sus productos, y particularmente los delimitan en cuanto a su Valor Asegurado, Vigencia, Deducibles, Primas

Rol de una persona en un contrato. Persona que tiene el interés real en evitar el riesgo, esto es, quien tiene el interés asegurable y a cuyo favor se contrata una póliza de seguro. Puede ser una persona diferente al tomador y es quien recibe la indemnización en caso de siniestro, si no se ha designado a otra

Rol de una persona en un contrato. Cada una de las personas en cuyo favor se ha constituido un seguro, pensión, renta u otro beneficio. El beneficiario puede ser a título gratuito y a título oneroso. A título gratuito es el que se designa por mera liberalidad del asegurado; puede ser revocado en cualquier momento de la vigencia. A título oneroso es aquel que se designa cuando el seguro ha sido contratado como protección de un interés económico; solo puede ser revocado con su consentimiento. Por políticas de las compañías el tomador del seguro de vida debe ser el mismo asegurado y otra persona el beneficiario. 


\begin{tabular}{|c|c|}
\hline Consecuencia & Resultado de un evento que afecta los objetivos \\
\hline Deducible & $\begin{array}{l}\text { Cantidad o porcentaje establecido en una póliza cuyo importe ha de superar- } \\
\text { se para que se pague una reclamación (Fundación Mapfre, 2016) }\end{array}$ \\
\hline Detrimento & Deterioro, daño o perjuicio. \\
\hline Exclusión & $\begin{array}{l}\text { Es la cláusula por medio de la cual la aseguradora limita la cobertura de la póli- } \\
\text { za, se puede dar en términos de tiempo, de lugar, de edad, de monto o de evento. }\end{array}$ \\
\hline Evento & $\begin{array}{l}\text { Incidente o situación que ocurre en un lugar particular durante un intervalo } \\
\text { de tiempo determinado. }\end{array}$ \\
\hline Fraude & $\begin{array}{l}\text { Acción contraria a la verdad y a la rectitud, que perjudica a la persona con } \\
\text { quien se comete (RAE, 2016). }\end{array}$ \\
\hline Indemnización & Cosa o cantidad con la que se indemniza. \\
\hline Pérdida & $\begin{array}{l}\text { Cuantificación económica de la ocurrencia de un evento de riesgo operativo, } \\
\text { así como los gastos derivados de su atención. }\end{array}$ \\
\hline Póliza & $\begin{array}{l}\text { Contrato de seguro. Documento que instrumenta el contrato de seguro. Re- } \\
\text { fleja las normas que regulan las relaciones contractuales entre las partes. }\end{array}$ \\
\hline Prima & $\begin{array}{l}\text { Es el precio que se pacta que debe pagar la persona que está transfiriendo su } \\
\text { riesgo a una aseguradora. }\end{array}$ \\
\hline Proceso & $\begin{array}{l}\text { Es el conjunto interrelacionado de actividades para la trasformación de ele- } \\
\text { mentos de entrada en productos o servicios, para satisfacer una necesidad. }\end{array}$ \\
\hline Ramo & $\begin{array}{l}\text { Agrupación de productos orientada a resolver al cliente un conjunto de necesi- } \\
\text { dades afines. Para seguros, es una modalidad relativa a riesgos de caracterís- } \\
\text { ticas similares. Cada ramo está adscrito a una y no más que una compañía. }\end{array}$ \\
\hline Reclamación & $\begin{array}{l}\text { Es el proceso por medio del cual una persona solicita formalmente y de por } \\
\text { escrito a la aseguradora la indemnización del seguro }\end{array}$ \\
\hline Riesgo & Suceso que produce un daño o una pérdida material considerable (RAE, 2016). \\
\hline Salvamento & $\begin{array}{l}\text { Recuperación por parte de la aseguradora del bien o bienes objeto del seguro } \\
\text { que han sido afectados por un siniestro en mayor o menor grado, sin ser des- } \\
\text { truidos, y, por lo tanto, pueden ser utilizados o reparados. Una vez recuperados, } \\
\text { se procede a valorarlos para luego posiblemente venderlos y registrarlos como } \\
\text { un ingreso. Si el salvamento corresponde a riesgos cedidos parcialmente en } \\
\text { coaseguro, se debe abonar al coasegurador la participación correspondiente. }\end{array}$ \\
\hline Siniestro & $\begin{array}{l}\text { Es un evento que significa un deterioro en una persona o un bien y que se ha } \\
\text { pactado que implica el pago de una indemnización. }\end{array}$ \\
\hline Tomador & $\begin{array}{l}\text { Es la persona (natural o jurídica) que traslada los riesgos para asegurar a un } \\
\text { determinado número de personas, y es el responsable del pago de las primas. }\end{array}$ \\
\hline $\begin{array}{l}\text { Transferencia de } \\
\text { riesgo }\end{array}$ & $\begin{array}{l}\text { Transmisión del riesgo de una persona/empresa a otra. En virtud del contra- } \\
\text { to de seguro, el asegurado a cambio del pago de la correspondiente prima, } \\
\text { «transfiere» sus riesgos al asegurador (Fundación Mapfre, 2016). }\end{array}$ \\
\hline Valor asegurado & $\begin{array}{l}\text { Valor que la aseguradora se compromete a pagar al cliente por un riesgo, en } \\
\text { caso de ocurrir el siniestro. Es el límite máximo de responsabilidad del ase- } \\
\text { gurador. Algunos productos permiten el incremento automático del valor } \\
\text { asegurado de acuerdo con una tasa acordada con el cliente }\end{array}$ \\
\hline
\end{tabular}


- - - 
Avalos, G. M. (Vol.9 no1). La evaluación de la calidad en la atención primaria en salud.Consideraciones teóricas y metodológicas. Horizonte Sanitario, 9(1). Recuperado el 20 de 11 de 2016, de http://revistas.ujat.mx/index.php/ horizonte/article/viewFile/158/102

Bernado, B. (2004). Microcrédito en Colombia. Estudios Gerenciales(90), 79-104. Recuperado el 15 de febrero de 2020 , de https://www.icesi.edu. co/revistas/index.php/estudios_gerenciales/article/view/132

Bolsa de Valores de Colombia. (2011). Metodología para el cálculo del índice COLCAP. Bogotá: BVC. Recuperado el 12 de mayo de 2020, de http://www.bvc.com.co/recursos/ Files/Mercados/Indices_Accionarios/Nueva_Metodologia_Calculo_ Indice_COLCAP.pdf

Camargo Suárez, A. C. (2005). Movimiento de la curva de rendimientos TES tasa fija Colombia. INNOVAR, 123-133.
Cole, J. (2014). Dinero y Banca (Novena ed.). Guatemala: Editorial de la Universidad Francisco Marroquín.

Damodaran, A. (20 de abril de 2020). Damodaran Online. Recuperado el 5 de mayo de 2020 , de http://pages. stern.nyu.edu/ ${ }^{\sim}$ adamodar/

Diz, C. E. (2004). Introducción a la teoría de riesgo. Riesgo actuarial, riesgo financiero. Bogotá : Gobal Ediciones .

El Espectador. (16 de marzo de 2018). El $62 \%$ de las pymes colombianas no tiene acceso a financiamiento. El Espectador. Recuperado el 12 de enero de 2020, de https://www.elespectador.com/economia/el-62-de-las-pymes-colombianas-no-tiene-acceso-financiamiento-articulo-744870

Fasecolda . (s.f.). ABC del seguro. Obtenido de Programa de educación financiera Viva seguro Fasecolda : https://vivasegurofasecolda.com/seguros/abc-del-seguro/ 
Fasecolda. (6 de 02 de 2020). www. facecolda.com. Obtenido de www.facecolda.com: https://vivasegurofasecolda.com/seguros/abc-del-seguro/

García, O. (2003). Valoración de Empresas, Gerencia del Valor y EVA. Medellín: Oscar Leo García Serna.

Guasca, D., \& Vergara, J. (2016). Determinantes del uso del Factoring: Evidencia empírica Factoring Bancolombia. Espacios, 37(28), 2.

Instituto Colombiano de Normas Técnicas ICONTEC. (16 de 02 de 2011). NTC-ISO 31000- Gestión del Riesgo. Principios y Directrices . NTC-ISO 31000- Gestión del Riesgo. Principios y Directrices. Bogotá.

J.P. Morgan. (febrero de 2019). J.P. Morgan. Recuperado el 18 de mayo de 2020 , de https://www.jpmorgan. com/country/US/EN/jpmorgan/invest$\mathrm{bk} /$ solutions/research/indices/product

Jonathan Berk, P. D. (2008). Finanzas Corporativas. México: Pearson Educación.
Keynes, J. M. (1965). Teoría general de la ocupación, el interés y el dinero. México: Fondo de Cúltura Económica.

Mapfre. (s.f.). Mapfre.com. Obtenido de Mapfre.com: https://www.mapfre.com. co/seguros-co/servicios/sistema-atencion-al-consumidor/educacion-financiera/diccionario-del-seguro/

Marsh. (2015). I Benchmark de gestión de riesgos en Latinoamérica. Marsh Ilc. Obtenido de Marsh: www. marsh.com

McLeay, M., Radia, A., \& Thomas, R. (2015). El dinero en la economía moderna: una introducción. Revista de Economía Institucional, 333-353. doi:DOl:https://doi. org/10.18601/01245996.v17n33.15.

Mejía D., H. (2011). Gestión integral de riesgos y seguros para las empresas de servicios, comercio e industria.

Bogotá: Ecoe Ediciones. Recuperado el 07 de 02 de 2020

Mejía, A., N. P., Isaias, M., Mejía Quijano, R. C., Nuñez Patiño, 
M. A., \& Martins, I. (2017). Admiistración de riesgos empresariales en Colombia, México y Argentina. Medellínn: EAFIT.

Mejía, R. (2006). Administración de Riesgos: un enfoque empresarial. Medellín: Universidad Eafit.

Morales, J. A., \& Morales, A. (2014). Crédito y Cobranza. México: Grupo Editorial Patria.

Pampillón, F., de la Cuesta, M., Ruza, C., Vázquez, O., \& Bustarviejo, Á. (2017). Sistema Financiero en Perspectiva. Madrid: Universidad Nacional de Educación a Distancia.

Prinseguros. (s.f.). Prinseguros.com. Obtenido de Prinseguros.com: https://www.prinseguros.com

Rísquez, J. (2006). Keynes: la teoría cuantitativa y la no neutralidad del dinero. Revista de Ciencias Sociales (RCS), XII(2), 308-318.

Segurossura. (s.f.). segurossura.com. Obtenido de segurossura.com: ht- tps://www.segurossura.com.co/paginas/glosario.aspx

Senado de la República Colombia. (20 de 02 de 2019). Leyexinfo. Obtenido de Leyexinfo: https://poligran-leyex-info.loginbiblio.poligran.edu.co/codigos/ detalle/codigo-de-comercio-33

Superfinanciera . (10 de 02 de 2020). www.superfinanciera.gov.co. Obtenido de www.superfinanciera.gov.co: https:// www.superfinanciera.gov.co/jsp/15545

Uribe, H. (2015). El contrato de Factoring: apuntes y comentarios. CRITERIOS: Cuadernos de Ciencias Jurídicas y Política Internacional, VIII(2), 19-70. doi:https://doi. org/10.21500/20115733.2203 


\section{LISTA DE TABLAS}

Tabla 1 Liquidación de intereses bajo la modalidad simple y compuesta

Tabla 2 Formulas básicas equivalencias de dinero en el tiempo

23

Tabla 3 Acumulación de intereses mediante la modalidad de 28 interés compuesto

Tabla 4 Precio y rendimiento índice Colcap y Nutresa

47

Tabla 5 Betas apalancados

52

Tabla 6 Clasificación por sector

62

Tabla 7 Flujo de Caja Proyectado

67

Tabla 8 Flujo de caja proyectado teniendo en cuenta el 70 valor residual

Tabla 9 Ingreso y salidas reales de efectivo

72

Tabla 10 Esquema flujo de caja por método directo

73

Tabla 11 Modelo de estado de resultados y Flujo de Caja por 74 método indirecto

Tabla 12 Ejemplo de cálculo de variación en los activos fijos

Tabla 13 Registro de la variación del activo fijo en el flujo de 79 caja libre 
Tabla 16 Registro de la variación del activo fijo en el flujo de caja libre

Tabla 17 Estado de Resultados Integral con deuda y sin deuda

84

Tabla 18 Flujo de caja con deuda y sin deuda

85

Tabla 19 Supuestos para estimación del flujo de caja por mé89 todo indirecto

Tabla 20 Cálculo de ventas, costos variables y gastos opera90 cionales para el año 1

Tabla 21 Estado de resultados proyectados

91

Tabla 22 Tabla de amortización del crédito

92

Tabla 23 Cálculo de variaciones en capital de trabajo y en 94 activos fijos

Tabla 24 Flujo de Caja proyectado por método directo

95

Tabla 25 Flujo de Caja proyectado por método indirecto

96

Tabla 26 Ejemplo de cálculo de Payback

106

Tabla 27 Presupuesto de ventas

109

Tabla 28 Presupuesto de inversión en activos fijos

112

Tabla 29 Presupuesto de Gastos preoperativos

113

Tabla 30 Presupuesto de inversión en capital de trabajo

114

Tabla 31 Estructura de capital

117

Tabla 32 Tabla de amortización del Crédito

118

Tabla 33 Flujo de caja libre operacional 
Tabla 34 Flujo de caja del accionista

Tabla 35 Análisis de sensibilidad

123

Tabla 36 Estado de resultados Integral

129

Tabla 37 Comparativo de empresa

131

Tabla 38 Estados financieros (Empresa X)

134

Tabla 39 Estado de Resultados Integral (Empresa X)

135

Tabla 40 Formulas para el cálculo de ROA

136

Tabla 41 Estado de resultados (Empresa X)

139

Tabla 42 Estado resultados integral (Empresa X)

140

Tabla 43 Tabla comparativa

141

Tabla 44 Caracterización de fuentes de recursos

144

Tabla 45 Fuente de recursos

145

Tabla 46 Ponderación y cálculo de costos por fuente de 147 financiamiento

Tabla 47 Estado de resultados integral (Estructura general) 149

Tabla 48 Comparativo de estructuras con deuda y sin deuda

151

Tabla 49 Elementos que componen el EVA

154

Tabla 50 Clasificación de los riesgos.

165

Tabla 51 Ejemplos de riesgos asegurables asociados a bienes 168 y activos de una empresa.

Tabla 52 Procedimiento básico para la gestión de riesgos 173 asegurables 


\section{LISTA DE GRÁFICAS}

Gráfica 1 Rentabilidad activos hipotéticos

Gráfica 2 Diferentes estructuras de capital

49

\section{LISTA DE ILUSTRACIONES}

Ilustración 1 Proceso de análisis de la idea a trabajar

59

Ilustración 2 Fases del ciclo del proyecto

60

Ilustración 3 Rubos que no representan salidas de efectivo

68

Ilustración 4 Flujo de Caja del Accionista

86

Ilustración 5 Valor Presente Neto

98

Ilustración 6 Fórmula de VPN

99

Ilustración 7 Ejemplo VPN

100

Ilustración 8 Ejemplo TIR

102

Ilustración 9 Formula de la RBC

104

Ilustración 10 Formula de Payback

106

Ilustración 11 Proceso básico de gestión de riesgos

175

asegurables

Ilustración 12 Recomendaciones al buscar una alternativa de cobertura

Ilustración 13 Ciclo Deming de la asegurabilidad y manejo 185 del riesgo para micro y pequeños empresarios 


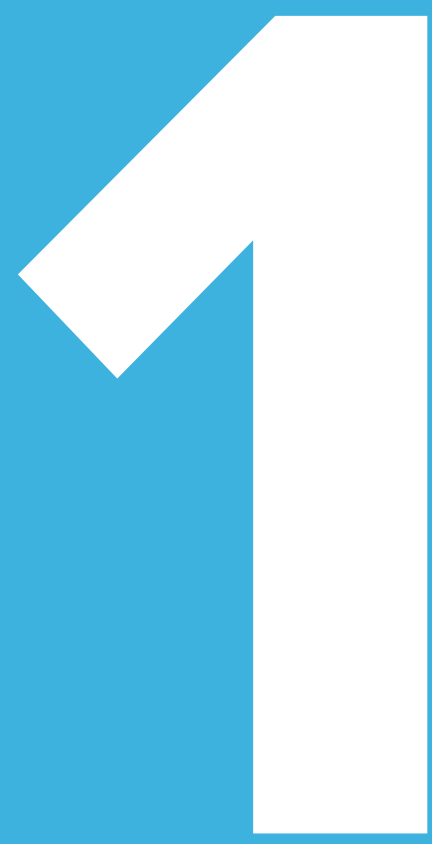

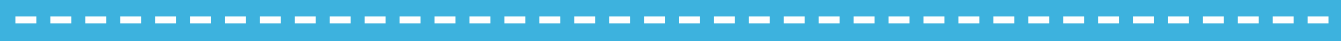

ANEXO

CÁLCULO DEL BETA

PARA NUTRESA S.A. 
Para el cálculo de este indicador se procede de la siguiente forma:

1. Con base en la variación de los rendimientos de la acción de Nutresa S.A., se calcula la varianza de dicha serie. Para el lector que no está familiarizado con este concepto, la varianza es una medida estadística que indica cuanto se alejan en promedio los datos de una serie de su media. Para su obtención se utilizó la hoja de datos de Microsoft Excel, y de la función VAR, así:

\section{FIGURA 1}

\section{CÁLCULO DE LA VARIANZA}

Fuente: Elaboración propia

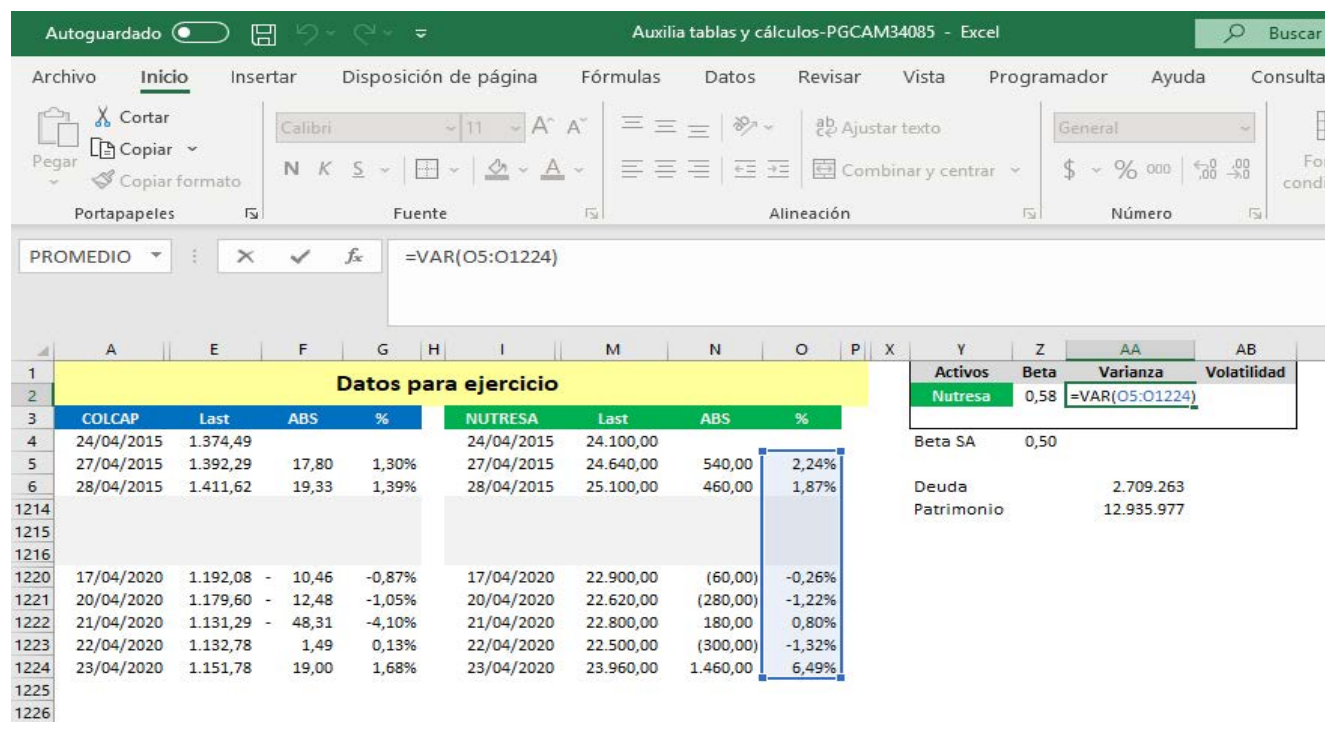


2. El siguiente paso consiste en calcular la covarianza entre los rendimientos del mercado (COLCAP) y la empresa que se está analizando. La covarianza mide la variación conjunta de un par de variables respecto a sus respectivas medias. En términos de nuestro modelo, este indicador nos mues- tra si la varianza de los rendimientos del valor de Nutresa se mueve en la misma dirección a la del mercado. Es decir, si cuando aumenta o disminuye uno, el otro también aumenta o disminuye, o si la relación es indirecta (por ejemplo, cuando COLCAP aumenta, NUTRESA disminuye):

\section{FIGURA 2}

\section{CÁLCULO DE LA COVARIANZA ENTRE COLCAP Y NUTRESA}

Fuente: Elaboración propia

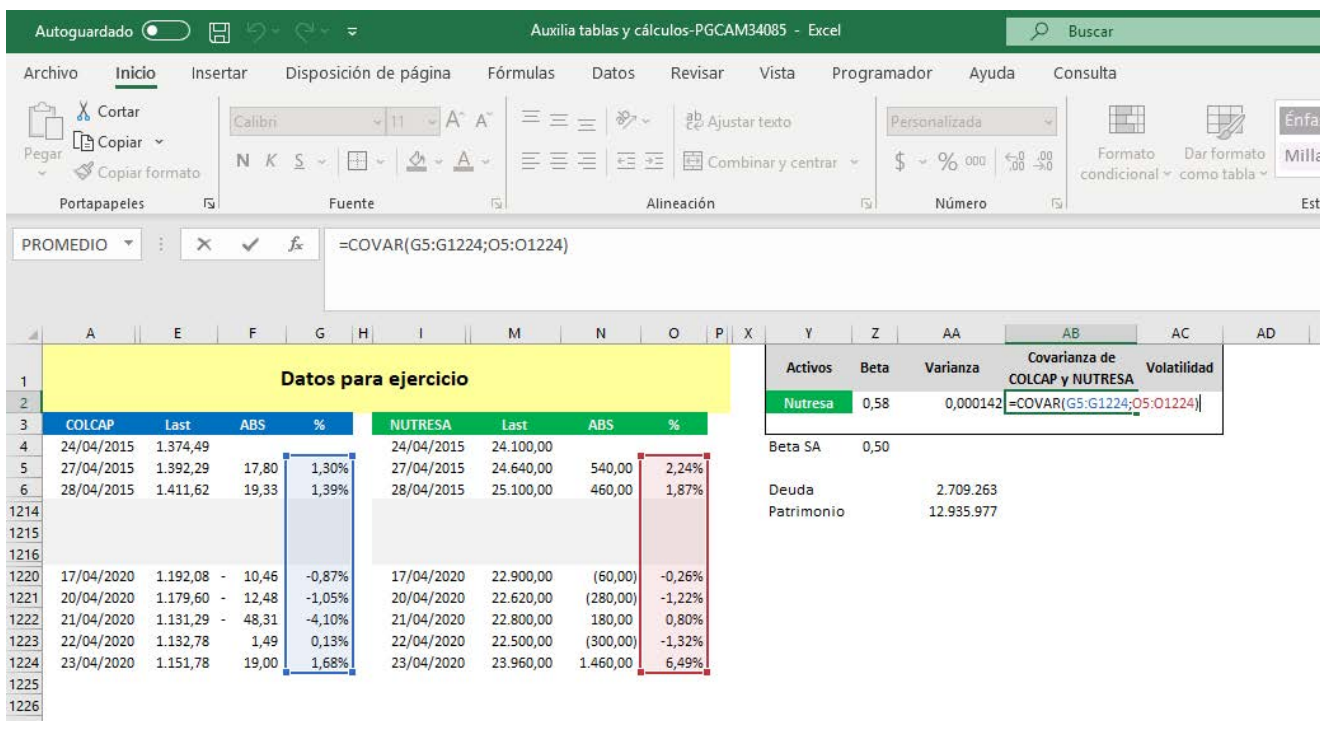


FIGURA 3

\section{CÁLCULO DEL BETA}

Fuente: Elaboración propia
3. Por último, se aplica la ecuación 2 de la siguiente manera:

De dónde se obtiene el valor 0,58

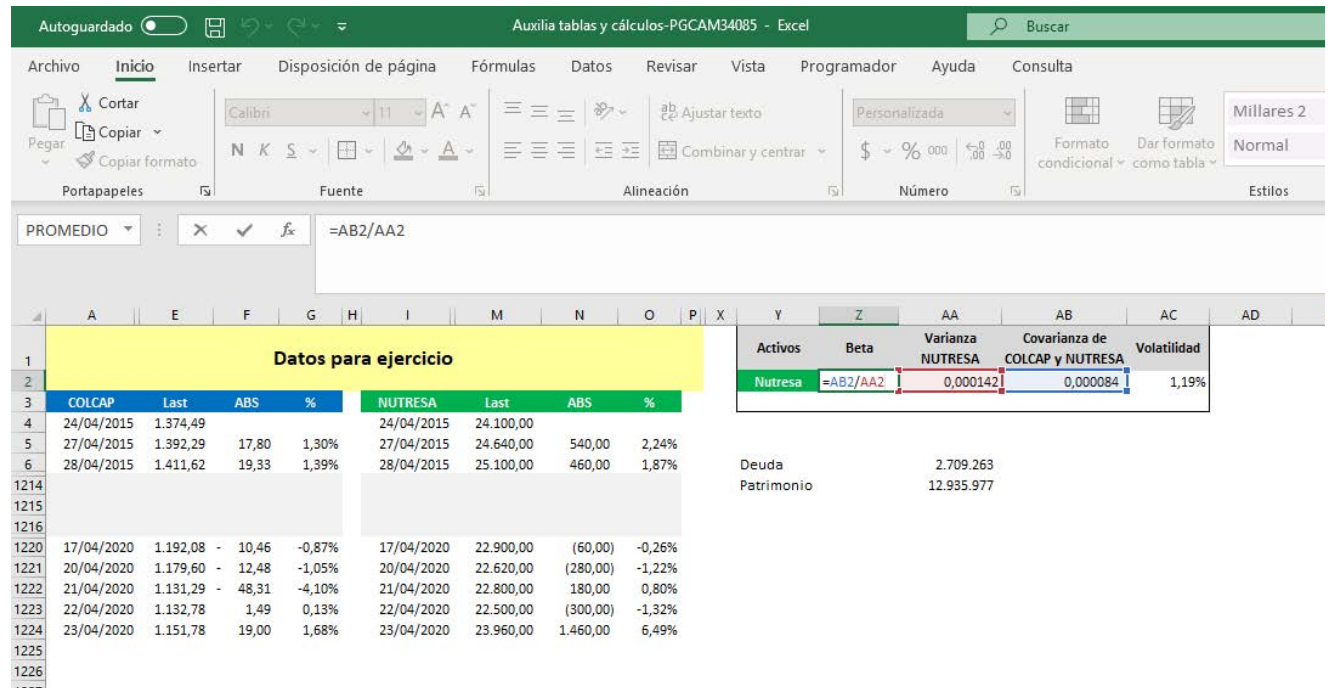




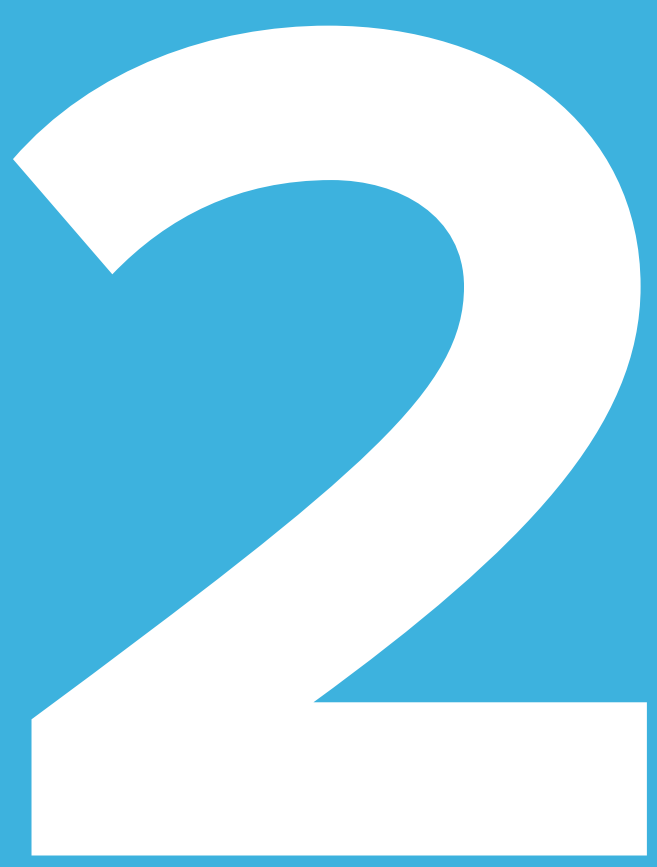

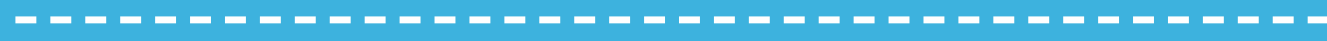

\section{ANEXO}

FORMULACIÓN EN MICROSOFT EXCEL 


\section{BÚSQUEDA DEL VALOR FUTURO:}

Solución: Para el cálculo de valor futuro en Excel se utiliza la función VF. Esta función le solicitará los siguientes argumentos:

» Tasa: es la tasa de interés de la operación
» Nper: tiempo que dura la operación (recuerde que la tasa y el tiempo deben estar en la misma periodicidad)

Va: es el valor presente equivalente al valor futuro que se quiere encontrar. Este debe ser precedido por un signo negativo (ver figura 1)

FIGURA 1

CÁLCULO DE VALOR FUTURO CON MICROSOFT EXCEL

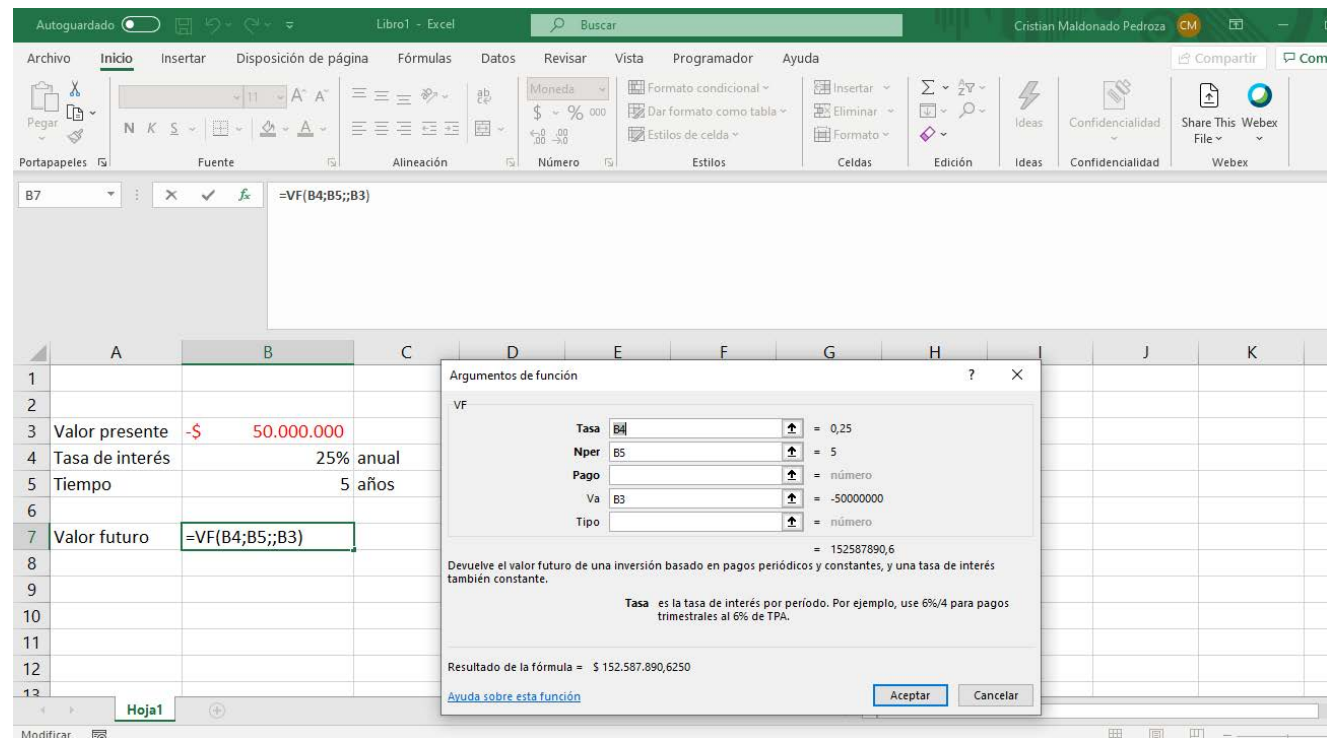




\section{BÚSQUEDA DEL VALOR PRESENTE:}

Solución: para el cálculo del valor presente utilizando Excel se utilizará la función VA, que solicita los siguientes argumentos:

» Tasa: es la tasa de interés de la operación
» Nper: tiempo que dura la operación (recuerde que la tasa y el tiempo deben estar en la misma periodicidad)

"Vf: es el valor futuro equivalente al valor presente que se quiere encontrar. Este debe ser precedido por un signo negativo (ver figura 2 )

\section{FIGURA 2}

\section{CÁLCULO DE VALOR PRESENTE} CON MICROSOFT EXCEL

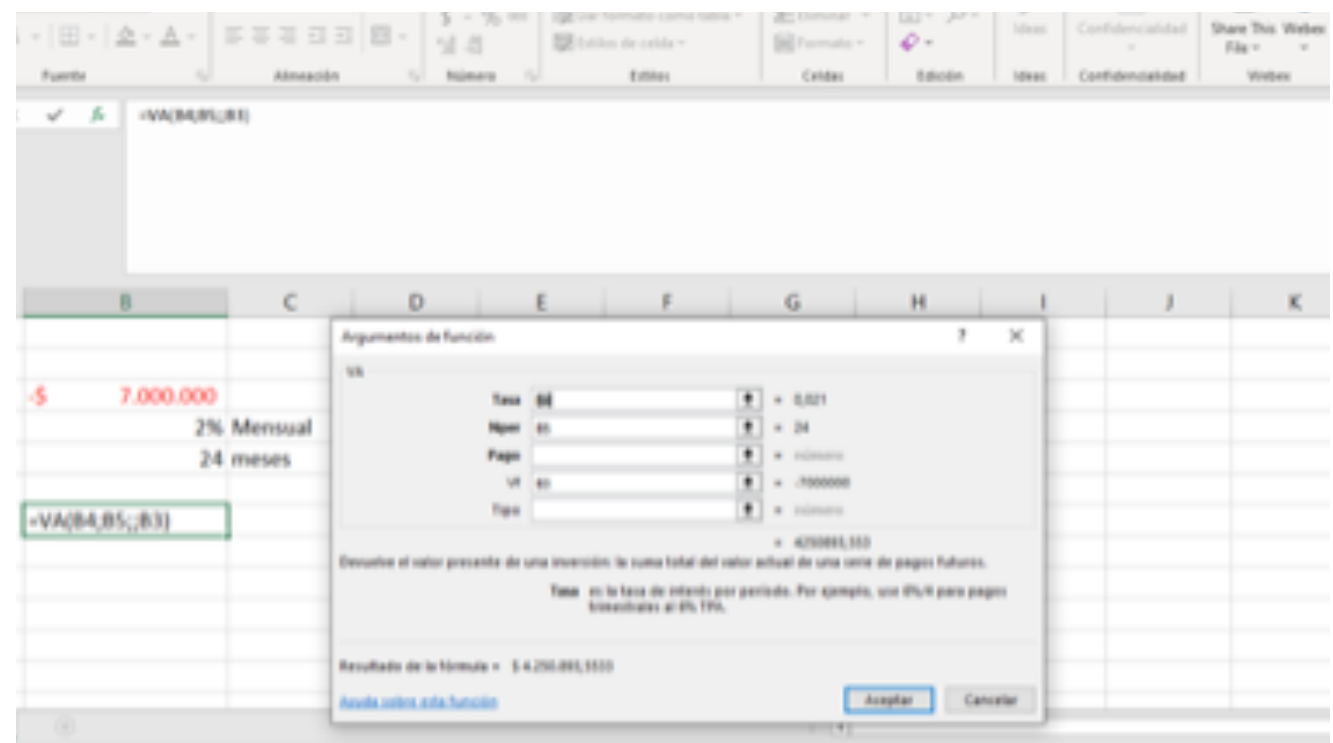




\section{BÚSQUEDA DE LA TASA DE INTERÉS:}

Solución: para el cálculo del valor presente utilizando Excel se utilizará la función TASA, que solicita los siguientes argumentos:

»Nper: tiempo que dura la operación (recuerde que la tasa y el tiempo deben estar en la misma periodicidad)
VA: valor presente de la operación

VF: valor futuro de la operación. Para poder obtener un resultado, se debe utilizar ya sea el valor presente o el valor futuro con signo negativo.

»La tasa de interés resultante estará en la misma frecuencia del tiempo de la operación (anual), ver figura 3:

\section{FIGURA 3}

\section{CÁLCULO DE LA TASA DE INTERÉS} CON MICROSOFT EXCEL

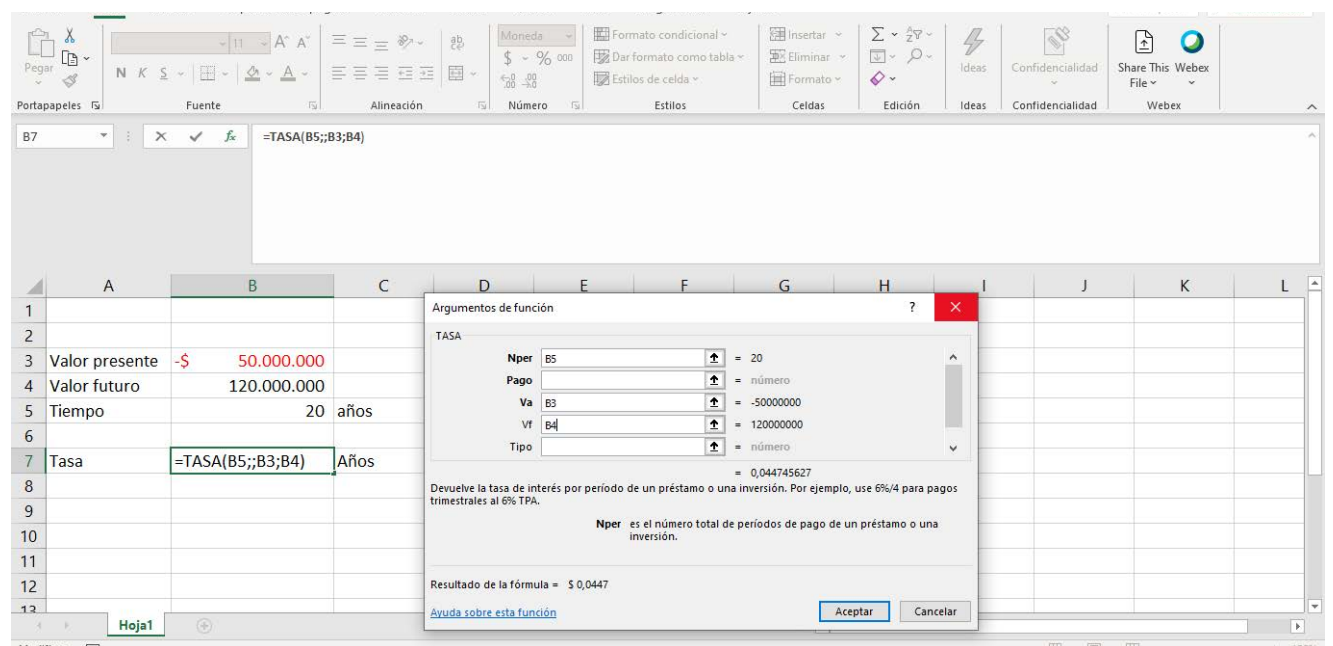




\section{BÚSQUEDA DE LA DURACIÓN DE LA OPERACIÓN:}

Solución: para el cálculo del valor presente utilizando Excel se utilizará la función NPER, que solicita los siguientes argumentos:

» Tasa: tasa de interés que actúa en la operación (recuerde que la tasa y el tiempo deben estar en la misma periodicidad)
»VA: valor presente de la operación

»VF: valor futuro de la operación. Para poder obtener un resultado, se debe utilizar ya sea el valor presente o el valor futuro con signo negativo.

» La duración resultante estará en la misma frecuencia del tiempo de la operación (anual), ver figura:

\section{FIGURA 4}

\section{CÁLCULO DEL TIEMPO DE LA}

\section{OPERACIÓN EN MICROSOFT EXCEL}

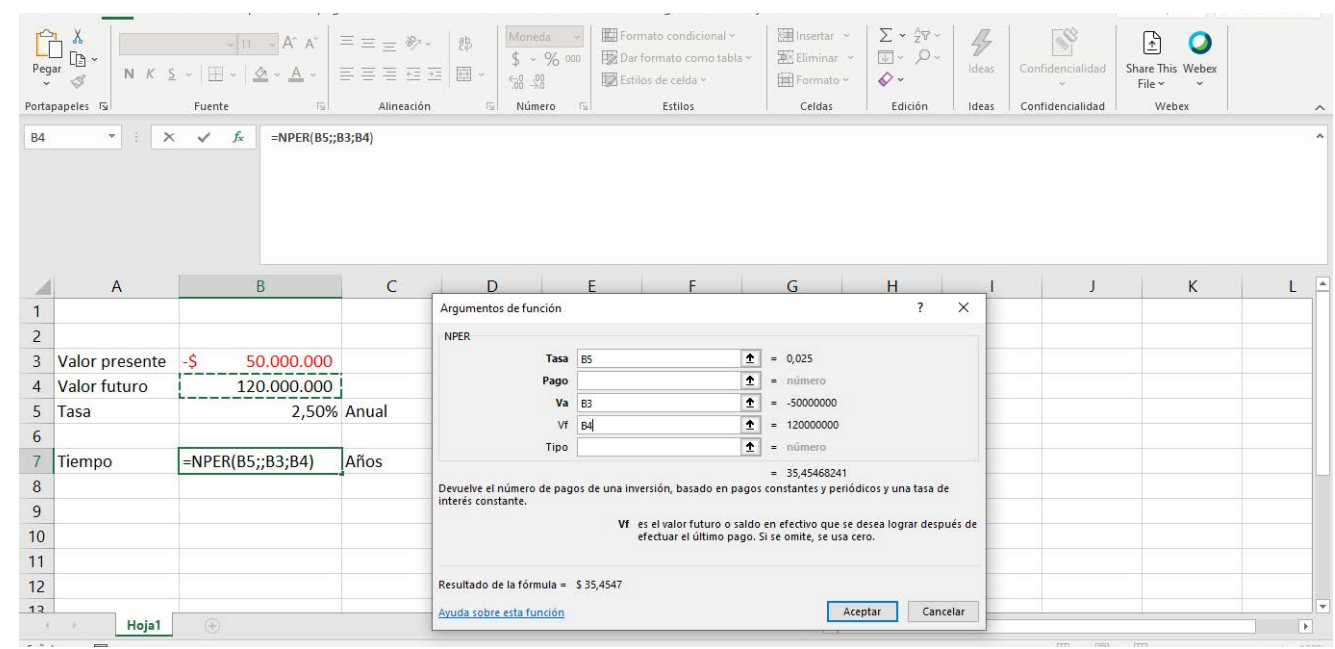



